San Jose State University

SJSU ScholarWorks

Master's Theses

Master's Theses and Graduate Research

1989

\title{
Separation and characterization of a subpopulation of mouse splenocytes which express the surface determinant XTC58
}

Jodi H. Schumacher

San Jose State University

Follow this and additional works at: https://scholarworks.sjsu.edu/etd_theses

\section{Recommended Citation}

Schumacher, Jodi H., "Separation and characterization of a subpopulation of mouse splenocytes which express the surface determinant XTC58" (1989). Master's Theses. 3223.

DOI: https://doi.org/10.31979/etd.8ec7-em8n

https://scholarworks.sjsu.edu/etd_theses/3223

This Thesis is brought to you for free and open access by the Master's Theses and Graduate Research at SJSU ScholarWorks. It has been accepted for inclusion in Master's Theses by an authorized administrator of SJSU ScholarWorks. For more information, please contact scholarworks@sjsu.edu. 


\section{INFORMATION TO USERS}

The most advanced technology has been used to photograph and reproduce this manuscript from the microfilm master. UMI films the text directly from the original or copy submitted. Thus, some thesis and dissertation copies are in typewriter face, while others may be from any type of computer printer.

The quality of this reproduction is dependent upon the quality of the copy submitted. Broken or indistinct print, colored or poor quality illustrations and photographs, print bleedthrough, substandard margins, and improper alignment can adversely affect reproduction.

In the unlikely event that the author did not send UMI a complete manuscript and there are missing pages, these will be noted. Also, if unauthorized copyright material had to be removed, a note will indicate the deletion.

Oversize materials (e.g., maps, drawings, charts) are reproduced by sectioning the original, beginning at the upper left-hand corner and continuing from left to right in equal sections with small overlaps. Each original is also photographed in one exposure and is included in reduced form at the back of the book.

Photographs included in the original manuscript have been reproduced xerographically in this copy. Higher quality $6 "$ " 9 " black and white photographic prints are available for any photographs or illustrations appearing in this copy for an additional charge. Contact UMI directly to order.

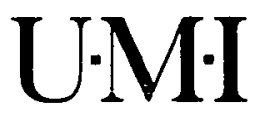

University Microfilms International

A Bell \& Howell Information Company

300 North Zeeb Road. Ann Arbor, MI 48106-1346 USA

$313 / 761-4700 \quad 800 / 521-0600$ 

Order Number 1939649

Separation and characterization of a subpopulation of mouse splenocytes which express the surface determinant XTC58

Schumacher, Jodi Hagin, M.A.

San Jose State University, 1989 

Separation and Characterization of

a Subpopulation of Mouse Splenocytes

Which Express the Surface Determinant XTC58

\author{
A Thesis \\ Presented to \\ The Faculty of the Department of Biology \\ San Jose State University
}

\author{
In Partial Fulfillment \\ of the Requirements for the Degree \\ Master of Arts
}

By

Jodi H. Schumacher

December, 1989 
APPROVED FOR THE DEPARTMENT OF BIOLOGY
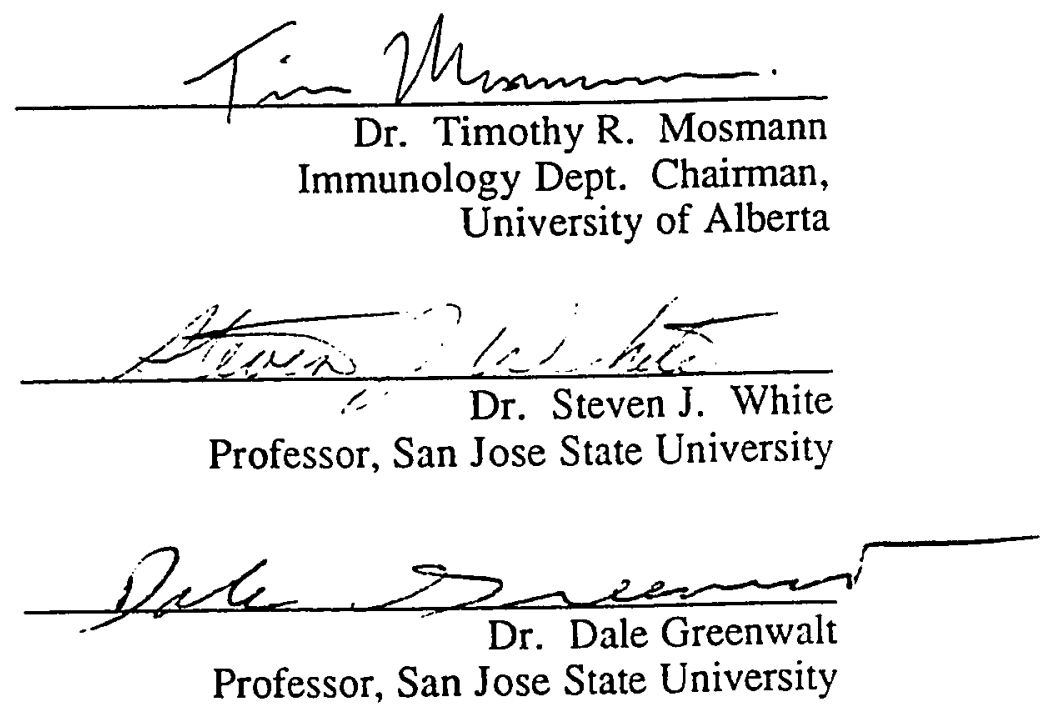

APPROVED FOR THE UNIVERSITY

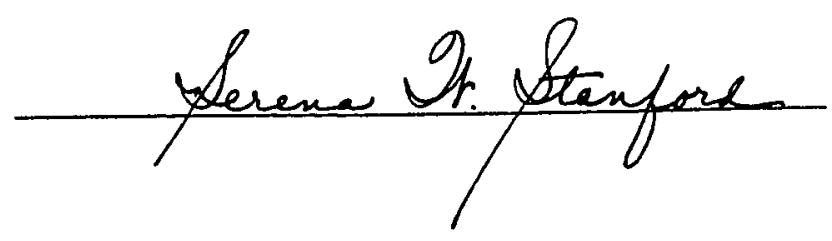




\begin{abstract}
SEPARATION AND CHARACTERIZATION OF A SUBPOPULATION OF MOUSE SPLENOCYTES WHICH EXPRESS THE SURFACE DETERMINANT XTC58

by Jodi H. Schumacher
\end{abstract}

Mouse helper $\mathrm{T}$ cell heterogeneity has been described in terms of differences in secreted cytokines. The effector functions of these subsets, Th1 and Th2, correlate with the cytokine patterns, and regulatory interactions between these subsets via their cytokine products play an important role in immune responses. A monoclonal antibody, XTC58, raised against the Th1 clone MD13-5.1, preferentially but not exclusively recognizes Th1 clones, and identifies cells from normal mice which seem to produce primarily IFN $\gamma$. Both depletion of XTC58-bearing cells by complementmediated cytotoxicity and mixing $\mathrm{XTC}^{+} 8^{+}$cells isolated using immunomagnetic beads with XTC58+-depleted cells suggests that XTC58+ cells suppress the production of $\Pi$-2 by XTC58- cells. In vitro, allogeneically expanded XTC58+ cultures are enriched for $\mathrm{CD}^{+}$and $\mathrm{XTC}^{+} 8^{+}$cells, and two-color fluorescent staining showed that although the XTC58 determinant is found on a small $\mathrm{CD} 4{ }^{+}$subset, it is primarily expressed on a subpopulation of normal $\mathrm{CD} 8+$ lymphocytes. 


\section{DEDICATION}

Perhaps the person who has sacrificed the most in

order for me to achieve this goal is Rich. I will love you always and dedicate this work to you. 


\section{ACKNOWLEDGEMENTS}

I am grateful to my advisors, Tim Mosmann, Steve White and Dale Greenwalt, for all of the guidance and wisdom they have given me throughout the last four years. Thank you. I also wish to thank Jim Cupp and Dixie Polakoff, without whose help I would not have been able to do the detailed FACS analysis and data display. In addition, I would not have been able to provide the literature background without the help of Lindy Hodgkin. I appreciate the patience and help from all of you. 


\section{LIST OF ABBREVIATIONS}

BSA, bovine serum albumin; CBSS, Coffman's basic salts solution; Con A, concanavalin A; Con A/PMA, concanavalin A plus phorbol 12-myristate 13-acetate; Con A/PMA/EBV, concanavalin A plus phorbol 12-myristate 13-acetate plus EBV Mann human lymphoblastoid cells; CSIF, cytokine synthesis inhibitory factor; CTL, cytotoxic T lymphocyte; DTH, delayedtype hypersensitivity; EDTA, ethylenediamine tetraacetic acid; ELISA, enzyme-linked immunosorbent assay; FSC, forward scatter; FACS, fluorescence activated cell sorter; FBS, fetal bovine serum; FITC, fluorescein isothiocyanate; GM-CSF, granulocyte-macrophage colony stimulating factor; IFN $\gamma$, gamma interferon; Ig, immunoglobulin; IL, interleukin; LPS, lipopolysaccharide; LT (TNFß), lymphotoxin; MHC, major histocompatibility complex; $\mathrm{M}_{\mathrm{r}}$, molecular weight; MTT, 3-(4,5dimethylthiazol-2-yl)-2,5-diphenyltetrazolium; PBS, phosphate buffered saline; PE, phycoerythrin; PMA, phorbol 12-myristate 13-acetate; PWM, pokeweed mitogen; RBC, red blood cell (erythrocyte); Th, helper T cell; Th1, type 1 mouse helper T cell; Th2, type 2 mouse helper T cell; TNF $\alpha$, tumor necrosis factor. 


\section{TABLE OF CONTENTS}

ABSTRACT

DEDICATION .............................................................................. i

ACKNOWLEDGEMENTS ......................................................... ii

LIST OF ABBREVIATIONS.............................................................. iii

TABLE OF CONTENTS .............................................................. iv

LIST OF FIGURES AND TABLES …............................................ vi

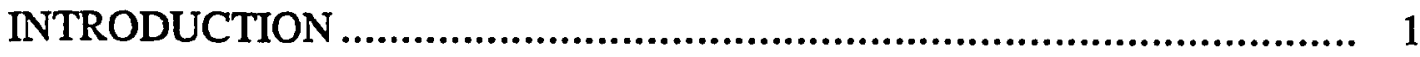

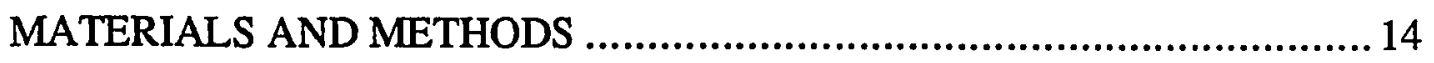

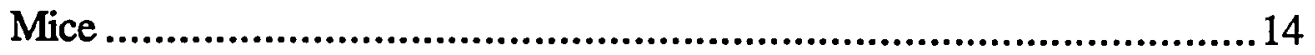

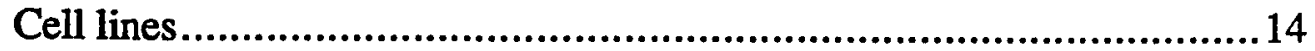

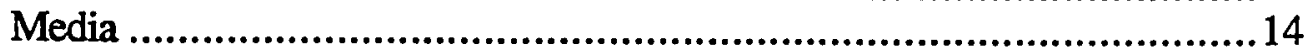

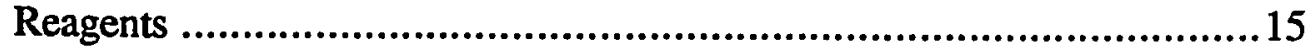

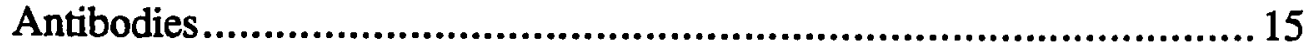

Antibody biotinylation ...............................................................16

Antibody-bead conjugation .........................................................17

Complement-mediated cytotoxicity .................................................. 18

In vitro allogeneic stimulation and expansion ...................................18

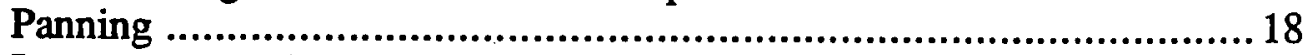

Immunomagnetic Bead Cell Separation .........................................20

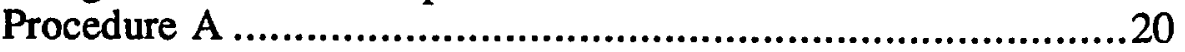

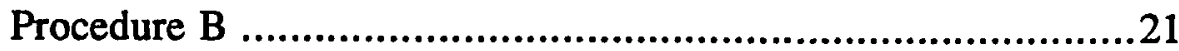

Procedure C .........................................................................22

In vitro allogeneic stimulation and expansion .................................. 23

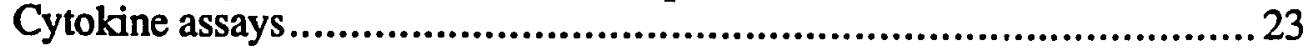

Fluorescent cell staining and analysis ........................................24

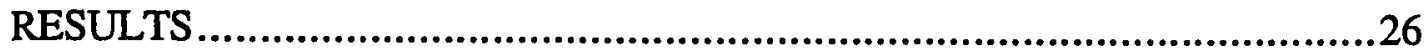

Adherent XTC58+ cells selected by panning do not make detectable IL-2, IFN $\gamma$, IL-4 or IL-5 
Lidocaine and EDTA treatments interfere with the ability of a T

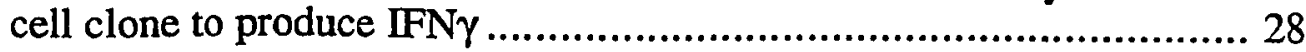

Fluorescent staining provides a useful tool for analyzing the purity of fractionated cell populations

Use of immunomagnetic bead separation to fractionate major splenocyte populations

Immunomagnetic beads efficiently remove $\mathrm{XTC}^{+} 8^{+}$cells from mixed cell populations

Measurement of secreted cytokines by monospecific bioassays and ELISA

Killing $\mathrm{XTC}^{2} 8^{+}$cells removes a IFN $\gamma$-producing cell, while relieving negative regulation of $\mathrm{IL}-2$

Cytokine analysis of cell populations separated by immunomagnetic beads

Allogeneic in vitro expansion of XTC58+-bead adherent cells effectively enriches for XTC58 ${ }^{+}$cells

Stimulation conditions must be optimized for accurate cytokine analysis

Allogeneically expanded XTC58+ cells are enriched for a CD8 ${ }^{+}$ phenotype, making more IFN $\gamma$, but less IL-2, IL-4 and IL-5 than XTC58- cells

XTC58+ cells suppress IL-2 production by XTC58- cells

Two-color fluorescent staining is useful for directly examining coordinate expression of cell surface molecules

All XTC58 ${ }^{+}$cells express CD45, but not necessarily the isoform recognized by the $2 \mathrm{C} 2 \mathrm{mAb}$.

The XTC58 determinant is expressed on B220 cells .......................6 69

There is a small subset of $\mathrm{CD}^{+} \mathrm{XTC}^{+} 8^{+}$cells ................................ 71 
The XTC58 determinant can also be found on a CD8 $8^{+}$cell subpopulation, but it does not appear to be an activation marker as assessed by cell size .....................................................................72

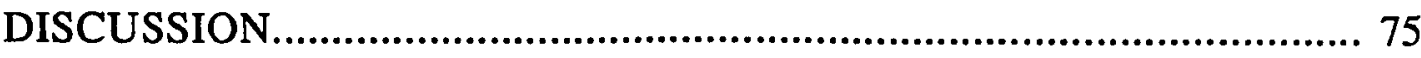

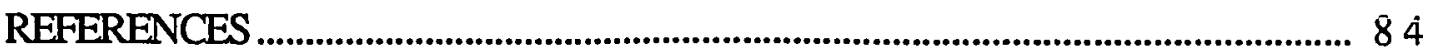

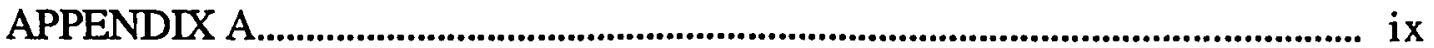

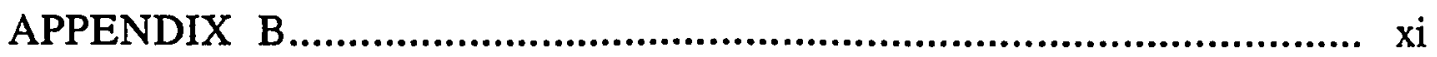

APPENDIX C..................................................................................................... xii 


\section{LIST OF FIGURES AND TABLES}

Table I. Cytokine analysis of cell populations separated by panning ........ 27

Table II. Effect of various adherent cell removal treatments on HDK-1 cytokine production ................................................. 28

Figure 1. Calculation of percent specific fluorescence …........................ 32

Figure 2. Isotype control versus specific histogram analysis of unfractionated splenocytes........................................................ 33

Figure 3. Expected isotype control histograms of unfractionated splenocytes

Figure 4. Flow diagrams of immunomagnetic bead separation Procedures A, B and C ...................................................... 35

Figure 5. Phenotypic analysis of bead separation Procedure A .............. 37

Figure 6. Phenotypic analysis of bead separation Procedure B ............... 39

Figure 7. Phenotypic analysis of bead separation Procedure C .............. 41

Figure 8. Phenotypic analysis of XTC58 depletion: comparison of Procedures A, B and C 44

Figure 9. XTC58 versus CD8 expression of CD8+-depleted, XTC58+-depleted or J5/ $\mathrm{D}^{+}$-depleted cultures .......................... 46

Figure 10. XTC58 and J5/D staining of XTC58+ andJ5/D+ cells................ 46

Figure 11. Cytokine patterns of XTC58- cells .................................... 50

Table III. Cytokine analysis of cell populations separated by immunomagnetic beads....................................................................... 52

Table IV. Cytokine patterns of in vitro allogeneically expanded XTC58+ and XTC58- cells at day 14 54 
Figure 12. Phenotype of day 9 expanded XTC58+ and XTC58cultures....

Table V. Cytokine patterns and phenotypes of XTC58+ and XTC58cells at day 9 following allogeneic stimulation

Figure 13. The effect of cell concentration on cytokine production by Con A/PMA stimulated splenocytes from Brucella abortusimmune mice 58

Figure 14. Phenotype analysis of allogeneically expanded XTC58+ and XTC58- cells at days 9 and 14

Figure 15. Cytokine profiles of XTC58+ versus XTC58- cells at days 9 and 14

Figure 16. Regulation of cytokine production between day 1 XTC58+ and XTC58- cells 64

Figure 17. Regulation of cytokine production between day 14 XTC58+ and XTC58- cells

Figure 18. CD4 versus CD8 two-color FACS analysis of normal $\mathrm{Balb} / \mathrm{c}$ splenocytes

Figure 19. All XTC58+ cells express T200, but not necessarily the isoform recognized by the $2 \mathrm{C} 2 \mathrm{mAb}$

Figure 20. The XTC58 determinant is not expressed by B220+ cells. 70

Figure 21. The XTC58 determinant identifies a small CD4+ subpopulation, but is primarily expressed by CD4- cells

Figure 22. The XTC58 mAb identifies a CD8+ subset, but does not appear to be an activation marker as judged by cell size (FSC) 


\section{INTRODUCTION}

T helper (Th, CD4 ${ }^{+}$) cells, identified by the surface molecule L3T4 (CD4) (1), were originally thought to be functionally homogeneous, mediating B cell help and participating in delayed-type hypersensitivity (DTH) $(2,3)$. B cell help is defined as T cell-mediated induction of B cell immunoglobulin (Ig) secretion, via soluble mediators (cytokines) and/or cell-cell contact and signalling. DTH is characterized by localized cytokine-induced tissue inflammation, cellular infiltration and edema 24-48 hours following intradermal antigen exposure, and displays minimal B cell involvement. Experimental investigations demonstrated that these two effector functions were reciprocally mediated $(4,5)$. Originally, it was unclear whether a single Th cell could be involved in both types of responses, or whether there were possibly discrete functional subpopulations within the Th compartment.

Historically, heterogeneity of Th function in vivo was first described in terms of the $\mathrm{T} 1$ and $\mathrm{T} 2$ helper $\mathrm{T}$ cell subsets (6-10). $\mathrm{T} 1$ cells express a higher concentration of the $\mathrm{T}$ cell surface marker Thy1, are short-lived as evidenced by rapid loss after adult thymectomy, are resistant to in vivo administration of antilymphocyte serum and are therefore probably not recirculating, are able to provide B cell help but with relatively slow kinetics and are thought to comprise the virgin $\mathrm{T}$ cell compartment. T2 cells express lower levels of Thy 1, are longlived, provide B-cell help with rapid kinetics, and are thought to include the memory $\mathrm{T}$ cell population. Since they recirculate, $\mathrm{T} 2$ cells are very sensitive to elimination by anti-lymphocyte serum. T2 cells can be derived from the T1 
compartment (8). These studies showed that functional heterogeneity exists in terms of naive and memory Th.

Using cloned Th cell lines, patterns of secreted cytokines were later correlated with differences in Th effector functions. In 1985, Bottomly and coworkers separated a panel of cloned, MHC-restricted $\mathrm{CD}^{+}$, Th cell lines into four groups based on differences in B cell help (11). Types 1 and 2 induced B cell proliferation and Ig secretion in an antigen-specific, MHC-restricted manner. Type 4 cells were autoreactive and induced B cell proliferation and Ig secretion independent of antigen. In contrast, type 3 Th clones induced antigen-specific, MHC-restricted B cell proliferation, but were incapable of B cell help, actually suppressing Ig production and sometimes even killing the B cells. A final conclusion of this work was that the quality of B cell help would ultimately be related to differences in cytokine production between these four Th types.

Indeed, in 1986 Mosmann et al. described two Th subsets, type 1 helper T cells (Th1) and type 2 helper T cells (Th2), which displayed reciprocal patterns of cytokine production following activation by Concanavalin $\mathrm{A}$ (Con $\mathrm{A}$ ) or antigen (12). Differences in the nature of in vitro B cell help provided by these Th subsets to lipopolysaccharide (LPS)-stimulated B cell blasts did correlate with the different cytokine patterns. Th1 secrete IFN $\gamma$ and IL-2 and no detectable IL4; Th2 produce IL-4 but no detectable IFNy or IL-2. Th2 supernatants induced the secretion of IgG1 and IgE by B cells in vitro, while incubation of LPSstimulated B cells with Th1 supernatants had relatively little effect on Ig secretion. Differences in secreted cytokines have been more recently expanded to include other factors using enzyme-linked immunosorbent assays (ELISA) and mRNA hybridization (13). From this and more recent data, the current picture 
is that IL-2, IFN $\gamma$ and lymphotoxin (LT,TNFß) production is exclusive to the Th1 subset. Both Th1 and Th2 produce the cytokines granulocyte- macrophage colony stimulating factor (GM-CSF), tumor necrosis factor (TNF $\alpha$ ), and IL-3, the neuropeptide preproenkephalin ( $\mathrm{ppENK}$ ), and three other induced proteins of unknown function, TY5, P500 and H400 $(13,14)$. Th1 clones make relatively greater amounts of GM-CSF, TNF $\alpha$, TY5, H400 and P500; Th2 clones make relatively more ppENK. Both types of Th clones make similar quantities of IL3. The Th2-specific factors include IL-4 (12)IL-5 (13), IL-6 (15), cytokine synthesis inhibitory factor (CSIF) (16), and the induced protein P600 (14) (Appendix A).

Th-secreted cytokines have been shown to be important mediators of B cell help, particularly in the regulation of Ig isotypes produced by activated B cells. The Th 2 cytokine IL-4 induces IgE and IgG1 secretion by LPS-stimulated B cell blasts in vitro (17-19). IFN $\gamma$, secreted by Th1, selectively induces the production of IgG2a, while inhibiting the production of IgG1, IgG2b and IgE (20). Thus, IFN $\gamma$ and $\mathrm{IL}-4$ reciprocally regulate Ig production (Appendix B). The cytolytic activity and suppression of Ig secretion by B cells by the Bottomly type 3 Th cells was attributed to the production of IFN $\gamma$ and LT, a known lytic factor $(21,22)$. Thus, qualitative differences in Th-mediated B cell help can be attributed to Th1 or Th2-specific cytokines.

There also appears to be cytokine-mediated cross- regulation between Th cells. Proliferation or cytokine production of one Th subset may be modulated in part by cytokines produced by the other subset. Addition of Th1 supernatant, or recombinant IFN $\gamma$, to Th2 cells in the presence of IL-2 and IL-4, selectively inhibits the proliferative response of Th2 cells in vitro (23). It appears that IFN $\gamma$ 
directly inhibits Th2 proliferation. Recently, Th2 clones have been discovered to secrete a factor, CSIF, which inhibits IFN $\gamma$ production by Th1 following antigen stimulation in vitro (16). Although this inhibition of Th1 cytokine synthesis may require preliminary processing by an accessory cell type, it provides a complementary example of regulation between Th1 and Th 2 cells.

Similarly, the regulation between Th1- and Th2-mediated immune responses in vivo appear to correlate with Th subset cytokine patterns and data collected from in vitro models. A function unique to the Th1 subset is its role in DTH(24), in which IFN $\gamma$ is a major mediator (25). Th1 clones injected into the footpad of a naive or unprimed mouse induce the footpad swelling characteristic of DTH, and injection of anti-IFN $\gamma$ monoclonal antibody (mAb) partially inhibits this reaction. Infection with a variety of parasites, e.g. Leishmania major or Nippostrongylus brasiliensis, causes activation of the Th2 compartment $(26,27)$, as evidenced by decreases in Th1-specific cytokines (28-31), increases in Th2specific cytokines in supernatants from induced splenic $T$ cells (N. Street, unpublished data), IL-4 dependent increased levels of serum $\operatorname{IgE}(32,33)$ and $I L-$ 5 dependent eosinophilia (34). In vivo administration of IFN $\gamma$, or anti-IL-4 $\mathrm{mAb}$, decreases the levels of IgE detected in these infected animals $(35,36)$. The magnitude of a DTH reaction in parasite-infected mice is diminished as compared to that elicited in uninfected animals (A. Fong, personal communication). Supernatant of induced cells from Trypanosoma cruzi-infected mice was able to inhibit the induction of DTH, indicating that a secreted factor was responsible for the suppression of DTH (37). In the parasite-induced Th2 environment, a likely candidate for this DTH-suppressing factor is the Th2 cytokine CSIF, suppressing the DTH response through inhibition of the production of IFN $\gamma$ and other Th1 
cytokines. Thus Th1 and Th2 cells, described using cytokine patterns of mouse Th clones, and their involvement with immune phenomena in vitro, can be inferred to be important mediators of immune responses in vivo as well.

It is unlikely that the $\mathrm{T} 1$ and $\mathrm{T} 2$ subsets first described correlate entirely with Th1 and Th2 phenotypes. Based on cytokine analysis of supernatant of induced cytotoxic T lymphocyte (CD8+, CTL)-depleted spleen cells, Street et al. suggested that there exists a population of lymphocytes which make exclusively IL-21. This population of cells, which they called ThP (Th presursor), would correspond to the naive, T1 population previously described (10,38). Analysis of cytokines secreted by short-term mouse $\mathrm{T}$ cell clones demonstrated a distinct phenotype, Th0, capable of secreting a mixture of Th1- and Th2-specific cytokines. It has been proposed that these Th0 cells differentiate into either Th1 or Th2 in response to appropriate stimuli ${ }^{1}$. Th1 and Th2 may represent terminally differentiated mouse $\mathrm{CD} 4^{+}$effector states, but are not necessarily the only phenotypes comprising the T2 population. Bottomly (11) and Glasebrook (39) have also described results consistent with the possibility of more than two mouse Th subsets. Results in the human indicate that activated human $\mathrm{CD}^{+}$ clones, thought to be fully differentiated, can simultaneously produce IL-2, IL-4 and IFN $\gamma(40)$. Thus, it is likely that $\mathrm{T} 1$ contains the ThP precursor phenotypes, differentiating into Th1 and Th2, which are contained in, but do not entirely compose, the T2 compartment (Appendix C).

\footnotetext{
${ }^{1}$ Street, N.E., J.H. Schumacher, T.A.T. Fong , H. Bass, D.F. Fiorentino, J.A. Leverah and T.R. Mosmann. Heterogeneity of mouse helper T cells: Evidence from bulk cultures and limiting dilution cloning for precursors of Th1 and Th2 cells. Submitted for publication.
} 
An alternative method for characterizing cell subpopulations is to identify the cells by labelling them with monoclonal antibodies specific for discriminatory cell surface molecules. The monoclonal antibody, IM7.8.1, recognizes the PGP-1 surface glycoprotein, which is differentially expressed on $\mathrm{T} 1$ and $\mathrm{T} 2$ helper $\mathrm{T}$ cells (41). Naive Th display low amounts of PGP-1 on their surface (PGP-10), the expression of which increases following antigen stimulation. In this way, the anti-PGP-1 $\mathrm{mAb}$ can be used to distinguish naive from memory $\mathrm{T}$ cells. Cytokine analysis of Th separated on the basis of PGP-1 expression indicate that the naive (PGP-10) Th secrete only IL-2, whereas PGP${ }_{1}$ hi (memory) Th are capable of secreting IL-2, IFN $\gamma$, IL-4 and IL-5 (42) (Budd, R., Schumacher, J.H. and T.R. Mosmann, manuscript in preparation). These results are consistent with the previous cytokine patterns of T1 and T2 cells as separated functionally.

Proof of the existence of Th1 and Th2 phenotypes within the T2 compartment has remained more obscure. Bulk stimulation of PGP-1 hi Th cells freshly isolated from parasite-infected mice, shows increased levels of Th2specific cytokines, suggestive of selective expansion of the Th2 phenotype (Budd, R., Schumacher, J.H., and T.R. Mosmann, manuscript in preparation). Definitive proof of this phenomenon will reside in single cell analysis of a frequency change of PGP-1 hi cells possessing the Th2 phenotype. Currently the only method for demonstrating this is to produce Th clones by limiting dilution and analyze their secreted products. Since it is known that culture conditions can directly influence the phenotype of clones $(23,43)$, this method may bias conclusions drawn from clones with in vitro culture artifacts. Therefore, single cell analysis of freshly isolated cells, labelled with an antibody capable of 
distinguishing Th1 from Th2, would probably be the most accurate method for determining the existence of these phenotypes in normal cell populations.

Antibody-labelling efforts have focussed on the surface molecule CD45, as having the greatest potential for describing diversity within the Th compartment. The Ly-5 system (L-CA,rat; T200/B220, mouse; CD45, human), is a series of transmembrane glycoproteins which characterize different lineages and stages of maturation of hematopoietic cells $(708,749,750)$. The cytoplasmic domain of CD45 molecules contains protein tyrosine phosphatase activity (44), possibly providing an accessory signal in $\mathrm{T}$ cell signalling (45). Several different molecular weight $\left(\mathrm{M}_{\mathrm{r}}\right)$ forms (isoforms) of CD45 (CD45R), ranging from $180,000-240,000 M_{r}$, have been isolated using polyacrylamide gel electrophoresis. The variety of CD45R isoforms arises through alternative mRNA splicing of three exons, $\mathrm{A}, \mathrm{B}$, and $\mathrm{C}$, close to the $\mathrm{NH}_{2}$-terminus. Each exon encodes a sequence of approximately 50 amino acids, which are differentially expressed to generate at least five forms of CD45R $(46,47)$. A combination of CD45R isoforms can be displayed on the cell surface at any one time, and the relative amounts of each isoform change relative to states of cell activation. Differences in the expression of CD45R isoforms have thus been focussed on in an attempt to phenotypically describe $T h 1$ and $T h 2$-equivalent $T h$ subsets in the human, rat and mouse.

In the human, two anti-CD45R mAbs, $2 \mathrm{H} 4$ and $\mathrm{UCHL} 1$, have been described which seem to identify reciprocal $\mathrm{CD}^{+}{ }^{+}$subpopulations. The $2 \mathrm{H} 4$ mAb identifies T200 molecules utilizing exon A, with $\mathbf{M}_{\mathbf{r}}$ of 200,000 and $220,000 \mathrm{M}_{\mathrm{r}}$ (48). $2 \mathrm{H} 4^{+} \mathrm{Th}$ make only $\mathrm{IL}-2$. When activated, these cells induce $\mathrm{CD} 8+$ suppressor cells, while themselves losing the expression of this CD45R 
isoform (49) and increasing the expression of the isoform recognized by the UCHL1 mAb (50). The UCHL1 mAb identifies a lower molecular weight form of CD45R $\left(180,000 \mathrm{M}_{\mathrm{r}}\right)(50,51)$. UCHL1 ${ }^{+}$cells make both IL-2 and IFN $\gamma$, and provide good B cell help. It seems that these two antibodies describe reciprocal Th subsets with characteristics similar to those described for $\mathrm{T} 1$ and $\mathrm{T} 2$ in the mouse, reflecting changes in the expression of CD45R concordant with changes in activation state (52). The potential of these antibodies to illustrate human Th1 and Th2 equivalents is doubtful, since the cytokine patterns of human $T$ cell lines have not been found to be the same as those secreted by mouse Th1 and Th2 subsets.

In the rat, the $\mathrm{OX} 22 \mathrm{mAb}$ identifies a $\mathrm{CD} 4^{+}$subset functionally similar to the $2 \mathrm{H} 4^{+}$human cells but which demonstrates a cytokine pattern more similar to $\mathrm{UCHL} 1^{+}$cells (53). The isoform recognized by the OX22 mAb maps to exon $\mathrm{B}$, binding to a subfraction of the $190,000,200,000$ and $220,000 \mathrm{M}_{\mathrm{r}}$ molecules (54). $\mathrm{OX22}+\mathrm{CD} 4+$ cells elicit relatively poor Ig production from B cells, while inducing suppressive activity in CD8+ cells (53). OX22+ Th make IFN $\gamma$ in addition to IL-2. In contrast, OX22- Th cells make relatively little IL-2 or IFN $\gamma$, but do invoke good Ig production from B cells. The determinant recognized by OX22 is downregulated following $\mathrm{T}$ cell activation, and to date there is no reciprocal determinant identified in the rat which concomitantly increases. Although there are similarities between the functions of the human and rat Th cells identified by $2 \mathrm{H} 4$ and $\mathrm{OX} 22$, respectively, it is difficult to tell whether these antibodies describe equivalent populations. In addition, the relationship of these subsets to Th1 and Th2 are obscure due to limited cytokine analysis in the human and rat studies. Since Th1 and Th2 were originally described in the mouse, and 
a relative plethora of cytokine assays are available for this species, most of the efforts creating $\mathrm{mAb}$ which distinguish $\mathrm{Th} 1$ and $\mathrm{Th} 2$ phenotypes have used mice.

The first report of antibodies which could possibly discriminate between mouse Th1 and Th2 was published by Hayakawa and Hardy in 1988 (55). Subpopulations of freshly isolated mouse $\mathrm{CD}^{+}$cells were distinguished using a pair of mAb, SM3G11 and SM6C10. SM3G11+ and SM6C10 ${ }^{+}$Th subsets differed in their ability to provide B cell help, and the corresponding cytokine patterns resembled the Th1/Th2 differences described in $\mathrm{T}$ cell clones. SM3G11+ cells secrete IL-2, but not IL-4, and lack the ability to induce a secondary antibody response from memory B cells. Con A-stimulation of SM3G11+ cells results in the loss of the SM3G11 marker, the loss of the ability to make detectable levels of $\mathrm{IL}-2$, and the acquisition of the ability to synthesize IL-4. This latter subset (SM3G11-), includes memory $\mathrm{T}$ cells which were extremely competent at inducing Ig secretion from memory B cells. Within this memory $T$ cell population, dependent on the type of stimulation used, e.g. keyhole limpet hematocyanin or alloantigen, the expression of the SM6C10 marker varies (56). Although these antibodies appear to distinguish Th1- and Th2-like subsets of normal mouse Th cells, reproducibility of these results in other laboratories has been difficult (F. Fitch, personal communication), and the results are still inconclusive.

The second group to document a putative Th1/Th2 discriminatory mAb was Bottomly et al. (21). C363.16A (16A) is a mAb which recognizes the mouse T200 (CD45R) isoform utilizing exon B (57). The epitope recognized by the $16 \mathrm{~A} \mathrm{mAb}$ was originally found at a higher density on $\mathrm{Th} 2$ clones ( $16 \mathrm{~A}$ hi), but identified a normal Th population originally claimed to secrete both IL-2 and 
IFN $\gamma$. Recently, more detailed experiments have shown that, in normal Th cells, $16 \mathrm{~A}^{10}$ cells produce $\mathbb{I L}-4, \mathbb{L}-5$ and IFN $\gamma$, and are proficient at $B$ cell help. The $16 \mathrm{~A}^{\text {hi }}$ population secretes IL-2 only, and is able to provide $\mathrm{B}$ cell help only at high antigen concentrations. The results from experiments using cloned $\mathrm{T}$ cell lines are inconsistent with those obtained from normal cells. They are more consistent with the T1/T2 phenotypes, and with the work of Swain and others indicating that greater than $99 \%$ of normal splenic T cells secrete only IL-2.1,2 However, the 16A antibody shows neither positive nor negative correlation with the PGP-1 memory $\mathrm{T}$ cell marker. Thus, $16 \mathrm{~A}$ does not define normal $\mathrm{Th}$ heterogeneity in terms of Th1 and Th2, and indicates that the number of Th subsets is probably much more diverse then originally thought.

A third attempt to identify Th1 and Th2 subsets using mAbs has come from Birkeland et al. (58). This group has most recently documented two antibodies, MB23G2 and MB15C11, which define a subset-restricted form of CD45R. IL-2 and IFN $\gamma$ - secreting Th1 clones express low to moderate levels of this isoform; IL-4 secreting Th2 clones express moderate to high levels. Activation of normal Th cells in a mixed lymphocyte reaction results in decreased expression of this determinant. The expression of this CD45R isoform appears to possess a reciprocal pattern of expression to that of the $16 \mathrm{~A}$ determinant. Although this study did show that the MB23G2/15C11 mA.bs immunoprecipitated a T200 isoform, it did not define which of the variant forms

1 See page 5.

2 Swain, S.L., A.D. Weinberg, and M. English. Lymphokine secretion of memory cells and effector cells which develop from precursors in vitro. Submitted for publication. 
of T200 were recognized. Again, it appears that these antibodies correlate more with the activation state of normal Th than with Th1- or Th2-like phenotypes.

A general conclusion which can be made from the above studies, using antibodies to define Th1/Th2 subsets in terms of CD45R expression, is that the pool of CD45R isoforms expressed on the cell surface changes with activation state of the cell. It is dangerous to use $\mathrm{T}$ cell clones for a comparison since they become activated by virtue of their existence in vitro, i.e. there are no naive $\mathrm{T}$ cell clones with which to compare results from freshly isolated cells. Looking at each study individually, it does not appear that any one antibody can define a Th1 or Th2 phenotype as it exists in vivo. Also, experiments on normal spleen cells indicate that the Th compartment of an animal is more complex than merely Th1 and Th2 alone, and antibody patterns describing this heterogeneity can be anticipated to be just as complex. The study which follows describes my attempt to generate a mAb which could discriminate between Th1 and Th2 phenotypes as they exist normally in the mouse.

The experiments of Mason et al (53) originally suggested that there was a unique marker on IL-2 producing, Th1-like cells in the rat. (Recent data suggests that this was not a Th1 marker, but an activation marker instead). To isolate antibodies which would recognize the corresponding mouse Th marker, three Lewis rats were immunized with the cloned Th1 cell line MD13-5.1(12). Serum titres were monitored by complement-mediated cytotoxicity against a Thl and a Th2 cell line (see Materials and Methods). The rat whose serum had the highest Th1 titre relative to the titre against Th2 cells was chosen for fusion. Spleen cells were fused with the P3X63Ag8.653 myeloma using polyethylene glycol in a modified method of Kohler and Milstein (59-62). Hybridoma 
supernatants were assayed using complement-mediated cytotoxicity against a panel of six Th1 lines and six Th2 lines. Ten hybridomas whose supernatants preferentially recognized Th1, measured first by cytotoxicity and later confirmed with fluorescent staining, were chosen for subcloning and further characterization on normal splenocytes. Normal splenocytes were first depleted of CTL using complement-mediated cytoxicity. Using complement and mAbcontaining hybridoma supernatants, these cultures were depleted of the cells bound by the different mAbs, and then stimulated at $5 \times 10^{6} / \mathrm{ml}$ with Con A ( 5 $\mu \mathrm{g} / \mathrm{ml}$ ). Controls included the anti-CD4 mAb GK1.5 (1), or cells plus complement alone (without antibody). Previous kinetics studies have shown that cytokines from induced Th are secreted between 12-24 $\mathrm{hr}$ (data not shown), so the supernatants were harvested at 24 hours for cytokine assay. Cytokine patterns were compared to the complement control, looking for a decrease in the Th1-specific cytokines IL-2 and IFN $\gamma$, with little or no effect on the TH2-specific cytokines IL-4 and IL-5. Using this method, none of the antibodies appeared to select for an IFNy and IL-2-producing cell type. Cytotoxicity using supernatant from one hybridoma, XTC58, consistently left a final population of cells secreting significantly lower amounts of IFN $\gamma$ than the unkilled control population. The results of the effect on IL4 and IL5 were inconsistent, with the levels of these sometimes being reduced slightly, sometimes the same as the control population. What was most striking, and consistent between experiments, was the observation that the XTC58-killed population, while secreting less IFN $\gamma$, secreted between $100-400 \%$ the amount of IL-2 that the control population produced. This suggested that killing XTC58+ cells removed a population of 
IFN $\gamma$-secreting cells, a population which negatively regulated (suppressed) $\mathbb{I L}-2$ secretion by the XTC58- cells.

The experiments described below examined panning and immunomagnetic bead separation as techniques to errich for and isolate lymphocyte subpopulations. Considerations in using immunomagnetic beads and fluorescent staining to isolate and characterize cell populations will be discussed. Using immunomagnetic beads, $\mathrm{XTC}^{+} 8^{+}$cells were isolated from normal mice, and their secreted cytokines compared to the Th1/Th2 pattern. Bead-separated populations were then expanded allogeneically in vitro to obtain a larger and more reproducible population of cells with which to work. These expanded XTC58+-enriched and XTC58+-depleted cultures were then analyzed for cytokine production. Addition of $\mathrm{XTC}^{+} 8^{+}$cells to an XTC58+-depleted population was performed to directly address the IL-2 suppression implied by the earlier cytotoxicity experiments. Although the original assumption was that the XTC58 mAb would describe a Th (CD4+ cell) surface molecule, two-color fluorescent staining of normal mouse spleen cells and immunomagnetic bead separations indicated that this antibody in fact mainly recognizes a $\mathrm{CD} 4{ }^{-} \mathrm{CD} 8^{+}$ lymphocyte population. XTC58+ cells make significantly more IFN $\gamma$, but less IL-2, IL-4 and IL-5 than XTC58- cells, consistent with a CD8+ phenotype. Experiments testing suppression intimate that not only do XTC58 ${ }^{+}$cells suppress IL-2 production by XTC58- cells, but also suggest that XTC58- cells may likewise regulate IFN $\gamma$ production by $\mathrm{XTC}^{+} 8^{+}$cells. Possibilities for future experiments will be discussed. 


\section{MATERIALS AND METHODS}

Mice. Balb/cByJ and CBA/J mice (female, aged 6-8 weeks), were purchased from Institute of Medical Research, San Jose, CA and The Jackson Laboratory, Bar Harbor, ME. Brucella abortus-immune mice received $0.2 \mathrm{ml}$ of $1 \%$ fixed Brucella abortus (ring test antigen) $(36,63)$ intraperitoneally, and were sacrificed 8 days after injection.

Cell lines. The mouse Th1 cell line HDK-1 was produced and maintained as described elsewhere (13). The EBV-Mann cell line was provided by T.R. Mosmann (DNAX Research Institute, Palo Alto, CA), and originally obtained from M. Feldmann, Charing Cross Sunley Research Center, London, England. Media. Cytotoxicity medium consisted of RPMI 1640 (JR Scientific, INC., Woodland, CA) with $25 \mathrm{mM}$ HEPES buffer (GIBCO, Grand Island, NY) and $0.3 \%$ bovine serum albumin (BSA, Sigma Chemical Co., St. Louis, MO). Immunomagnetic beads medium contained RPMI 1640 with 5\% fetal bovine serum (FBS, JR Scientific). Growth medium was RPMI 1640 containing 7\% FBS, $50 \mathrm{uM}$ 2-mercaptoethanol (Sigma) and $0.5 \mathrm{mg} / \mathrm{ml}$ gentamicin sulfate (provided by Schering Research, Bloomfield, NJ). T cell culture medium was growth medium supplemented with recombinant mouse IL-2 (330 standard U/ml, provided by Schering Research). Th2 supernatant used for overnight culture of cells in Procedure B was obtained from D10.G4.1 cells (64) stimulated at $5 \mathrm{x}$ $10^{6} / \mathrm{ml}$ with Con A (5 ug/ml, Sigma) and used at $0.2 \mathrm{ml} / 500 \mathrm{ml} \mathrm{T}$ cell medium. Stimulation medium was growth medium containing either Con $\mathrm{A}(5 \mu \mathrm{g} / \mathrm{ml})$, Con A $(5 \mu \mathrm{g} / \mathrm{ml})$ and phorbol 12-myristate 13-acetate (PMA, $10 \mathrm{ng} / \mathrm{ml}$, Sigma) 
(Con A/PMA), or Con A (5 $\mu \mathrm{g} / \mathrm{ml})$, PMA (10 $\mathrm{ng} / \mathrm{ml})$ and EBV-Mann human lymphoblastoid cells at $2 \times 105 / \mathrm{ml}$ (Con A/PMA/EBV).

Reagents. Phosphate buffered saline (PBS, 10X), was made by dissolving 169.6 $\mathrm{g} \mathrm{NaCl}$ (Mallinckrodt Inc., Paris, $\mathrm{KY}$ ), $7.7 \mathrm{~g} \mathrm{KH}_{2} \mathrm{PO}_{4}$ (Mallinckrodt) and $25 \mathrm{~g}$ $\mathrm{K}_{2} \mathrm{HPO}_{4}$ (Mallinckrodt) in 2 liters distilled water, adjusting the $\mathrm{pH}$ to 7.0 with 1 $\mathrm{M} \mathrm{NaOH}$ (J.T. Baker Chemical Co., Phillipsburg, NJ), and then bringing the volume to 20 liters with distilled water. 6X ACKS lysing buffer stock consisted of $0.155 \mathrm{M} \mathrm{NH}_{4} \mathrm{Cl}$ (Mallinckrodt) $0.1 \mathrm{M} \mathrm{KHCO}_{3}$ (J.T. Baker) and $0.1 \mathrm{mM}$ ethylenediamine tetraacetic acid (EDTA, Sigma) in 1 liter distilled water. Working solution consisted of $16.7 \mathrm{ml} \mathrm{6X}$ ACKS stock solution and $83.3 \mathrm{ml}$ distilled water, with the $\mathrm{pH}$ adjusted to 7.4 with $\mathrm{NaOH}$ if necessary and filtersterilized before use. Coffman's basic salt solution (CBSS) was made as a $25 \mathrm{X}$ stock, consisting of $200 \mathrm{~g} \mathrm{NaCl}, 10 \mathrm{~g} \mathrm{KCl}$ (Mallinckrodt), $8.95 \mathrm{~g}$ $\mathrm{Na}_{2} \mathrm{HPO}_{4} .7 \mathrm{H}_{2} \mathrm{O}$ (Mallinckrodt), $1.5 \mathrm{~g} \mathrm{KH}_{2} \mathrm{PO}_{4}$ and $25 \mathrm{~g}$ glucose (dextrose, Mallinckrodt). The solids were dissolved in a final volume of 1 liter distilled water.

Antibodies. S4B6 anti-IL-2 mAb was prepared as ascites in irradiated (2500R) Balb/cByJ mice (12). Purified 11B11 anti-IL4 mAb was obtained from J. Abrams (DNAX). The hybridoma cell line was originally obtained from W.E. Paul (National Institute of Health, Bethesda, MD)(65). Purified anti-B220 mAb (RA3-3A1) (66,67), anti-B220 mAb (RA3-2C2) $(67,68)$ anti-Thy1 (69) and rat IgM anti-nitroiodophenyl acetate (J5/D) were generous gifts of R.L. Coffman (DNAX). TIB122 is a rat IgG2a mAb specific for all isoforms of L-CA/T200 (pan-T200), and was provided as culture supernatant by E. Pure (The Rockefeller University, NY). The original cell line, M1/9.3.HL.2, was obtained 
from the American Type Culture Collection, Rockville, MD. 6B7C is rat IgG2a, recognizing an $F_{c}$ receptor epitope, and was provided as culture supernatant by M. Birkeland (University of Texas Southwestern Medical Center at Dallas, Dallas, TX). GL117, a $\beta$-galactosidase specific rat IgG2a, was obtained from J. Abrams (DNAX). Rat anti mouse-CD8 antibody used for panning was a kind gift of H. Bass (Stanford University, Department of Immunology, Palo Alto, $\mathrm{CA})$. Mouse anti-mouse-CD8 mAb used in immunomagnetic bead separation and complement-mediated cytoxicity was purchased from Cedarlane Laboratories Ltd. through Accurate Chemical and Scientific Corp., Westbury, NY. Rat antimouse CD8 mAb used for fluorescent staining was purchased from PelFreez Biologicals, Rogers, AK. Anti-CD4 mAb was provided by R. Coffman (DNAX) as culture supernatant of the hybridoma cell line GK1.5 (1). Goat anti-mouse Ig (for panning) was purchased from TAGO Inc., Burlingame, CA. Goat anti-rat IgG/IgM (heavy and light chain specific) was purchased from Jackson Immunoresearch Laboratories, West Grove, PA. Purified goat anti-rat Ig (crossreacting with mouse Ig) was a kind gift of R. Coffman, DNAX. Phycoerythrin (PE)-conjugated anti-CD4 and fluorescein (FITC)-conjugated anti-CD8 antibodies were purchased from Becton Dickinson, San Jose, CA. FITC-conjugated Affinipure mouse anti-rat IgG (Heavy and light chain specific) was purchased from Accurate Chemical and Scientific Corp.

Antibody biotinylation. Purified XTC58 and J5/D, in PBS, were dialyzed overnight at $4^{\circ} \mathrm{C}$ against $0.1 \mathrm{M} \mathrm{NaHCO}_{3}$. Protein concentrations after dialysis were adjusted to $1 \mathrm{mg} / \mathrm{ml}$ with $0.1 \mathrm{M} \mathrm{NaHCO}_{3}$. $\mathrm{N}$-hydroxysuccinimide ester with a 6-aminohexanoic acid spacer (ENZOTIN, ENZO Diagnostics,Inc., New York, NY) was dissolved in dimethyl-sulfoxide (Servanal grade, Pierce Chemical 
Co., Rockford, IL) at $1 \mathrm{mg} / \mathrm{ml}$. ENZOTIN and antibody were combined at a ratio of $0.12: 1$, mixed immediately, and incubated at room temperature for 4 hours. The solution was then dialyzed against PBS at $4^{\circ} \mathrm{C}$ overnight. Solutions were sterile-filtered using Uniflo $0.22 \mu$ syringe filters (Schleicher and Schuell, Keene, NH). Final protein concentrations were determined by absorbance at 280 nm.

Antibody-bead conjugation. Purified antibodies were conjugated to immunomagnetic beads carrying primary amine groups (BioMag M4100, Advanced Magnetics Inc., Cambridge, MA), using a glutaraldehyde method (70). Forty $\mathrm{ml} 0.01 \mathrm{M}$ potassium phosphate, $\mathrm{pH} 7$, was added to $10 \mathrm{ml}$ BioMag M4100 in a 75 tissue culture flask (Falcon ${ }^{\mathrm{TM}}$, Becton Dickinson). Mixture was shaken vigorously and the beads separated magnetically. Washing was repeated four times. To the wet bead cake, $20 \mathrm{ml} \mathrm{5 \%}$ glutaraldehyde (Sigma) was added and agitated for 3 hours at room temperature (approximately $25^{\circ} \mathrm{C}$ ). The activated beads were separated magnetically to remove the unreacted glutaraldehyde. Fifty $\mathrm{ml} 0.01 \mathrm{M}$ potassium phosphate, $\mathrm{pH} 7$, was added, the mixture vigorously shaken and the beads magnetically separated. Washing was repeated 4 times. The beads were again separated, and the final volume of $0.01 \mathrm{M}$ potassium phosphate aspirated. To the moist cake, a solution of antibody at $3.5 \mathrm{mg} / \mathrm{ml}$ in $10 \mathrm{ml} 0.01 \mathrm{M}$ potassium phosphate, $\mathrm{pH} 7$ was added, and the beads in solution gently agitated overnight at room temperature. The antibody-conjugated beads were separated magnetically. The supernatant was saved and assayed for remaining protein by absorbance at $280 \mathrm{~nm}$ to determine coupling efficiency. Coupling efficiencies in these experiments ranged between 50-100\%. Fifty $\mathrm{ml}$ of $1 \mathrm{M}$ glycine, $\mathrm{pH} 8$, was added to bead cake and shaken well for 10 minutes. The 
beads were washed four times in $50 \mathrm{ml}$ each wash of $0.01 \mathrm{M}$ PBS, $\mathrm{pH} 7.4$, containing $0.1 \%$ BSA. Antibody-conjugated beads were stored at $4{ }^{\circ} \mathrm{C}$ in the final wash buffer solution.

Complement-mediated cytotoxicity. Cells $\left(10^{7} / \mathrm{ml}\right)$ were incubated with antibody, diluted in cytotoxicity medium, for $30 \mathrm{~min}$. on ice. They were then centrifuged at $200 \mathrm{x} \mathrm{g}$ for $10 \mathrm{~min}$., and resuspended in cytotoxicity medium $\left(10^{7} / \mathrm{ml}\right)$ containing a 1:20 dilution Low Tox-M rabbit complement (Accurate Scientific), and incubated for $1 \mathrm{hr}$ at $37^{\circ} \mathrm{C}$. Diluted antibody and complement solutions were sterile-filtered before addition to cells. Cells were then centrifuged (200 x g for $10 \mathrm{~min}$.), and washed once in assay medium before stimulation.

Panning. Falcon ${ }^{\mathrm{TM}} 1005$ petri dishes (Becton Dickinson) containing $10 \mathrm{ml}$ goat anti-mouse Ig in PBS at $2.5 \mu \mathrm{g} / \mathrm{ml}$, were coated by incubation at $4^{\circ} \mathrm{C}$ overnight. Falcon $^{\mathrm{TM}} 1005$ petri dishes containing $10 \mathrm{ml}$ goat anti-rat $\mathrm{Ig}$ (crossreacting with mouse Ig) in PBS at $5 \mu \mathrm{g} / \mathrm{ml}$ were coated by incubation at $4^{\circ} \mathrm{C}$ overnight. Falcon $^{\mathrm{TM}} 1005$ petri dishes with $10 \mathrm{ml}$ goat anti-rat IgG/IgM (Heavy and light chain specific, Jackson ImmunoResearch) in PBS at $5 \mu \mathrm{g} / \mathrm{ml}$, were coated by incubation at $4{ }^{\circ} \mathrm{C}$ overnight. Plates were pre-wetted first with PBS before adding antibody solution to insure even antibody distribution. A single cell suspension of mouse splenocytes was prepared, and pelleted by centrifugation at $200 \mathrm{x} \mathrm{g}$ for $10 \mathrm{~min}$. Five ml ACKS lysing buffer/spleen was added to the loosened cell pellet, mixed gently and incubated at room temperature for 5-7 min to lyse red blood cells (RBC). This solution was then diluted at least 5-fold with growth medium, centrifuged at $200 \mathrm{x}$ g and resuspended in $20 \mathrm{ml} \mathrm{CBSS} / \mathrm{spleen}$. To each Falcon ${ }^{\mathrm{TM}} 3003$ tissue culture dish (Becton Dickinson), $10 \mathrm{ml}$ splenocyte 
suspension was added and incubated at $37^{\circ} \mathrm{C}$ for 2 hours to remove adherent cells. The non-adherent cells were collected by gently pipetting CBSS containing 2\% FBS across the plate several times and combining in a $50 \mathrm{ml}$ centrifuge tube (Falcon). Cells were then centrifuged at $200 \mathrm{x}$ g and resuspended at $107 / \mathrm{ml}$ in CBSS containing $2 \%$ FBS. Sterile anti-B220 mAb was then added to a concentration of $20 \mu \mathrm{g} / \mathrm{ml}$, and incubated with cells on ice for $30 \mathrm{~min}$. Cells were then centrifuged and resuspended in CBSS at $10 \mathrm{ml} / \mathrm{spleen}$. The goat antirat Ig (crossreacting with mouse Ig)-coated dishes were washed with sterile PBS, and add $10 \mathrm{ml}$ cell suspension was added to each washed dish. The non-adherent cells were removed as before by gentle pipetting after incubation on ice for 30 min. The cells were centrifuged at $200 \mathrm{x}$ g, resuspended at $107 / \mathrm{ml}$ in CBSS with 2\% FBS and rat anti-mouse CD8 antibody at 1:10, and incubated $30 \mathrm{~min}$ on ice. Cells were centrifuged and resuspended in CBSS in $5 \mathrm{ml} / \mathrm{spleen}$. Goat anti-rat IgG/IgM (Heavy and light chain specific)-coated plates were washed with PBS, $10 \mathrm{ml}$ spleen cell suspension added to each dish, and then incubated on ice 70 min. Non-adherent cell were removed, centrifuged and resuspended at $10^{7} / \mathrm{ml}$ in CBSS with 2\% FBS and XTC58 $\mathrm{mAb}(100 \mu \mathrm{g} / \mathrm{ml})$, and incubated on ice $30 \mathrm{~min}$. Antibody-coated cells were centrifuged at $200 \mathrm{~g}$, resuspended in $10 \mathrm{ml} \mathrm{CBSS}$ and incubated in washed goat anti- rat IgG/IgM-coated dishes for $30 \mathrm{~min}$. Plates were then swirled gently, and incubated on ice 30 additional min. Non-adherent cells were removed as before. Adherent cells in the dish were gently washed five times with cold $\mathrm{Ca}^{++} / \mathrm{Mg}^{++}$-free PBS (GIBCO). Five $\mathrm{ml}$ of a 1:5 dilution of lidocaine (Xylocaine ${ }^{\circ}$, Astra Pharmaceutical Products, Inc., Westborough, $\mathrm{PA}$ ), in $\mathrm{Ca}^{++} / \mathrm{Mg}^{++}$- free PBS, was added to each dish. $\mathrm{Ca}^{++} / \mathrm{Mg}^{++}$-free PBS minimizes non-specific binding on the basis of adherence to solid substrates. The 
dish(s) were allowed to stand undisturbed for 10-15 min at room temperature. Adherent cells were removed by vigorously pipetting the overlaying solution onto the cells. Removal of adherent cells was monitored microscopically, and pipetting continued until all the cells were dislodged. Cells were centrifuged at $200 \mathrm{x} \mathrm{g}$ at $4^{\circ} \mathrm{C}$, and washed twice in growth medium. Cell viabilities were monitored after each panning step by $0.2 \%$ trypan blue dye exclusion.

Immunomagnetic Bead Cell Separation. Procedure A. A single cell suspension of mouse splenocytes was prepared in cytotoxicity medium. RBCs were lysed with ACKS as described above for panning procedure. An aliquot of cells was removed for fluorescent staining and cytokine analysis (whole spleen). The remaining cells were suspended at $107 / \mathrm{ml}$ in cytotoxicity medium containing a 1:10 dilution of mouse anti-CD8 antibody (Cedarlane), and incubated on ice for $1 \mathrm{hr}$. Using $3 \mathrm{ml}$ anti-mouse IgM bead suspension per $10^{8}$ cells, magnetic beads were washed three times with beads medium. To minimize cell loss, a maximum of $6 \mathrm{ml}$ beads $/ 2$ spleens per $15 \mathrm{ml}$ polystyrene tube (Falcon ${ }^{\mathrm{TM}}$ ) was used. Cells were pelleted by centrifugation at $200 \mathrm{x}$ g for $10 \mathrm{~min}$, resuspended in $100 \mu \mathrm{l} / 10^{8}$ cells and carefully added to bead cake. An additional $100 \mu 1 / 10^{8}$ cells beads medium was added to the cell tube to remove any remaining cells, and combined with the first bead-cell mixture. The tube wall was gently washed with the total bead-cell mixture until the side of the tube was clean, and the mixture entirely contained in the bottom of the tube. This mixture was incubated on ice $45 \mathrm{~min}$, gently shaking tube three times during the incubation. The tube was then filled with $10 \mathrm{ml}$ beads medium $/ 10^{8}$ cells and magnetically separated. Taking care not to disturb the bead-cell cake on the tube wall, the non-adherent cells were gently removed with a pasteur pipet. The non-adherent cells were centrifuged. 
Completeness of the separation of non-adherent from adherent cells could be monitored by the color of the cell pellet. If the cell pellet was brown, i.e. still contained beads, a second magnetic separation was performed. When the cell pellet was clean, a second separation with washed goat anti-mouse IgM beads was performed. Non-adherent cells were gently removed as before, and an aliquot retained for fluorescent staining and cytokine analysis (sIgM-CD8-). The cells were then centrifuged, and resuspended in beads medium ( $200 \mu 1 / 10^{8}$ cells). The cell suspension was incubated with washed XTC58-conjugated beads $(1.5 \mathrm{ml}$ beads $/ 10^{8}$ cells) on ice for 45 min., shaking gently three times during the incubation. Adherent cells $\left(\mathrm{XTC}^{2} 8^{+}\right)$were separated magnetically from nonadherent, XTC58- cells. Adherent cells (bead-cell mixture) were examined microscopically, and the bound:unbound cells noted. Cell viabilities were monitored throughout using $0.2 \%$ trypan blue dye exclusion. Aliquots of all non-adherent fractions were stimulated immediately at $10^{6} / \mathrm{ml}$ with Con A/PMA/EBV and analyzed phenotypically with fluorescent staining. The cell count of XTC58+-adherent cells was calculated using only the cells observed that were bound to beads.

Procedure B: A single cell suspension of mouse splenocytes was prepared in growth medium, RBCs lysed with $\mathrm{ACK}$ and an aliquot retained for stimulation and phenotypic analysis (whole spleen). Cells were pelleted by centrifugation and added to washed magnetic anti-mouse IgM beads as described for Procedure A. Cell-bead mixture was incubated on ice $45 \mathrm{~min}$, gently shaking three times during the incubation. Adherent cells were removed magnetically and nonadherent cells collected. Non-adherent cells were centrifuged, and incubated at $107 / \mathrm{ml}$ in cytotoxicity medium containing anti-CD8 antibody (1:20, Cedarlane) 
on ice for $1 \mathrm{hr}$. Cells were then pelleted and added to washed magnetic antimouse IgM beads as previously described. Following incubation on ice for 45 min with periodic gentle shaking, adherent cells were magnetically separated, non-adherent cells removed and an aliquot retained for stimulation and analysis (sIgM-CD8-). The remaining non-adherent cells were pelleted, and resuspended in $200 \mu \mathrm{l}$ beads medium $/ 10^{8}$ cells. Half of the cells were added to XTC58 mAbconjugated beads, and the second half added to J5/D mAb-conjugated (isotype control) beads. Bead-cell mixtures were incubated on ice for 45 min with occasional shaking. Adherent cells $\left(\mathrm{XTC} 8^{+}, \mathrm{J} 5 / \mathrm{D}^{+}\right.$) cells were separated magnetically, and the non-adherent cells (XTC58-, J5/D') removed. All nonadherent cell aliquots were stimulated immediately at $106 / \mathrm{ml}$ in Con $\mathrm{A} / \mathrm{PMA} / \mathrm{EBV}$, and analyzed by fluorescent staining. $2 \mathrm{TC} 58^{+}$and $\mathrm{J5} / \mathrm{D}^{+}$cells were incubated overnight at $37^{\circ} \mathrm{C}$ in $\mathrm{T}$ cell medium to detach the beads from the cells. The free beads were separated magnetically. The XTC58+ cells remaining in suspension were carefully removed. Separate aliquots were stimulated at $10 \% / \mathrm{ml}$ in Con A/PMA/EBV for cytokine analysis or analyzed phenotypically with fluorescent staining.

Procedure C: A single cell suspension of mouse splenocytes was prepared in growth medium, $\mathrm{RBCs}$ lysed with $\mathrm{ACK}$, and an aliquot removed for stimulation and analysis (whole spleen). Cells were centrifuged, resuspended at $107 / \mathrm{ml}$ in cytotoxicity medium containing anti-CD8 antibody (1:20, Cedarlane), and incubated on ice for 1 hour. A washed 3:1 mixture of magnetic anti-mouse IgM:anti-mouse IgG beads ( $3 \mathrm{ml}$ beads total $/ 10^{8}$ cells) was prepared, and cells added in a volume of $200 \mu \mathrm{l} / 10^{8}$ cells as described above. Following incubation on ice for $45 \mathrm{~min}$ with occasional gentle shaking, adherent cells were separated 
magnetically from the non-adherent cells. An aliquot of non-adherent cells (sIgM-CD8-) was retained for stimulation and analysis. SIgM-CD8- cells were added to washed XTC58 mAb-conjugated beads, and incubated on ice $45 \mathrm{~min}$ with shaking. XTC58+ cells were magnetically separated from the non-adherent, XTC58-, cells. Whole spleen and SIgM-CD8- aliquots were stimulated immediately at $106 / \mathrm{ml}$ in Con A/PMA/EBV and analyzed by fluorescent staining. XTC58 ${ }^{+}$cell-bead conjugates and XTC58- cells were incubated overnight at $37^{\circ} \mathrm{C}$ in $\mathrm{T}$ cell medium. Following overnight incubation, XTC58 ${ }^{+}$cells were magnetically separated from the beads. Aliquots of XTC58- and XTC58+ cells were then stimulated at $106 / \mathrm{ml}$ with Con A/PMA/EBV.

In vitro allogeneic stimulation and expansion.. After overnight incubation in $\mathrm{T}$ cell medium containing $0.2 \%$ Th 2 supernatant, XTC58- cells and XTC58+ cells free of beads were expanded in vitro by allogeneic stimulation. A single cell suspension of CBA/J splenocytes was prepared in assay medium (15 ml/spleen), and irradiated $(2500 \mathrm{R})$. Irradiated splenocytes were washed once in assay medium, and then resuspended in $T$ cell medium at a concentration of $4 \times 10^{6}$ cells $/ \mathrm{ml}$. XTC58- and XTC58+ cells were mixed with irradiated CBA/J splenocytes at a 1:1 ratio, at a final total cell concentration of $4 \times 10^{6}$ cells $/ \mathrm{ml}$. Cultures were split $1: 2$ at 48 hours, and then as needed to maintain a cell density of $4-10 \times 10^{5} / \mathrm{ml}$. Partial replacement of T cell media was performed every 72 hours until the cells were harvested.

Cytokine assays. IL-2 and IL-4 were assayed by the response of the HT2 cell line using the colorimetric 3-(4,4-dimethyliazol-2-yl)-2,5-diphenyltetrazolium bromide (MTT) assay described previously $(71,72)$. Briefly, culture supernatants were titrated in 96-well flat bottomed microtitre trays (Falcon ${ }^{\mathrm{TM}}$ ). 
HT2 cells ( $1 \times 10^{3} /$ well) were added in the presence of $5 \mu \mathrm{g} / \mathrm{ml} 11 \mathrm{~B} 11$ anti-IL-4 $\mathrm{mAb}$ (for IL-2-specific assay), or $2 \times 10^{3}$ cells/well in the presence of a 1:100 dilution of S4B6 anti-IL-2 ascites fluid (for II-4-specific assay). Proliferation was measured at $24 \mathrm{hr}$. Standard units (stdU) of IL-2 and IL-4 were defined by assigning values of 40,000 and $4,000 \mathrm{stdU} / \mathrm{ml}$ to the laboratory reference standards of recombinant IL-2 and IL-4, respectively. IFN $\gamma$ and IL-5 were assayed using two-site sandwich ELISAs previously described $(13,73)$. Purified cytokine standards used were; recombinant mouse IFN $\gamma$ expressed in $E$. coli (Schering Research), and purified natural mouse IL-5 (74). Cytokines were quantitated by comparison with standard curves, using either linear or 4parameter curve fitting programs. Sensitivity limits for the bioassays and ELISAs were: IFN $\gamma, 200 \mathrm{pg} / \mathrm{ml} ; \mathrm{IL}-2,5 \mathrm{stdU} / \mathrm{ml} ; \mathrm{IL}-4,2$ stdU/ml; IL-5, 30 $\mathrm{pg} / \mathrm{ml}$.

Fluorescent cell staining and analysis. In procedures A and B, all antibodies (except IgM isotypes and PE-conjugates) were centrifuged at $100,000 \mathrm{xg}$ at 20 psi for $15 \mathrm{~min}$. to remove aggregatd antibody. Cells were aliquotted $\left(10^{6}\right.$ cells per well) in a 96-well round-bottomed microtitre tray (CoStar, Van Nuys, CA), centrifuged at $200 \mathrm{x} \mathrm{g}$ at $4^{\circ} \mathrm{C}$, and washed once in cold CBSS with $2 \%$ FBS. Cell pellets were resuspended in $20 \mu \mathrm{l}$ primary antibody dilution, and incubated 30 min on ice. To each well, $200 \mu 1$ cold CBSS with $2 \%$ FBS was added, underlaid with $20 \mu \mathrm{l}$ FBS to eliminate the need for more extensive washing, and centrifuged at $350 \mathrm{x}$ g for $5 \mathrm{~min}$. Cell pellets were then resuspended in $20 \mu \mathrm{l}$ PE- or FITC-labelled anti-primary antibody and incubated on ice for $30 \mathrm{~min}$. Pellets were again washed with cold CBSS and underlaid with FBS described above. For one- color analysis, pellets were washed a second time in CBSS 
without serum, then diluted in CBSS with $0.1 \%$ formalin (Mallinckrodt) at an approximate cell concentration of $1 \times 10^{6}$ cells/ml, and analyzed within 48 hours using a FACScan ${ }^{\mathrm{TM}}$ immunocytometry instrument (Becton Dickinson). For twocolor analysis, after the second wash and serum underlay, cells were incubated on ice for $30 \mathrm{~min}$ in $10 \mathrm{mg} / \mathrm{ml}$ rat IgG (a kind gift of R. Budd, Univ. of Vermont School of Medicine, Burlington, VT) or $10 \%$ normal rat serum (graciously obtained by D. Hopman, DNAX). Cells were washed and underlaid, and resuspended in $20 \mu \mathrm{l}$ biotin-conjugated secondary antibody, PE-conjugated anti-CD4, or FITC-conjugated anti-CD8 mAb.. Following incubation on ice for $30 \mathrm{~min}$, cells were washed and underlaid. For cells incubated with biotinconjugated second antibodies, a final incubation with streptavidin-PE (Caltag Laboratories, South San Fransisco, CA) or streptavidin-FITC (Caltag Laboratories) was performed. Cells were then washed with serum, washed again in serum-free CBSS, resuspended in CBSS (without formalin) and analyzed immediately using the FacScan ${ }^{\mathrm{TM}}$ instrument. Data analysis utilized the LYSYS ${ }^{\mathrm{TM}}$ software program (Becton Dickinson). 


\section{RESULTS}

Adherent XTC58+ cells selected by panning do not make detectable IL-2, IFNy IL-4 or IL-5. The use of antibody- coated polystyrene dishes has been shown to be an effective, simple method for fractionating cell subpopulations (75-77). To assess the feasibility of this method for isolating XTC58+ cells, a RBC-depleted splenocyte suspension was first depleted of adherent cells (macrophages). To deplete CTLs, the non-adherent cells were then incubated with anti-CD8 antibody, and $\mathrm{CD} 8+$ cells removed by absorption to goat anti-rat Ig-coated petri dishes. This CD4+-enriched culture was then incubated with XTC58 mAb, and XTC $58^{+}$cells separated by binding to goat anti-rat IgG/IgM-coated petri dishes. Adherent XTC58+ cells were removed by vigorous pipetting following brief incubation in cold lidocaine. Cytokines secreted in response to Con A/PMA stimulation were measured to assess the efficiency of separation (Table I). The data suggest that, in the CD8- population, XTC58- cells are responsible for all of the cytokine production, which is possible if this fraction contains all of the CD4 ${ }^{+}$cells. $\mathrm{XTC}^{+} 8^{+}$cells purified and stimulated by this method do not make any detectable levels of any cytokine tested. Also, the XTC58 mAb might identify a non-T cell type, incapable of producing cytokines. Alternatively, the purified XTC58+ cells may be lacking an accessory cell needed to process the Con $\mathrm{A}$ and mediate $\mathrm{T}$ cell stimulation, e.g. the adherent cells removed initially. It is also likely that the lidocaine treatment used in the removal of the XTC58+ cells interfered with the cell membranes, and consequently the ability of these cells to respond to Con A. 
TABLE I

Cytokine analysis of cell populations separated by panning $a$

Cytokine per $1 \times 10^{6}$ cells $^{b}$

Cell Population

IFN $\gamma \quad$ IL2 IL4 IL5

$(\mathrm{ng} / \mathrm{ml})(\mathrm{stdU} / \mathrm{ml})(\mathrm{stdU} / \mathrm{ml})(\mathrm{ng} / \mathrm{ml})$

\begin{tabular}{llrrr}
\hline & 4 & 1826 & 15 & $<0.20$ \\
AC- & 10 & 2096 & 19 & $<0.20$ \\
AC-sIg-B220- & 14 & 1584 & 22 & $<0.20$ \\
AC-sIg-B220-Lyt2- & 15 & 1107 & 88 & $<0.20$ \\
AC-sIg-B220-Lyt2-XTC58- & 15 & $<6$ & $<0.20$ \\
AC-sIg-B220-Lyt2-XTC58+c & $<1.6$ & $<12$ & $<$ \\
\hline
\end{tabular}

$a$ Splenocytes from Balb/cByJ mice $(\mathrm{n}=2)$, depleted of adherent cells (AC), were incubated with rat antimouse cell surface antibody and separated by incubation on anti-rat Ig-coated petri dishes as described in Materials and Methods. All cell populations were stimulated with Concanavalin A (5 $\mu \mathrm{g} / \mathrm{ml})$ and PMA $(10 \mathrm{ng} / \mathrm{ml})$ at a cell concentration of $5 \times 10^{6} \mathrm{cells} / \mathrm{ml}$. Supernatants were collected at 24 hr, and assayed by bioassay (IL-2 and IL-4) or ELISA (IFN $\gamma$ and IL5).

$b$ IL 2 and IL 4 values were assigned by normalizing against assigned standard values of 40,000 U/ml and $4,000 \mathrm{U} / \mathrm{ml}$ respectively. Sample IFN $\gamma$ and IL5 values were calculated using four-parameter curve fitting against standard curves of titrated recombinant cytokine.

c XTC58 ${ }^{+}$cells were removed following incubation with lidocaine $\left(4 \mathrm{mg} / \mathrm{ml}, 4^{\circ} \mathrm{C}\right.$ for 15 minutes) followed by vigorous pipetting, washed and stimulated immediately using conditions described above. 
Lidocaine and EDTA treatments interfere with the ability of a $\mathrm{T}$ cell clone to produce IFNy. Recommended procedures to dislodge adherent cells from antibody-coated plates involved incubation of adherent cells with lidocaine or EDTA, followed by vigorous pipetting (H. Bass, S. White, personal communication). The ability of the Th1 cell line HDK-1 to secrete IFN $\gamma$ after these treatments is shown in Table II. Incubation of cells in CBSS or CBSS with

\section{TABLE II}

Effect of various adherent cell removal treatments on HDK-I cytokine production

\begin{tabular}{|c|c|c|c|}
\hline Treatment $a$ & Recovery $b$ & \multicolumn{2}{|c|}{ IFNg (ng/ml) $\%$ control $c$} \\
\hline none & - & 1142 & 100 \\
\hline CBSS & - & 828 & 73 \\
\hline FCS/CBSS & - & 816 & 71 \\
\hline $\mathrm{CBSS}+\mathrm{EDTA}$ & - & 361 & 32 \\
\hline " " & $4 \mathrm{hr}$ & 712 & 62 \\
\hline$"$ & $12 \mathrm{hr}$ & 462 & 40 \\
\hline CBSS + lidocain & ne & 130 & 11 \\
\hline & " $4 \mathrm{hr}$ & 183 & 16 \\
\hline$"$ & " $12 \mathrm{hr}$ & 116 & 10 \\
\hline
\end{tabular}

$a$ HDK-1 cells were incubated in CBSS, CBSS containing $2 \%$ FCS, $50 \mathrm{mM}$ EDTA or $4 \mathrm{mg} / \mathrm{ml}$ lidocaine at $4^{\circ} \mathrm{C}$ for 15 minutes.

$b$ Cells were washed and incubated in T cell medium at $37^{\circ} \mathrm{C}$ prior to stimulation.

$c$ Cells were stimulated using Concanavalin A (5 $\mu \mathrm{g} / \mathrm{ml}$ ) at a cell concentration of $5 \times 10^{6} / \mathrm{ml}$. Supernatants were harvested at $24 \mathrm{hr}$ and assayed for IFN $\gamma$ by ELISA. Results are expressed as $\mathrm{ng} / \mathrm{ml} \mathrm{IFN \gamma}$ per $5 \times 10^{6}$ cells. 
$2 \%$ FBS resulted in a $25 \%$ decrease in the levels of IFN $\gamma$ detected as compared to no treatment. Incubation in CBSS containing $50 \mu \mathrm{M}$ EDTA for $15 \mathrm{~min}$ decreased the cytokine levels by $68 \%$. Allowing the cells to recover by incubation in $\mathrm{T}$ cell medium for $4 \mathrm{hr}$ restored cytokine production to nearly the levels in CBSS alone. A longer recovery time of $12 \mathrm{hr}$ resulted in a decrease from the levels seen with a $4 \mathrm{hr}$ recovery time, possibly from decreasing cell vitality. Lidocaine treatment caused a 90\% reduction in IFN $\gamma$ levels, which could not be restored by incubation in $\mathrm{T}$ cell medium for up to $12 \mathrm{hr}$ following lidocaine treatment. Thus, the use of lidocaine or EDTA to remove adherent cells during panning did not prove efficacious when analyzing cytokine production by panned cell populations.

Fluorescent staining provides a useful tool for analyzing the purity of fractionated cell populations. Mouse spleen contains a multitude of cell types. An efficient way to define these cell types is by fluorescent staining, analyzing the labelled cells using a fluorescence activated cell sorter (FACS $\left.{ }^{\mathrm{TM}}\right)(78-80)$. Using different fluorochromes, FACS analysis can be used to identify subpopulations of cells, on a single cell level, within heterogeneous mixtures of cells as well as measuring relative amounts of surface molecules. Cells are incubated with a primary antibody which binds to specific determinants on the cell surface, followed by incubation with an anti-primary second antibody which has been conjugated to a fluorescent molecule. Cells are passed single file in a liquid stream through a laser beam, and the size, fluorescence intensity and number of cells recorded. Data collected in this way are most commonly displayed as a one dimensional histogram. Cell frequency is indicated on the vertical axis, and cell size or fluorescence intensity displayed on the horizontal 
axis. Cell size is measured by forward-angle light scatter (FSC) and is recorded based on diffraction of the laser beam as the cell passes. Although there is a strong positive correlation with cell size, it is not exactly proportional because of the influence of properties such as assymetry, reflectivity, refractive index, granularity and nuclear size.

Fluorescence intensity can also be displayed on the horizontal axis. Fluorescence intensity reflects the number of fluorescent molecules bound per cell, and as the fluorescence increases, the cells are recorded in increasingly higher channels. Just because two cells fall in the same channel does not necessarily mean that they possess the same density of a particular marker. A small cell with a large number of determinants may be collected in the same channel as a larger cell displaying a lower density of that marker, since the absolute number of fluorescent molecules per cell is the same. Plotting FSC against fluorescence intensity in a two-dimensional dot plot is a useful way of approaching this phenomenon. There are now reagents available which can be used to quantitate the number of molecules per cell. The staining intensity of pre-sized beads with a known number of reactive sites can be matched to the size and staining intensity of a sample preparation to determine the approximate number of sites per cell.

The horizontal axis displays units of light scatter or units of fluorescent molecules per cell. These units are proportional to the size, or number of fluorescent molecules bound, respectively. Data can be collected using linear or logarithmic scales. A linear scale divides the horizontal axis into 256 equal divisions. Acquiring data using this scale is more appropriate for detecting subtle changes, occuring over a small range of fluorescence intensitity. When this 
scale is used to collect data from a mixture of dull (few determinants) and very bright (many determinants) cells, resolution of the dimly staining cells will be poor. A logarithmic scale compresses four decades of fluorescence into 256 channels, and is more appropriate for analyzing a wide range of intensities, with equal resolution at all intensities. For this purpose, data in the experiments discussed below were collected using a logarithmic scale.

To determine non-specific binding of primary antibody reagents to cell surfaces, an irrelevant antibody of the same isotype as the specific reagent is used (isotype control). All non-IgM antibodies and conjugates should be centrifuged at $100,000 \mathrm{~g}$ at $20 \mathrm{psi}$ (airfuged) to remove large antibody aggregates, which can bind to $F_{\mathcal{C}}$ receptors and create high background staining. IgM antibodies and PE-conjugated antibodies cannot be airfuged since they will be separated by virtue of their inherently large size. Non-specific second antibody/reagent staining is measured by eliminating the primary antibody, incubating the cells with only the final reagent, e.g. streptavidin-PE, streptavidin-FITC or FITC-goat anti-rat Ig (for mouse cell staining). This will accurately reflect non-specific binding providing that the second reagent is known not to crossreact with, or has been absorbed against, the primary species. A method useful for minimizing non-specific binding is to incubate the cells in Ig-containing serum (the same species as the staining reagent), prior to addition of specific reagents, to occupy the free $\mathrm{F}_{\mathrm{c}}$ receptors. This blocks the sites available for non-specific binding of other reagents with non-detectable molecules.

The percent positive cells are calculated within a set gate, which is usually placed upon inspection of the isotype control staining profile. The gate is set at 
the trailing edge of the appropriate isotype control histogram peak, such that only a small number of cells recorded fall within the set window (Fig. 1). This

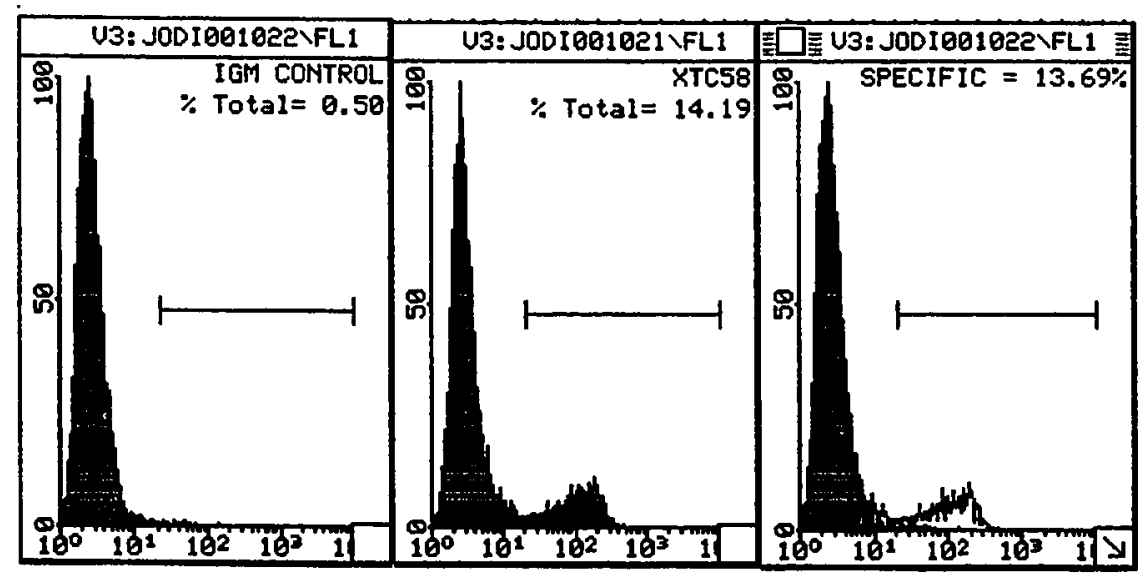

Figure 1. Calculation of specific fluorescence. The total percent of cells which stain with the isotype control antibody (IgM control), is subtracted from the total percent which stain with the specific reagent (XTC58), to arrive at the percent of cells actually positive (specific).

small, non-specific percent is subtracted from the total percent positive obtained when this gate is applied to a specifically stained population, which results in a value indicative of the percent specifically stained cells.

In the FACS analyses for Procedures A, B and C, although all IgG isotype antibodies were airfuged, non-specific staining of the IgG2a and IgG2b isotype controls were, surprisingly, greater than staining of specific IgG antibodies (Fig. 2). Specific binding should normally be the same or greater than non-specific binding. For this reason, it was suspected that the isotype control reagents were contaminated, making it unsuitable to use these controls to represent non-specific IgG binding. The IgM isotype control showed the low staining profile typical of 


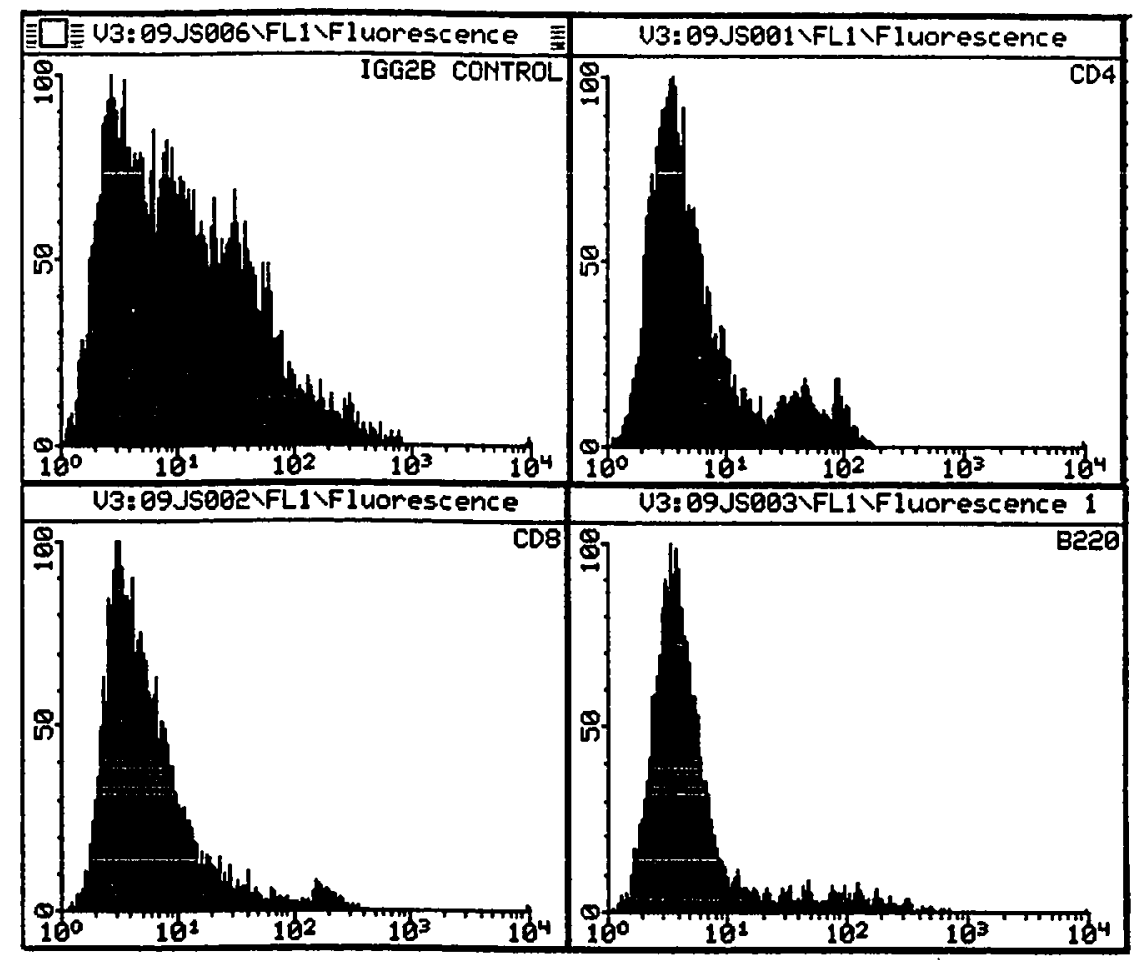

Figure 2. Isotype control versus specific histogram analysis of unfractionated splenocytes. Whole spleen was stained with IgG2b isotype control antibody, antiCD4, anti-CD8 or anti-B220 mAbs, followed by incubation with FITC-conjugated anti-rat Ig. Data shown here was obtained from the splenocyte preparation used for immunomagnetic bead separation Procedure A, and is representative of nonspecific staining observed in Procedures A, B and C.

IgM, but since non-specific IgM staining is generally less than IgG isotypes (Fig. 3 ), this control was inappropriate to represent non-specific IgG binding. Applying the IgM isotype control to IgG isotypes would create an artificially high percent specific staining for the IgG isotypes. For these reasons, the second antibody (no primary antibody) control (Fig. 3, 2nd ab) was chosen as the most objective indicator of experimental background which would be consistent at 


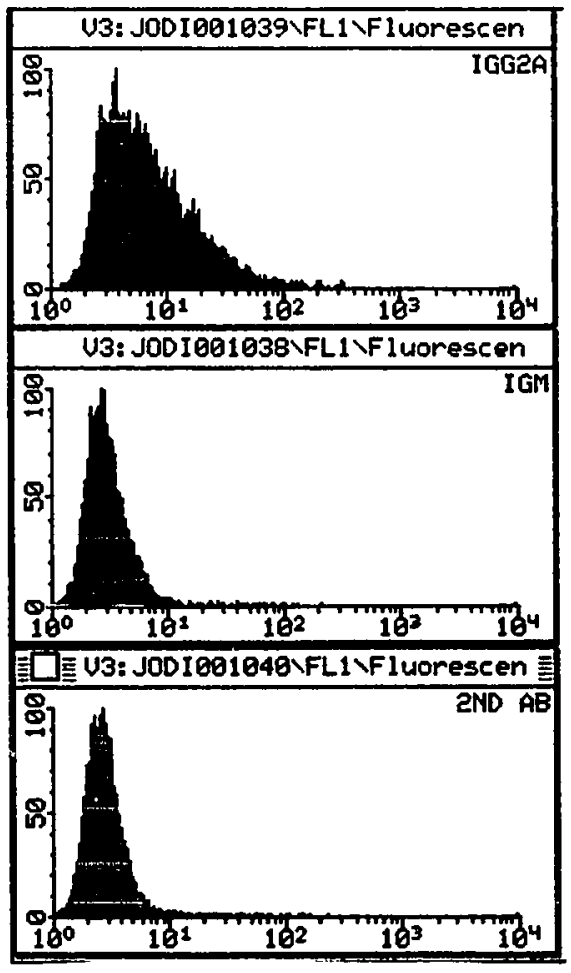

Figure 3. Expected isotype control histograms of unfractionated splenocytes. RBC were lysed with ACKS and then incubated with IgG2a or IgM isotype control $\mathrm{mAb}$, followed by goat anti-rat Ig-FITC (IgG2a, IgM), or FITC-conjugate alone (2nd ab).

channel 50. The percent positive in the second antibody control was subtracted from the total percent positive (within this window) cells stained with primary and secondary antibody, to obtain the percent of cells specifically stained. Another consideration in these experiments was that the background fluorescence in whole spleen was significantly higher than in depleted populations. Consequently, when the background was subtracted from the specific staining, in many instances it appeared that the specific percent positive actually increased after depletion for that cell type. Therefore, it is important not only to consider the numerical data, but to also scrutinize the histogram, combining information from both into the final conclusions.

Use of immunomagnetic bead separation to fractionate major splenocyte populations. An alternative to fractionating populations by panning employs 
immunomagnetic beads $(81,82)$. Antibody-coated magnetic iron oxide particles bind cells which can then be removed from suspension by the application of a magnetic field. Based on the assumption that the XTC58 determinant would identify a $\mathrm{CD} 4^{+}$subset, immunomagnetic beads were used to enrich for $\mathrm{CD} 4^{+}$ cells by depleting whole spleen cell suspensions of $\mathrm{B}$ cells and $\mathrm{CD} 8{ }^{+}$cells. The efficiency of separation was monitored with fluorescent staining, and changes in cytokine patterns in induced cell supernatants measured by bioassay and ELISA. Three different bead protocols were evaluated (Fig. 4). In Procedure A, cells

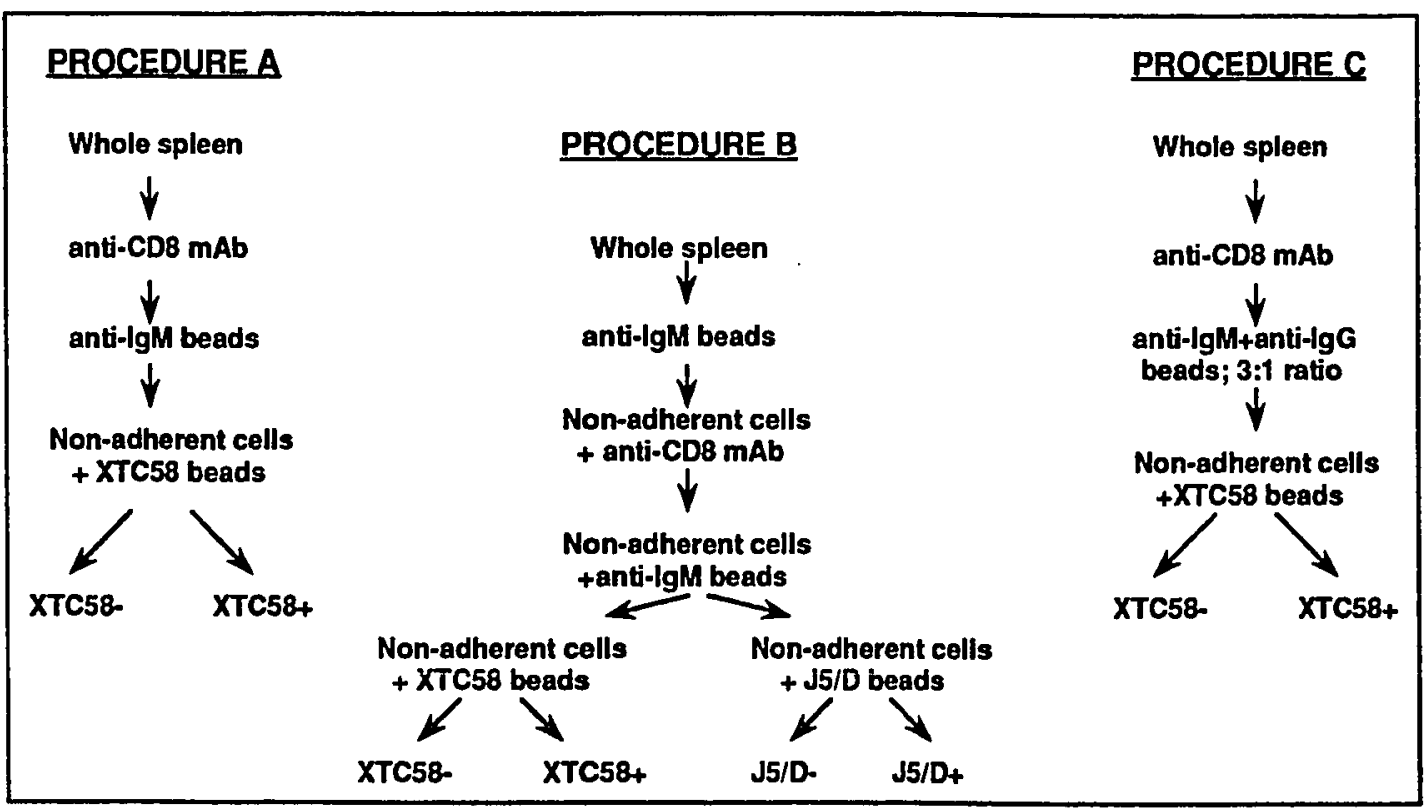

Figure 4. Flow diagrams of immunomagnetic bead separation Procedures A, B and C.

were incubated with mouse anti-CD8 $\mathrm{mAb}$ (mouse IgM), and depleted for sIgMbearing B cells and CTL simultaneously by subsequent incubation with antimouse IgM beads. In procedure B, sIgM-bearing B cells were first removed 
with anti- mouse IgM beads, followed by incubation with mouse anti-CD8 mAb and removal of antibody-coated CD8 cells (and a simultaneous second round of depletion of sIgM-bearing $B$ cells) with anti-mouse IgM beads. Procedure $\mathrm{C}$ was similar to Procedure A, except that anti-mouse IgG beads were combined with the anti-mouse $\operatorname{IgM}$ beads to additionally remove $\operatorname{sIgG}^{+} \mathrm{B}$ cells.

All procedures took advantage of the fact that B cells express surface immunoglobulin. The mouse anti-CD8 reagent used here was also a mouse IgM, so anti-mouse IgM beads could be used to remove both $B$ cells and mouse antiCD8 antibody-coated CTL in the same step. An alternative method for B cell removal could have been to coat the cells with rat anti-B220 mAb and remove them with anti-rat IgG beads in an additional step.

The efficacy of these procedures to deplete B cells and CTL, enriching for CD4+ cells, is shown in Figures 5, 6 and 7 (Procedures A,B and C respectively). The histogram data is illustrated in the upper portion of each figure, with the raw and specific percent positive staining indicated in text below. Inspection of the numerical data for Procedure A (Fig. 5), suggests that depletion of B cells by removing $\operatorname{sIgM}^{+}$cells actually increases the percent of $\mathrm{B}^{2} 20^{+}$cells. This is created by the high background staining in whole spleen as compared tothe depleted populations, and examination of the histogram shows that this method effectively removes the majority of brightly staining $\mathrm{B}^{2} 2 \mathrm{O}^{+}$cells. In contrast, removal of the $\mathrm{CD}^{+}$cells is inconclusive. The $\mathrm{CD} 8+$ cells should appear as a distinct, brightly staining population of cells, similar to the $\mathrm{CD}^{+}{ }^{+}$staining profile. In addition, the bead-mediated removal of the $\mathrm{CD} 8^{+}$cells removed only dim cells, leaving behind the small number of CD8-bright cells. The 


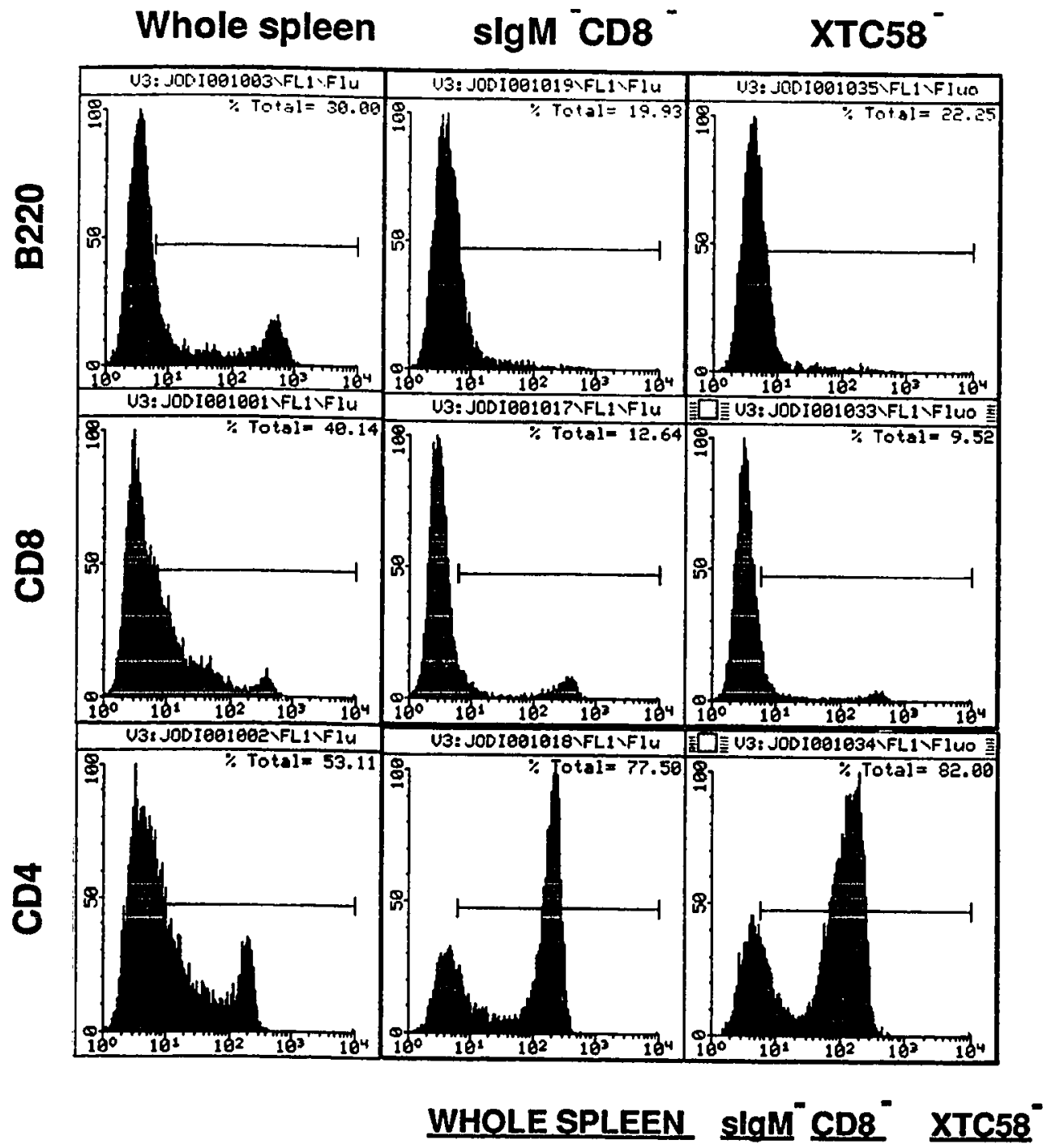

Before background subtraction

$\begin{array}{lrrr}\text { B220 } & 30.00 & 19.93 & 22.25 \\ \text { CD8 } & 40.14 & 12.64 & 9.52 \\ \text { CD4 } & 53.11 & 77.50 & 82.00 \\ & & & \\ \text { 2 antlbody only(background) } & 26.21 & 2.39 & 3.94 \\ & & & \\ \text { After background subtraction } & & & \\ \text { B220 } & 3.79 & 17.54 & 18.31 \\ \text { CD8 } & 13.93 & 10.25 & 5.58 \\ \text { CD4 } & 26.90 & 75.11 & 78.06\end{array}$


Figure 5. Phenotypic analysis of bead separation Procedure A. Unfractionated (whole spleen), sIg M+C D 8+-depleted (sIgM-CD 8-) and sIgM ${ }^{+} \mathrm{CD} 8+\mathrm{XTC}^{+} 8^{+}-$depleted (XTC58-) cells were stained with the primary rat anti-mouse B220, CD8 or CD4 mAbs, followed by incubation with goat antirat Ig-FITC. Total percent positive cells within the set gate are indicated on the histograms, and in the text below (Before background subtraction). After background subtraction values were obtained by subtracting non-specific goat anti-rat Ig-FITC staining (secondary antibody only, background), from total percent staining.

combination of these two aspects suggest that the anti-CD8 staining reagent used in this experiment was faulty, making it difficult to determine the efficiency of $\mathrm{CD} 8+$ cell depletion. This method did prove efficacious for enrichment of $\mathrm{CD}^{+}$ cells, however, resulting in an overall $200 \%$ (three-fold) enrichment for $\mathrm{CD}^{+}{ }^{+}$ cells. The optimum enrichment for $\mathrm{CD} 4^{+}$cells which can be expected, is a final population of approximately $80 \% \mathrm{CD}^{+}$, because of the presence of non- $\mathrm{B}$, non$\mathrm{T}$ cells not removed by this method. Removal of XTC58+ cells did result in a decrease in the CD8+-bright cells, indicating that XTC58 possibly identifies a CTL subpopulation. Likewise, the increase in the percent $\mathrm{CD} 4+$ cells following $\mathrm{XTC} 58^{+}$cell depletion supports this by the fact that removing XTC58+ cells depletes a non-CD4+ cell type.

The number of cells positive for B220, CD8 and CD4 in Procedure B (Fig. 6) in general appears less than in the first experiment, indicating weaker staining. However, since the background staining was also lower, the adjusted values for specific staining usually appear higher than in Procedure A. The percent of whole spleen cells staining specifically for B220 in Procedure B is 


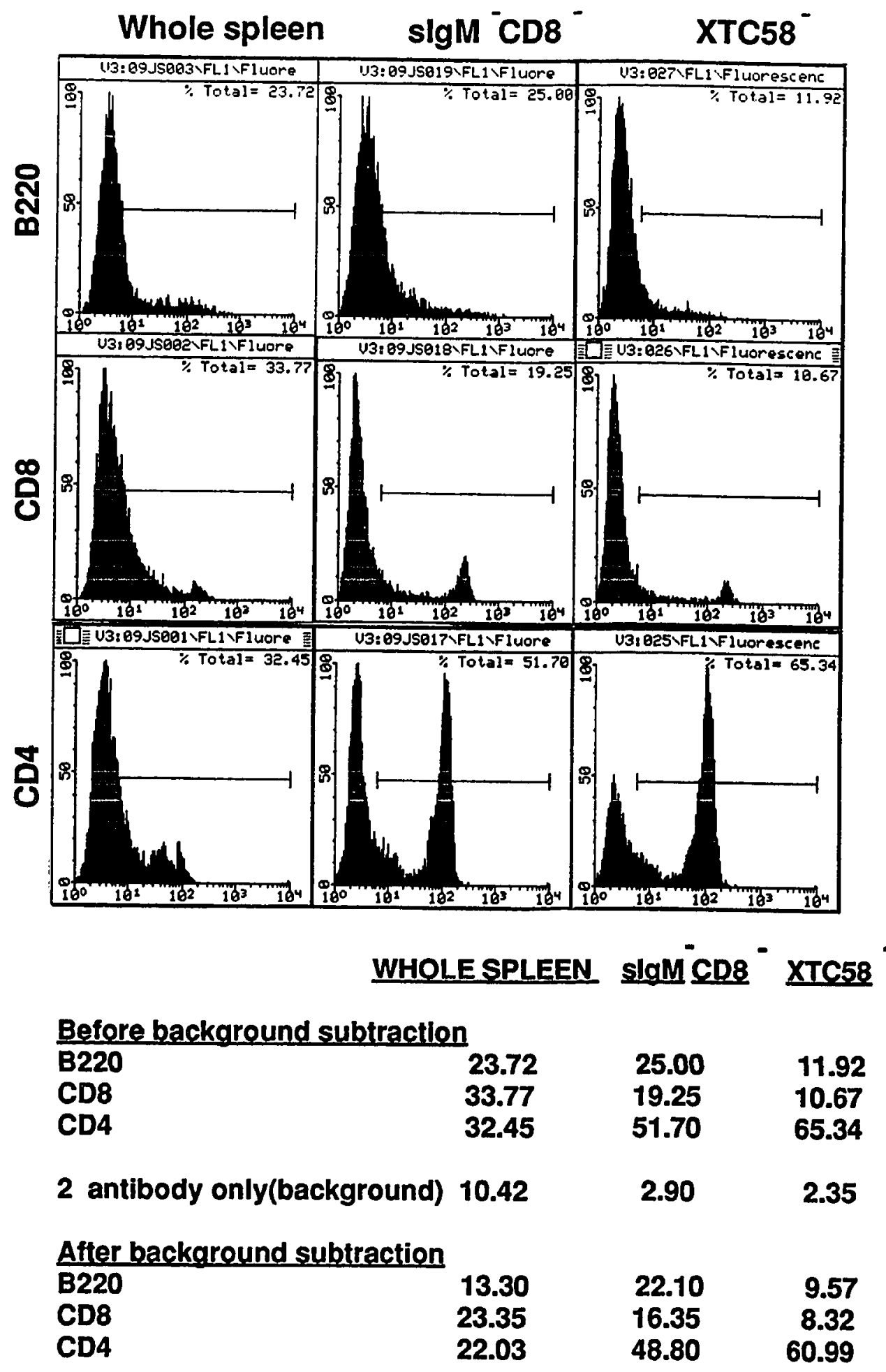


Figure 6. Phenotypic analysis of bead separation Procedure B. Unfractionated (whole spleen), s I g M+C D 8+-depleted (sIgM-C D 8 ${ }^{-}$) and sIgM ${ }^{+} \mathrm{CD} 8{ }^{+} \mathrm{XTC}^{+} 8^{+}$-depleted (XTC58-) cells were stained with the primary rat anti-mouse B220, CD8 or CD4 mAbs, followed by incubation with goat antirat Ig-FITC. Total percent positive cells within the set gate are indicated on the histograms, and in the text below (Before background subtraction). After background subtraction values were obtained by subtracting non-specific goat anti-rat Ig-FITC staining (secondary antibody only, background), from total percent staining.

higher than Procedure A, but is still not near the $40-50 \%$ expected in a normal mouse spleen. Consistent with Procedure $A$ is the high second antibody (background) staining in whole spleen relative to the depleted populations. This again results in an apparent increase in the absolute percent $\mathrm{B} 22 \mathrm{O}^{+}$cells in the numerical sIgM-CD8- data, which may be an artifact of the high background. It is not reflected by the histogram, as the number of low positive $\mathrm{B} 220^{+}$cell appears to increase after depletion for sIgM $^{+}$and $\mathrm{CD}^{+}$cells. Similar to Procedure A, depletion of $\mathrm{CD} 8+$ cells is again confined to those cells expressing low amounts of the CD8 marker. Procedure B was not significantly different that Procedure $\mathrm{A}$ in terms of enrichment for CD4+ cells.

In Procedure B, dim B220+ cells were removed by $\mathrm{XTC}^{+} 8^{+}$cell depletion, suggesting that removal of XTC58+ cells is removing a $\mathrm{B} 220^{+}$ subpopulation. Depletion of $\mathrm{XTC}^{+} 8^{+}$cells also appears to remove a CD4-CD8 ${ }^{+}$ cell phenotype.

The fractionation protocol in Procedure C (Fig. 7) was the same as Procedure A, except that for B cell depletion, a combination of anti-mouse IgM and anti-mouse IgG beads were used instead of anti-mouse IgM beads alone. 


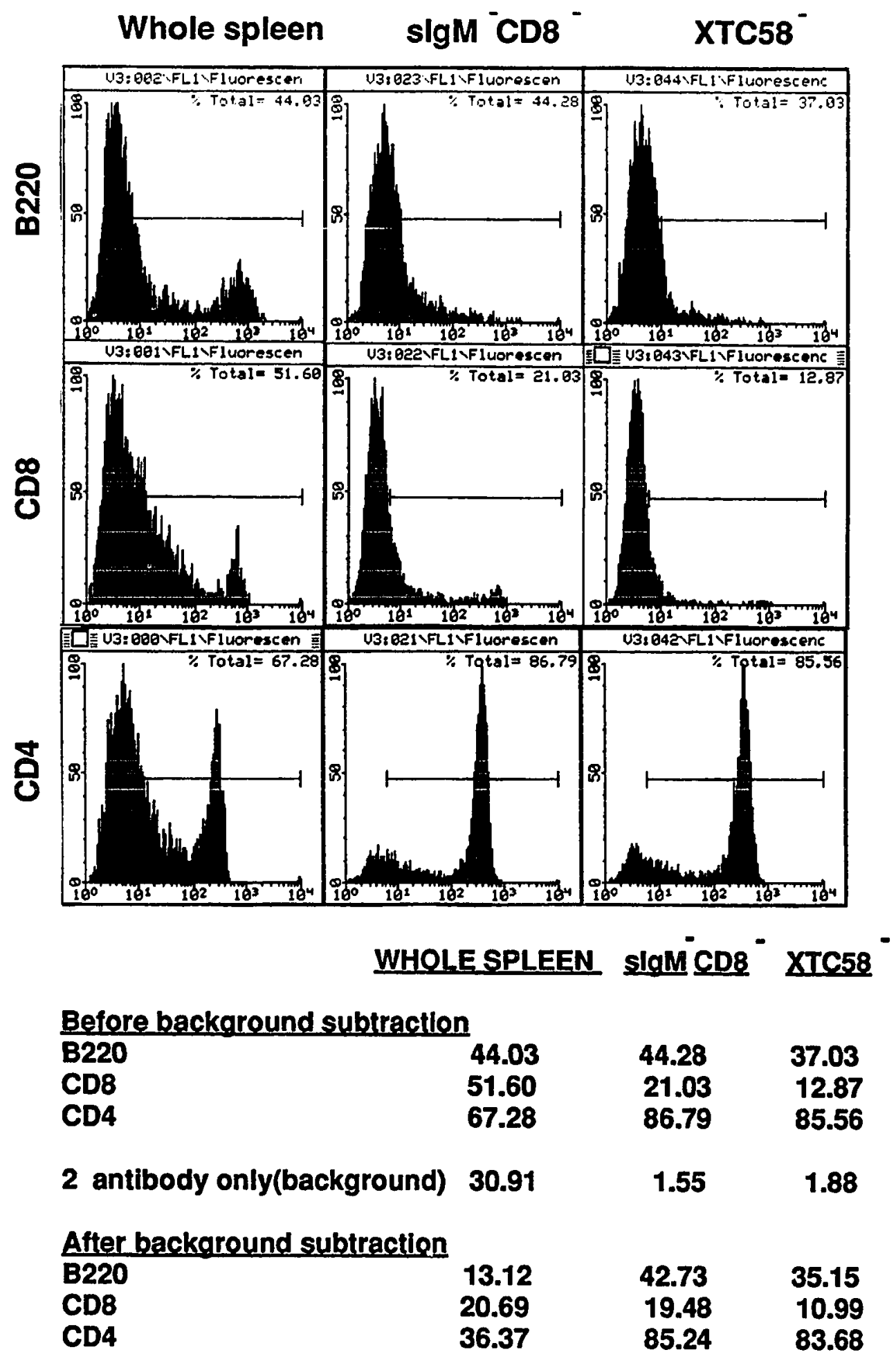


Figure 7. Phenotypic analysis of bead separation Procedure C. Unfractionated (whole spleen),

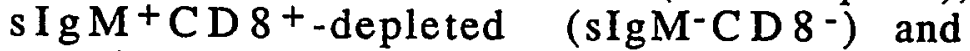
sIgM+CD8 ${ }^{+} \mathrm{XTC}^{+} 8^{+}$-depleted (XTC58-) cells were stained with the primary rat anti-mouse B220, CD8 or CD4 mAbs, followed by incubation with goat antirat Ig-FITC. Total percent positive cells within the set gate are indicated on the histograms, and in the text below (Before background subtraction). After background subtraction values were obtained by subtracting non-specific goat anti-rat Ig-FITC staining (secondary antibody only, background), from total percent staining.

Addition of anti-mouse IgG beads does appear to deplete significantly more $\mathrm{B} 220^{+}$cells. Depletion of XTC58+ cells again resulted in a decrease in the

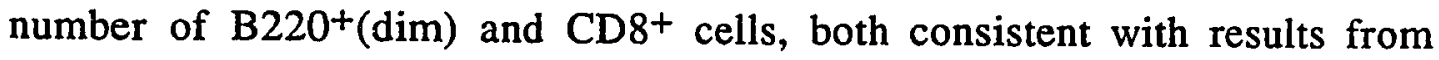
Procedure B. The final population in Procedure $\mathrm{C}$ was the most enriched for the CD4+ phenotype, $83.68 \%$.

In summary, of the three protocols examined, Procedure A affords the best enrichment for CD4+ cells as judged by percent increase (290\%), but the final population of Procedure $\mathrm{C}$ contained more $\mathrm{CD} 4+$ cells $(83.68 \%)$ than Procedures A $(78.06 \%)$ or B $(60.99 \%)$. It is doubtful if this reflects a significant difference in the efficiency of the bead separation protocols, and more likely arises from differences in the starting spleen populations. All three methods effectively remove B220+ cells. Thus, it appears that removing B cells via sIgM and sIgG is an efficacious means of depleting B cells from whole spleen.

The results of CTL (CD8+ cell) depletion are inconclusive. It appears that all of the procedures removed primarily those cells expressing lower levels of surface CD8. However, the reagents used for fluorescent staining failed to 
demonstrate the bright $\mathrm{CD}^{+}$cells known to exist in whole spleen. Since the quality of the anti-CD8 staining reagent is questionable, it is difficult to determine if these immunomagnetic bead procedures could separate $\mathrm{CD} 8^{+}$cells.

Consistent between all procedures is the suggestion that the XTC58 mAb recognizes a subpopulation of $\mathrm{CD} 4-\mathrm{CD} 8+$ lymphocytes, and Procedures $\mathrm{B}$ and $\mathrm{C}$ indicate that the XTC58 determinant may also be found on a subpopulation of B220lo cells as well.

Immunomagnetic beads efficiently remove XTC58 ${ }^{+}$cells from mixed cell populations. XTC58-specific staining in XTC58+-depleted populations from all three magnetic bead procedures is compared in Figure 8. Since the specific staining is more accurately calculated by subtracting background staining of the proper isotype control, the percent positive staining of the IgM isotype control was subtracted from total $\mathrm{XTC}^{+} 8^{+}$staining to derive the percent specific XTC58+ shown in the text of Figure 8. Depletion of XTC58+ cells in all three protocols was successful, ranging from $69.8 \%$ (Procedure A) to $88.3 \%$ (Procedure C).

Specificity of depletion for XTC58+ cells was demonstrated by a parallel removal of cells with immunomagnetic beads conjugated to the irrelevant isotype-control antibody (J5/D). Figure 9 illustrates that depletion with XTC58beads (XTC58-depleted) removes $93 \%$ of the XTC58+ cells, and $40 \%$ of the $\mathrm{CD}^{+}$cells, from the sIgM- CD8- fraction (CD8-depleted).

Separation of the CD8+-depleted starting population with J5/D-conjugated beads (J5/D-depleted), failed to remove a significant amount of XTC58+ or 


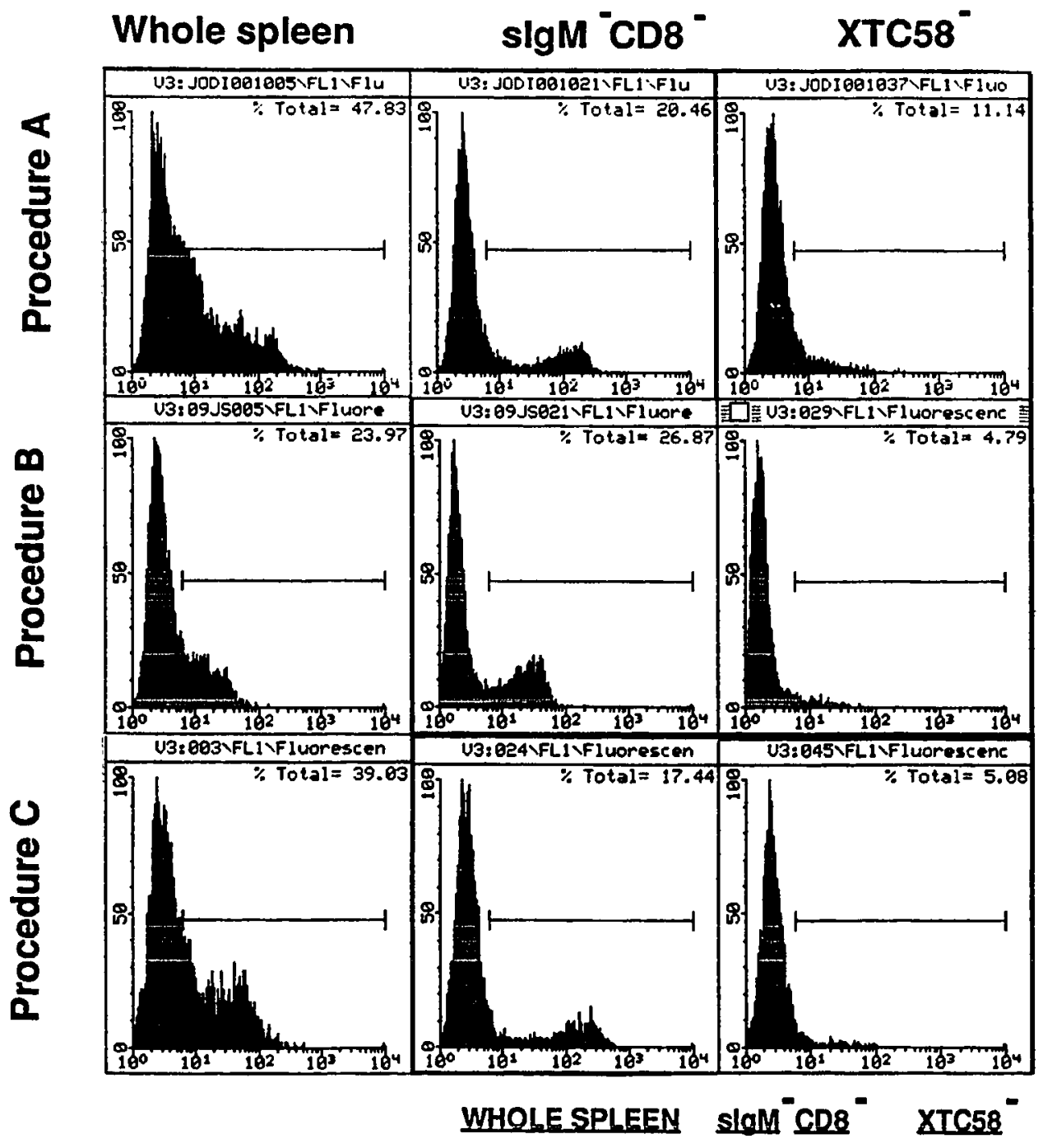

Before backoround subtraction

$\begin{array}{lrrr}\text { XTC58 } & 47.83 & 20.46 & 11.14 \\ \text { Isotype control } & 30.19 & 3.33 & 6.17 \\ \text { XTC58 } & & & \\ \text { Isotype control } & 23.97 & 26.87 & 4.79 \\ & 14.32 & 2.72 & 2.90 \\ \text { XTC58 } & & & \\ \text { Isotype control } & 39.83 & 17.44 & 5.08 \\ & 23.40 & 4.67 & 3.16 \\ \text { After backoround subtraction } & & & \\ \text { Procedure A } & & & \\ \text { Procedure B } & 17.64 & 17.13 & 4.97 \\ \text { Procedure C } & 9.65 & 24.15 & 1.89 \\ & 16.43 & 12.77 & 1.92\end{array}$


Figure 8. Phenotypic analysis of $\mathrm{XTC}^{2} 8^{+}$cell depletion: Comparison of Procedures A, B, and C. Unfractionated spleen (whole spleen), sIgM+CD8 $8^{+}$ depleted (sIgM-CD8-) and sIgM+CD8+XTC58+depleted (XTC58-) cells were stained for XTC58, followed by goat anti-rat Ig-FITC. Total percent staining is shown in the histogram panels. Specific XTC58 staining (after background staining) was determined by subtraction of IgM isotype control (J5/D) staining from total XTC58 staining.

CD8+ cells. These results suggest that depletion of XTC58+ cells with XTC58conjugated beads is a result of XTC58-conjugated beads binding specifically to the XTC58 determinant, and not the result of a non-specific isolation of $F_{c} \mu-$

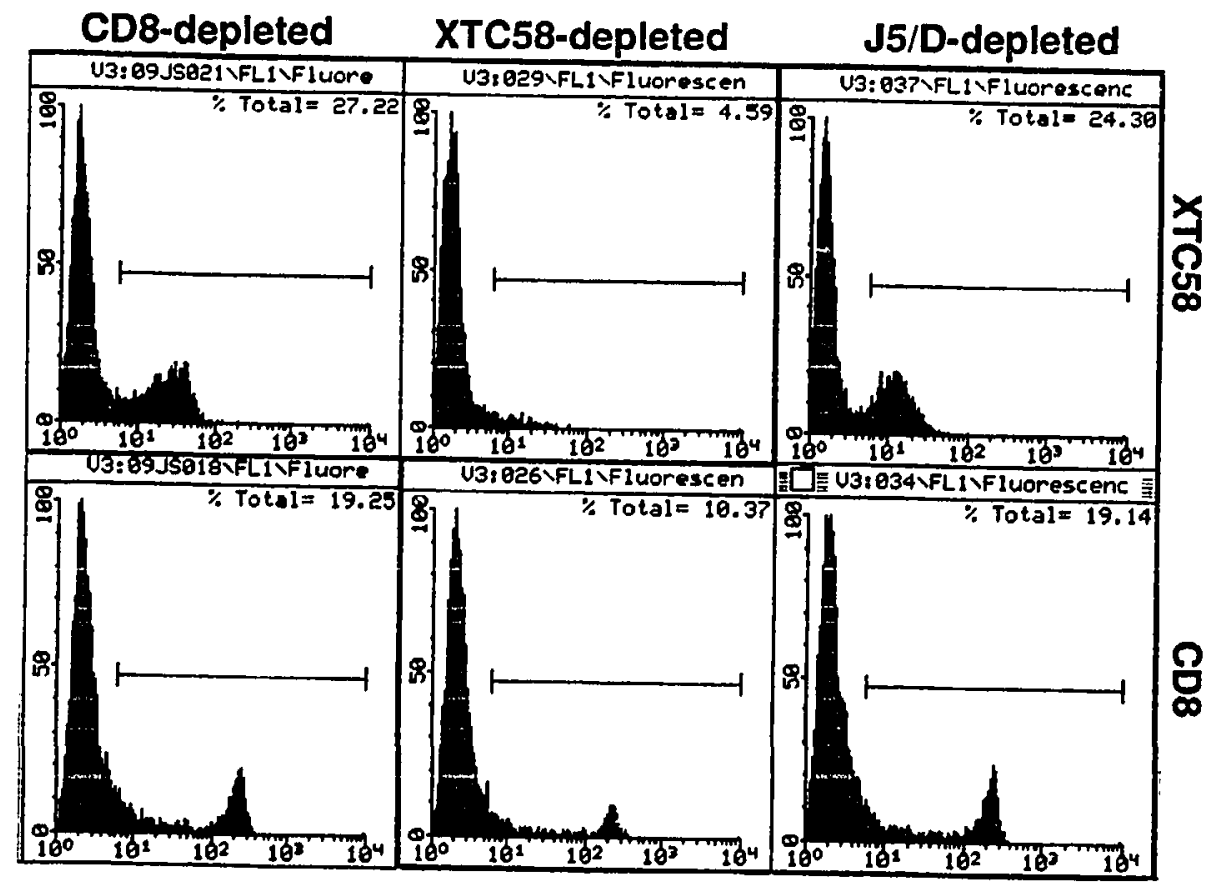

CD8-depleted XTC58-depleted J5/D-depleted

$\begin{array}{llll}\% \text { XTC58 } & 24.50 & 1.69 & 21.03 \\ \% \text { CD8 } & 16.35 & 8.02 & 16.92\end{array}$


Figure 9. XTC58 versus CD8 expression in CD8+. depleted, XTC58+-depleted or J5/D-depleted cultures. CD8-depleted, XTC58-depleted or isotype control (J5/D)-depleted cells were stained for XTC58 or CD8. Total percent staining is indicated in the histogram windows. Specific staining is indicated as the percent total stained minus the second antibody control.

bearing cells.

It was difficult to directly measure the positivity of the adherent, $\mathrm{XTC} 8^{+}$cells. Fluorescent staining of cells directly after adsorption to XTC58-conjugated beads was uninterpretable (data not shown). It was

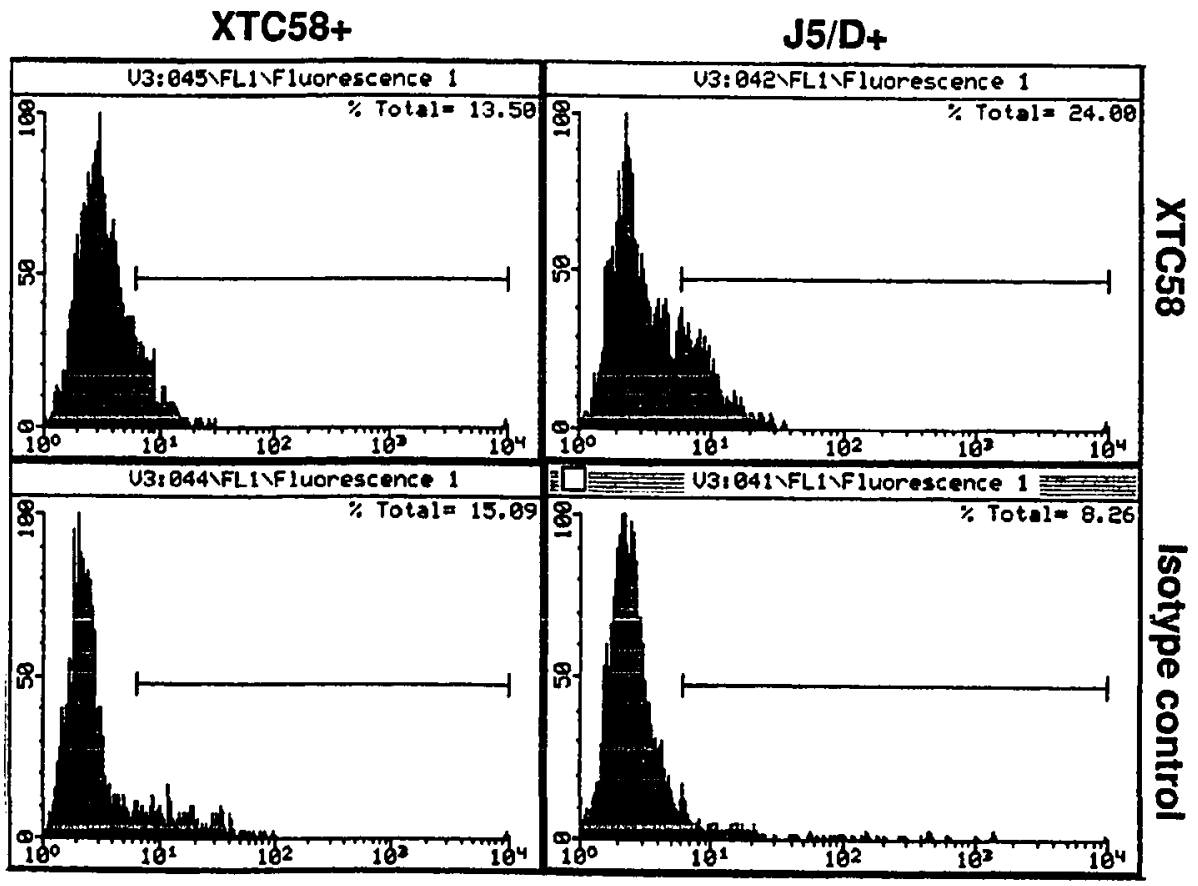

Figure 10. XTC58 and J5/D staining of XTC58+ and J5/D+ cells. $\mathrm{XTC}^{+} 8^{+}$and $\mathrm{J} 5 / \mathrm{D}^{+}$-bead-adherent cells were incubated overnight in $T$ cell medium, and then separated magnetically from the beads. Cells were then analyzed for the expression of XTC58 or J5/D (isotype control) using FACS analysis. 
suggested that incubating the cell-bead conjugates overnight would allow the dissociation of the cells and beads ( $H$. Bass, personal communication), so the $\mathrm{XTC} 8^{+}$cell-bead or $\mathrm{J5} / \mathrm{D}^{+}$cell-bead mixtures from Procedure B were incubated overnight in $\mathrm{T}$ cell medium. The beads were magnetically removed and the suspended cells stained for XTC58 (Fig. 10) . In the XTC58+ fraction, examination of the histogram indicated a shoulder of ceils expressing low levels of XTC58 as compared to the isotype control. However, with the gate set at 50, the actual percent positive between the XTC58 and isotype control J5/D staining was not significantly different. XTC58 staining of J5/D+ cells actually appeared higher than the XTC58+ fraction, the specificity of which was significant after subtraction of the isotype control staining. It is possible that binding of the XTC58 mAb to the cell surface caused internalization of the XTC58 determinant, and within the incubation time used here it has not been reexpressed in quantities sufficient to be visible over the isotype control staining. This would result in an apparently low percent $\mathrm{XTC}^{+} 8^{+}$cells. Likewise, a similar phenomenon may be occuring with the $\mathrm{J} 5 / \mathrm{D}^{+}$cells, resulting in an internalization of $\mathrm{F}_{\mathrm{c}} \mu$. This would result in low $\mathrm{J} 5 / \mathrm{D}$ staining of the $\mathrm{J} 5 / \mathrm{D}^{+}$cells, and an artificially high expression of XTC58 relative to the isotype control.

Measurement of secreted cytokines by monospecific bioassays and ELISA. Bioassays are used to quantitate bioactive cytokines in cell supernatants, by measuring the effect of secreted functional proteins on an indicator cell line. Traditional measurement of a proliferative response employs the uptake of the radioactive nucleotide $\left[{ }^{3} \mathrm{H}\right]$ thymidine by proliferating cells. An alternative method is based on the metabolism of the tetrazolium salt 3-(4,5-dimethylthiazol2-yl)-2,5-diphenyltetrazolium bromide (MTT). MTT is cleaved by 
mitochondrial succinic dehydrogenase into a colored formazan product in metabolically active cells. This modification was used here with the mouse $\mathrm{T}$ cell line HT2 (83), to measure IL-2 and IL-4.

All known cytokines have effects on more than one cell type, and all cells typically respond to more than a single factor. For this reason, monoclonal antibodies are routinely used in bioassays to ensure monospecificity. Monoclonal antibodies can be used to block undesired activity, for example, in the HT2 bioassay, the anti-IL-2 mAb S4B6 (12) is used to neutralize IL-2 activity, making the measured response specific for $\mathrm{IL}-4$. Conversely, addition of the anti-IL-4 mAb 11B11 (84) creates an IL-2-specific bioassay with this cell line. Mabs also can be used confirm that the assay signal is specifically due to the correct cytokine. Addition of the anti-IL-4 antibody should have no effect on a sample containing only IL-2. If, when the anti-IL-2 and anti-IL-4 mAbs are combined in this system, the proliferative response of HT2 cells disappears completely, this confirms that the sample originally contained only IL-2. There is often a nonspecific response of the HT2 cell line to factors in the test supernatants, e.g. Con A/PMA, at high starting concentrations of sample. Thus, assaying supernatants in the HT-2 bioassay with anti-IL-2, anti-IL-4, or both anti-IL-2 and anti-IL-4, can be used to quantitate $\mathbb{L}-4$, IL-2, and background values, respectively.

Monoclonal antibodies can also be used in an immunochemical format as a two-site sandwich ELISA. Typically, one antibody is adhered to a 96-well tray, followed by incubation with cytokine-containing supernatant, and then addition of a second anti-cytokine antibody. The second antibody can be either monoclonal, as in the IL-5 ELISA (73), or polyclonal, as in the IFN $\gamma$ ELISA (13). If the first and second antibodies are from different species, e.g. rat and 
goat, respectively, an enzyme-conjugated anti-goat Ig can be used in the final step prior to substrate addition. If this second antibody is of the same species as the first, it can be conjugated to biotin, and subsequent incubation with a streptavidin-enzyme-conjugated reagent and substrate will provide color development in the wells in which cytokine was present. The ELISA offers an advantage in that it is monospecific, can afford a sensitivity comparable to a bioassay, and is much less affected by inhibitory or interfering substances, such as serum. It does not, however, reflect biologic activity, which can only be measured by bioassay. (For a review, see Mosmann, T.R. and T.A.T. Fong (72)).

Killing XTC58 ${ }^{+}$cells removes a IFN $\gamma$-producing cell, while relieving negative regulation of IL-2. Preliminary experiments using complement-mediated cytotoxicity to remove $\mathrm{XTC}^{+} 8^{+}$cells from $\mathrm{CD} 8^{+}$-depleted cultures, had consistently shown decreased amounts of IFN $\gamma$ and dramatically increased levels of IL-2 in the killed population relative to the unkilled control population (Fig. 11). Although in this representative experiment the IL-4 levels also were increased, the level of IL-4 fluctuated dramatically between experiments and was not consistently reproducible. These experiments suggested that $\mathrm{XTC}^{2} 8^{+}$cells secreted IFN $\gamma$, and removing XTC58+ cells relieved suppression of the IL-2 production by the remaining XTC58- cells. 


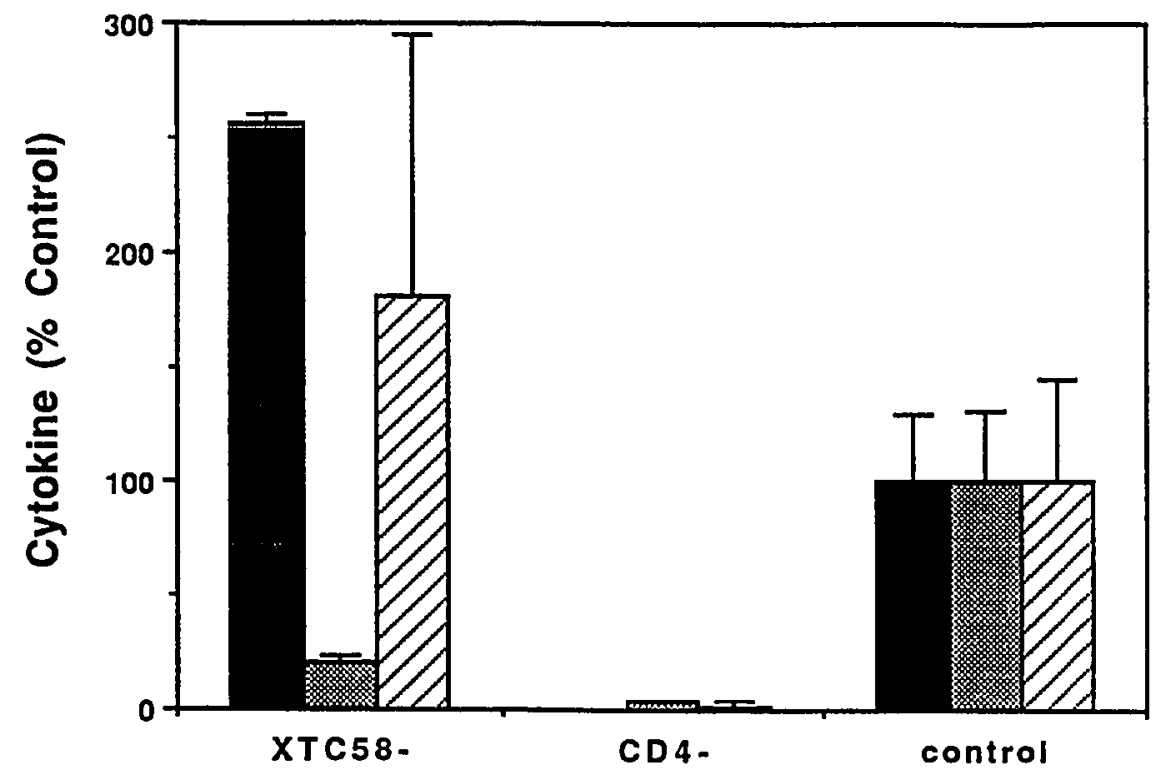

Figure 11. Cytokine patterns of XTC58- cells. CD8+depleted splenocytes were incubated with complement plus XTC58 mAb (XTC58-) or anti-CD4 mAb (CD4-), or complement alone (control). Each killed population was stimulated in triplicate at $5 \times 10^{6} / \mathrm{ml}$ with Con A, and the supernatants analyzed for cytokines. IL-2 (dark bars), IFN $\gamma$ (grey bars) and IL-4 (hatched bars), are shown as percent cytokine relative to the complement control, with standard deviations indicated by bars.

Cytokine analysis of cell populations separated by immunomagnetic beads. Cells from Procedures A, B, and C were separated as described previously and all were stimulated at $106 / \mathrm{ml}$ with Con A/PMA/EBV. EBV-Mann cells were included in the stimulation medium to supply an accessory cell capable of processing Con $\mathrm{A}$, in case this was a necessary signalling requirement for cytokine production by the purified cells. Preliminary experiments showed that this stimulation condition tended to give a more linear cytokine response per cell that was more independent of cell concentration than Con A or Con A/PMA. All cells were stimulated immediately after isolation with the exception of the $\mathrm{XTC}^{+} 8^{+}$and $\mathrm{J} 5 / \mathrm{D}^{+}$cells (Procedure $\mathrm{B}$ ), which were incubated overnight in $\mathrm{T}$ 
cell medium and magnetically separated from the beads before stimulation the following day at $10^{6} / \mathrm{mi}$ with Con A/PMA/EBV.

As shown in Table III, XTC58- cells in Procedure A appeared to be responsible for most of the cytokine production. The XTC58+ cells did not seem to make the levels of IFN $\gamma$ anticipated. These cells were stimulated immediately after isolation while still bound to the beads, which could have interfered with their ability to be adequately stimulated. Although IFN $\gamma$ levels were higher in the XTC58- population, it could not be determined whether the XTC58+ cells, if removed from the beads, would have been capable of greater IFN $\gamma$ production.

The XTC58- fraction from Procedure B secreted higher levels of IL-2, but this was not significantly different from the isotype control. It was, however, comparably higher relative to the SIgM-CD8- population as that seen in earlier cytotoxicity experiments. Most noteworthy were the decreased levels of IFN $\gamma$ in the XTC58- cells, while the majority of IFN $\gamma$ production specifically resided in the XTC58+ fraction. XTC58+ cells, when separated from the beads, could make over six times the amount of IFNy than the XTC58- culture, and three times that of the control cells $\left(\mathrm{J}^{2} / \mathrm{D}^{-}, \mathrm{J} 5 / \mathrm{D}^{+}\right)$. IFN $\gamma$ detected in the supernatants of XTC58- cells isolated in Procedure C was similarly decreased.

Cytokine analysis of bead-separated populations showed hints of being consistent with the cytotoxicity experiments, but except for the IFN $\gamma$ patterns observed in Procedure B, the correlation was not strong. A basic difference between the two control populations was that the CD8- control group in the cytotoxicity experiments were not depleted of $\mathrm{sIgM}^{+}$cells. An attempt to 
TABLE III

Cytokine patterns of immunomagnetic bead fractionated spleen cell populations $a$

\begin{tabular}{|c|c|c|c|c|c|c|}
\hline Procedure & \multicolumn{2}{|c|}{ Population } & $\mathrm{IL}-2 \mathrm{~b}$ & IFN $\gamma \mathrm{c}$ & IL-4b & IL-5C \\
\hline \multirow[t]{4}{*}{$\overline{\mathrm{A}}$} & \multicolumn{2}{|c|}{ Whole spleen } & 1465 & 3.78 & 108 & $\overline{0.171}$ \\
\hline & \multicolumn{2}{|c|}{ sIgM-CD8- } & 2327 & 5.75 & 277 & 0.203 \\
\hline & \multicolumn{2}{|c|}{ sIgM-CD8-XTC58- } & 2407 & 6.84 & 613 & 0.627 \\
\hline & \multicolumn{2}{|c|}{ sIgM-CD8-XTC58+ } & 74 & 0.56 & 51 & $<0.040$ \\
\hline \multirow[t]{6}{*}{ B } & \multicolumn{2}{|c|}{ Whole spleen } & 555 & 2.79 & $<7$ & 0.277 \\
\hline & \multicolumn{2}{|c|}{ sIgM-CD8- } & 646 & 2.82 & 16 & 0.211 \\
\hline & 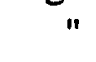 & XTC58- & 1049 & 1.49 & 22 & 0.303 \\
\hline & $"$ & $\mathrm{~J} 5 / \mathrm{D}^{-}$ & 935 & 3.40 & 29 & 0.283 \\
\hline & " & $\mathrm{J} 5 / \mathrm{D}+d$ & 618 & 3.20 & 27 & 0.149 \\
\hline & $"$ & $\mathrm{XTC} 58^{+} d$ & 598 & 9.03 & 39 & 0.105 \\
\hline \multirow[t]{4}{*}{ C } & \multirow{2}{*}{\multicolumn{2}{|c|}{$\begin{array}{l}\text { Whole spleen } \\
\text { sIgM-CD }^{-}\end{array}$}} & 2240 & 8.14 & 52 & 0.335 \\
\hline & & & 3094 & 5.91 & 133 & 0.491 \\
\hline & $"$ & XTC58- & 2624 & 3.21 & 62 & 0.384 \\
\hline & $"$ & XTC58+ & ND & ND & ND & $\mathrm{ND}$ \\
\hline
\end{tabular}

a Cells were stimulated immediately after isolation at a cell concentration of $1 \times 10^{6} / \mathrm{ml}$ in assay medium containing Con A/PMA/EBV.

$b \quad \mathrm{IL}-2$ and $\mathrm{IL}-4$ are expressed as standard units/ml per $1 \times 106$ cells.

$c$ IFN $\gamma$ and $\mathrm{IL}-5$ are expressed as $\mathrm{ng} / \mathrm{ml}$ per $1 \times 106$ cells.

$d \mathrm{XTC}^{2} 8^{+}$and $\mathrm{J} 5 / \mathrm{D}^{+}$cells were incubated overnight in $\mathrm{T}$ cell medium prior to stimulation with Con A/PMA/EBV. 
minimize the effect of differences in accessory cells was made by supplying the human lymphoblastoid B cell line EBV-Mann to the stimulations. It appeared that the beads interfered with stimulation of $\mathrm{XTC}^{2} 8^{+}$cells, and separating them from the beads in culture restored their ability to respond (Table III). Since it was difficult to define the percent $\mathrm{XTC} 58^{+}$cells in the one day old cultures (Fig. 10 ), a direct correlation of increased IFN $\gamma$ with the XTC $58^{+}$phenotype could not be made.

Allogeneic in vitro expansion of XTC58 ${ }^{+}$bead adherent cells effectively enriches for XTC $58^{+}$cells. To obtain a population of cells which could be more accurately measured for the specific expression of the XTC58 determinant, XTC58- and XTC58+ cells isolated using bead separation Procedure C, were expanded allogeneically in vitro, and analyzed with fluorescent staining and cytokine production. Following fractionation with magnetic beads, XTC58- cells and $\mathrm{XTC}^{+} 8^{+}$cell-bead conjugates were cultured overnight in $\mathrm{T}$ cell medium containing $0.2 \%$ Th2 supernatant. Beads were magnetically separated from XTC58 ${ }^{+}$cells, and both XTC58- and XTC58+ cells stimulated with irradiated $\mathrm{CBA} / \mathrm{J}$ splenocytes at a final total cell concentration of $4 \times 10^{6} / \mathrm{ml}$ in $\mathrm{T}$ cell medium. At day 14, a sample of each was removed for phenotyping and the remainder stimulated for cytokine production at $1 \times 10^{6} / \mathrm{ml}\left(\mathrm{XTC}^{2} 8^{+}\right)$and $1.12 \times 10^{6} / \mathrm{ml}^{\left(\mathrm{XTC} 58^{-}\right)}$with Con A (Table IV). These results support the original observation that XTC58- cells make IL- 2, IL-4 and IL-5. XTC58+ cells make predominantly IFN $\gamma$, and can be seen here to make almost ten-fold more IFN $\gamma$ than XTC58- cells under identical conditions. The experiment was repeated, this time with phenotypic analysis by fluorescent staining in addition to cytokine analysis at day 9 (Fig. 12). 


\section{TABLE IV}

Cytokine patterns of in vitro allogeneically expanded XTC58+ and XTC58- cells at day 14

\begin{tabular}{lrrrr}
\hline & $\underline{\text { IL-2 }}$ & $\underline{\text { IFN } \gamma}$ & $\underline{\text { IL-4 }}$ & $\underline{\text { IL-5 }}$ \\
XTC58- $^{-}$ & 15954 & 43 & 22975 & 168.0 \\
XTC58 $^{+}$ & 290 & 379 & 120 & $<0.08$ \\
& & & & \\
\hline
\end{tabular}

Following isolation, XTC58- and XTC58+ cells were incubated overnight inT cell medium containing $0.2 \%$ Th2 supernatant. They were then stimulated allogenically with irradiated CBA/J splenocytes (2500 R) at a final total cell concentration of $2 \times 10^{6} / \mathrm{ml}$ in T cell medium. At 14 days, both cultures were stimulated for cytokine production with Con A/PMA/EBV at cell concentrations of $1.12 \times 106 / \mathrm{ml}$ (XTC58-) and $1 \times 10^{6} / \mathrm{ml}^{-} \mathrm{XTC}^{-} 8^{+}$). IL-2 and IL-4 are expressed as standard U.ml per $1 \times 10^{6}$ cells; IFN $\gamma$ and $I-5$ are expressed as $\mathrm{ng} / \mathrm{ml}$ per $1 \times 10^{6}$ cells. 


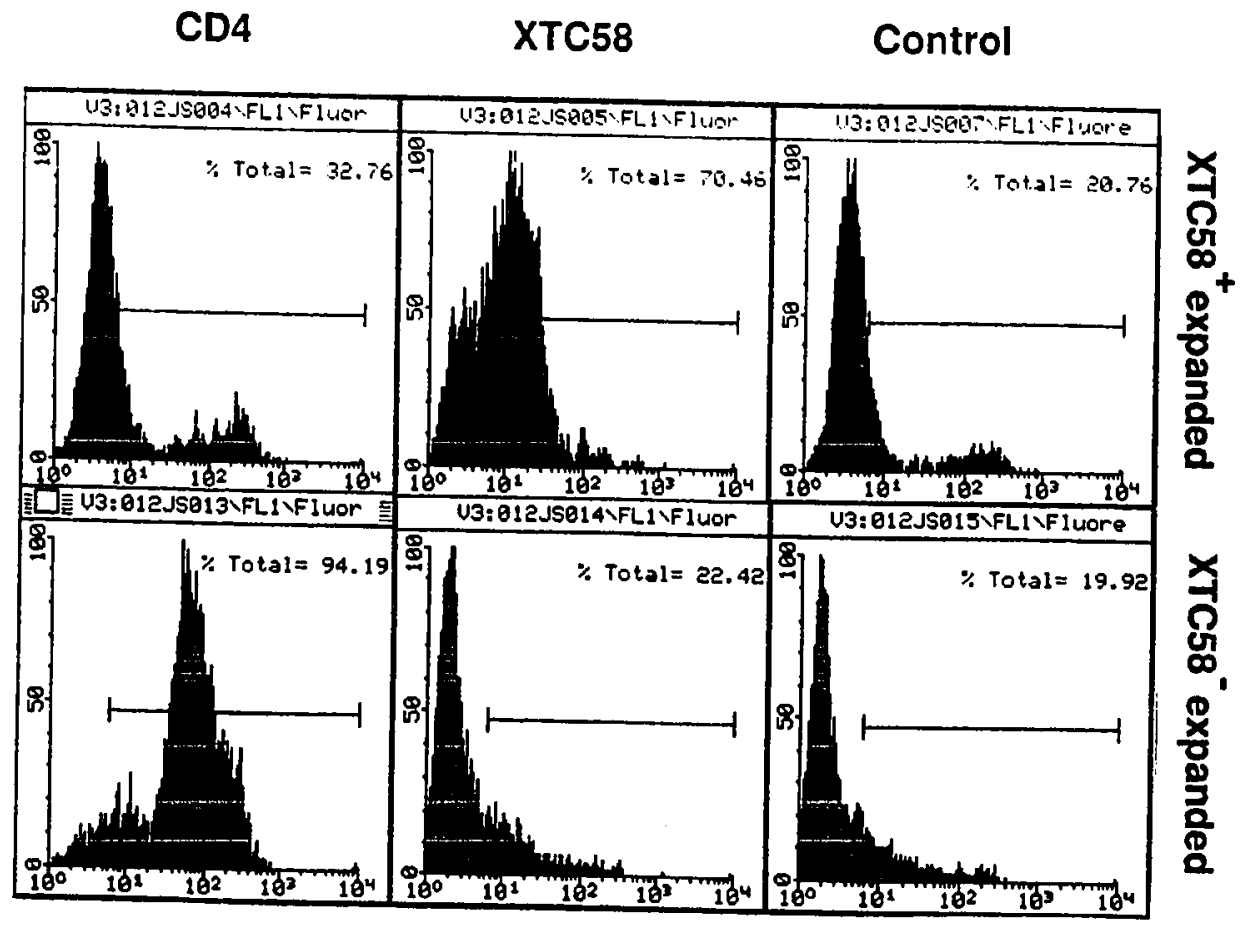

Figure 12. Phenotype of day 9 expanded XTC58+ and XTC58- cultures. XTC58- cells were separated from XTC58- cells magnetically according to Procedure C. Both were incubated overnight in $\mathrm{T}$ cell medium, at which time the XTC58+ cells were magnetically separated from thebeads. Both populations were allogeneically stimulated with irradiated $\mathrm{CBA} / \mathrm{J}$ splenocytes, and phenotypically analyzed by FACS analysis at 9 days following stimulation. XTC58+ (XTC58+ expanded) and XTC58- (XTC58- expanded) were analyzed for CD4, XTC58, or IgM isotype control staining, with the total percent staining indicated in the upper right of each frame.

Expanded XTC58- cells are enriched for $\mathrm{CD}^{+}$cells, whereas expanded XTC58+ consist of lower numbers of Th. The XTC58+ population consists of $50 \%$ 
$\mathrm{XTC} 8^{+}$cells. Allogeneic in vitro expansion seems to provide a means of specifically enriching for a responsive, phenotypically analyzable XTC58 + cell population. Cytokine analysis of supernatants from these cells (Table V) indicates that a culture enriched for XTC58+ cells makes relatively less IL-2,

\section{TABLE V}

Cytokine patterns and phenotypes of XTC58+ and XTC58- cells at day 9 following allogeneic stimulation

\begin{tabular}{lrrrrrrr}
\hline & $\underline{\text { \%CD4 }}$ & & \%XTC58 & $\underline{\text { IL-2 }}$ & $\underline{\text { IFN }}$ & $\underline{\text { IL-4 }}$ & $\underline{\text { IL-5 }}$ \\
XTC58- $^{-74.27}$ & 2.50 & 5696 & 90 & 1022 & 6.652 \\
XTC58 $^{+}$ & 12.00 & 49.70 & 920 & $>900$ & 158 & 0.382 \\
& & & & & & \\
\hline
\end{tabular}

Following isolation, XTC58- and XTC58 ${ }^{+}$cells were incubated overnight in $\mathrm{T}$ cell medium. Beads were magnetically separated from the XCTC $58^{+}$cells, and then both cell populations were allogeneically stimulated with irradiated $\mathrm{CBA} / \mathrm{J}$ splenocytes at a total final cell concentration of $2 \times 10^{6} / \mathrm{ml}$ in T cell medium. At 9 days, aliquots from both cultures were stained for CD4 and XTC58, with the remaining cells stimulated for cytokine production with Con A/PMA/EBV at cell concentrations of $0.8 \times 10^{6} / \mathrm{ml}^{\left(X^{\prime} C 58^{-}\right)}$and $0.5 \times$ $106 / \mathrm{ml}\left(\mathrm{XTC}^{+} 8^{+}\right)$. IL-2 and IL-4 are expressed as standard U.ml per $1 \times 10^{6}$ cells; IFN $\gamma$ and IL-5 are expressed as $\mathrm{ng} / \mathrm{ml}$ per $1 \times 10^{6}$ cells. 
IL-4 and IL-5, and at least ten-fold more IFNy per $10^{6}$ cells than a $\mathrm{CD}^{+}{ }_{-}$ enriched, XTC58- culture.

Stimulation conditions must be optimized for accurate cytokine analysis. Using single point stimulations such as those used in the cytokine analyses so far, apparent differences in cytokine levels may have been created by differences in the ability of purified cell populations to respond to a given stimulation condition, rather than an absolute difference in cytokine production. Data collected as single points are untrustworthy, since they provides no indication of internal experimental variability and error. For this reason, experiments of this type should preferably be performed with each point in triplicate, or for a more limited number of cells, a titrated range of cell concentrations. It is important that the cytokine output per cell be in the linear range for the cell concentration and stimulation condition used, in order to make accurate claims about true differences in cytokine production.

Cell concentration can have a dramatic effect on the cytokine output by freshly isolated lymphocytes. Stimulation of unfractionated splenocytes from mice immunized with Brucella abortus bacterial antigen, emphasize this phenomenon well (Fig. 13). At low cell concentrations, the number of cells required for effective stimulation becomes limiting. The total cytokine production may appear (artificially) low, since, although once triggered a cell makes a constant amount of factor, less than $100 \%$ of the cells may be adequately stimulated. At high cell concentrations, the cytokine output can appear suppressed due to cell crowding and the inability of all the cells to receive necessary signals. Although immunization can exaggerate the suppressive effects, this effect on cytokine production is commonly observed in stimulations 


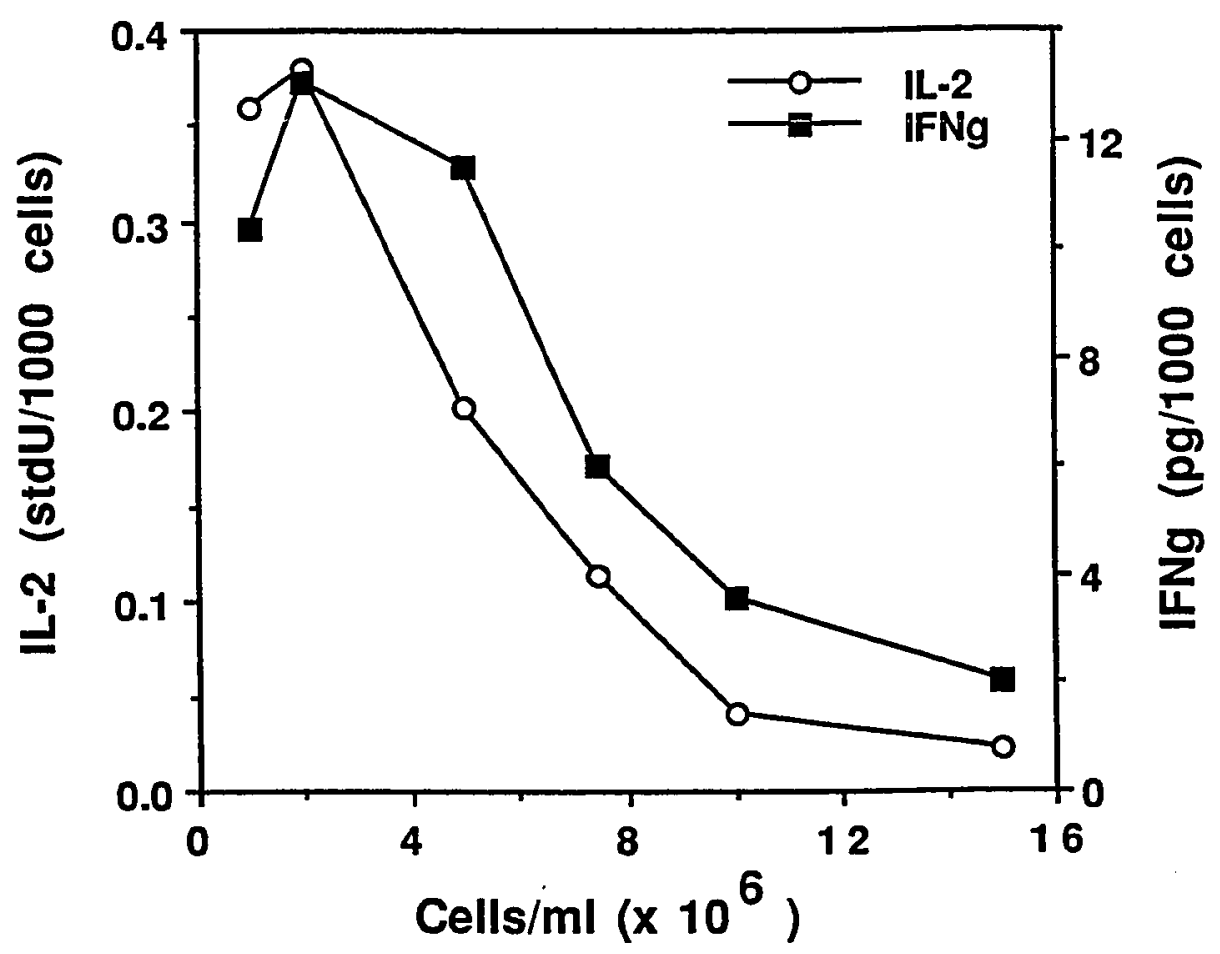

Figure 13. Splenocytes from Brucella abortus immune $\mathrm{Balb} / \mathrm{c}$ mice $(\mathrm{n}=3)$ were stimulated in a range of cell concentrations with Con A/PMA/EBV. IL-2 (O) and IFNy (D) are shown as stdU/1000 cells or $\mathrm{pg} / 100$ cells respectively.

of cells from non-immune mice as well. Extensive and complex experiments show that the optimum stimulation condition and range of cell concentrations which provide a maximum, linear cytokine output per cell, for cells from nonimmune or immune mice, is different for each cytokine (data not shown). Thus, stimulation conditions must be optimized for accurate analysis of cytokine production by purified cell populations. With this in mind, subsequent stimulations of purified XTC58+ and XTC58- cells were performed over a range of cell concentrations with ConA/PMA/EBV. To avoid suppression of cytokine production by high cell concentrations, titrations were begun at $106 / \mathrm{ml}$, in two- 
fold dilutions down to $1.5 \times 10^{4} / \mathrm{ml}$. EBV Mann cells were added, since at these low cell concentrations accessory cells may be limiting, and other experiments have shown that the ConA/PMA/EBV stimulation provides a more linear output of cytokine/cell relatively independent of cell concentration (data not shown). Thus, for the final cytokine analysis, in vitro stimulation conditions were modified to provide a more accurate picture of true cytokine differences between XTC58- and XTC58+ cells.

Allogeneically expanded $\mathrm{XTC}^{\mathrm{T}} 8^{+}$cells are enriched for a CD8 ${ }^{+}$phenotype making more IFNy, but less IL-2, IL-4 and IL-5 than XTC58- cells. Allogeneically expanded XTC58 ${ }^{+}$and XTC58- cells differed in cytokine profile at days 9 and 14, however the results at different days had been derived from separate experiments. To insure reproducibility of these results within one experiment, the procedure was repeated, and aliquots of continued XTC58- and XTC58+ cultures taken at days 9 and 14 for phenotyping and cytokine analysis. Histograms depicting relative differences in expression of CD4, CD8 and XTC58 determinants are shown in Figure 14.

At days 9 and 14, XTC58- cells are predominantly CD4+. Relatively few XTC58- cells express CD8 or XTC58 on their surface. In contrast, at day 9, XTC58+ cultures appear enriched for CD8+ cells. The lack of XTC58-specific staining was puzzling, but could not repeated due to paucity of cells. The percent of expanded XTC58+ cells appeared to increase by day 14 . This population was still predominantly $\mathrm{CD}^{-}$- as compared to the XTC58- cells. Likewise, the expression of XTC58 and CD8 in the expanded XTC58+ culture at day 14 is relatively increased over that displayed by the XTC58- counterpart. Both XTC58 and CD8 expression appeared reciprocal to CD4. 


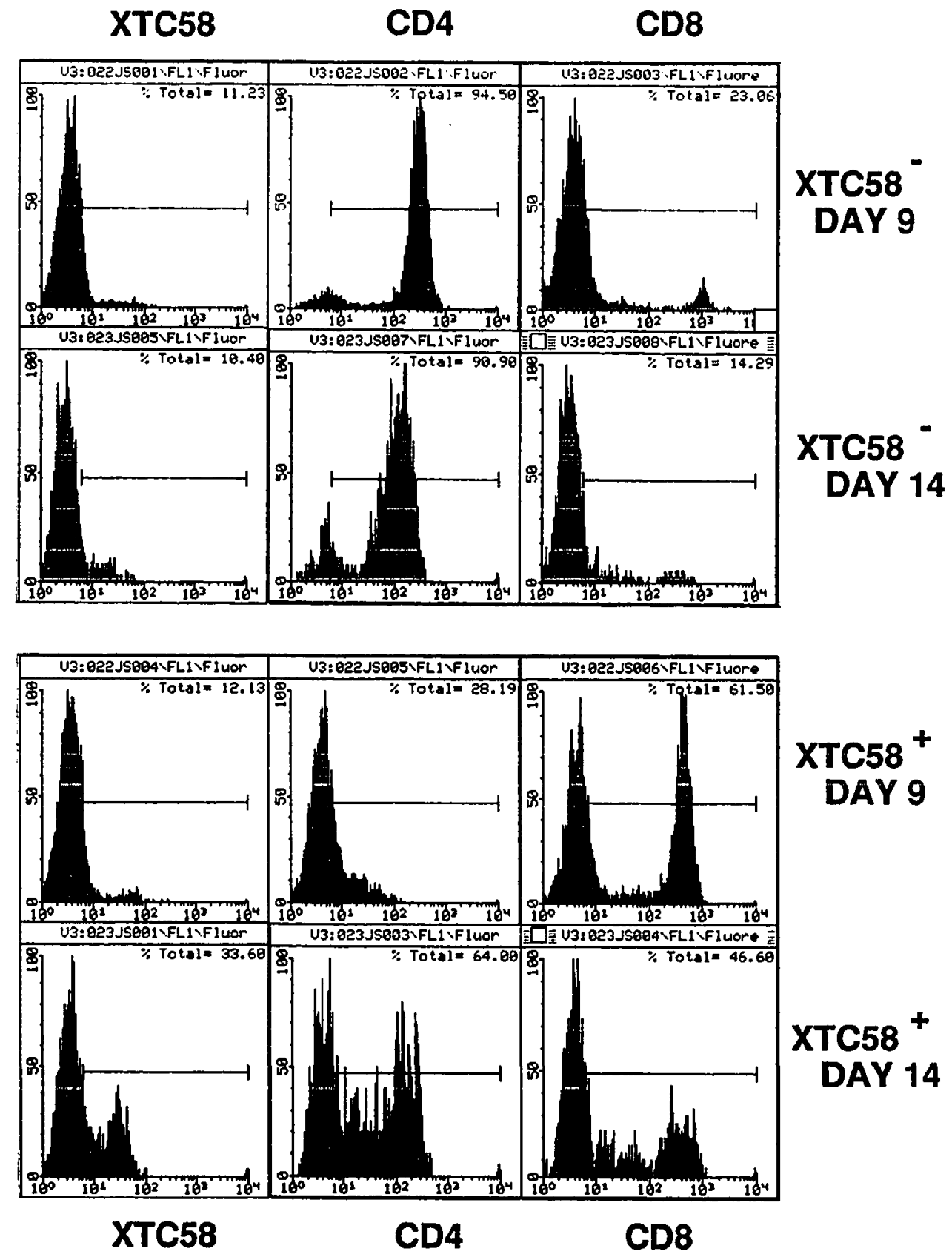


Figure 14. Phenotype analysis of allogeneically expanded XTC58 ${ }^{+}$and XTC58 - cells at days 9 and 14. XTC58+ andXTC58- cells were isolated according to Procedure C. Aliquots of each were taken at days 9 and 14 , and analyzed for the expression of XTC58, CD4 or CD8 by FACS.

The cytokine patterns of these cells is shown in Figure 15. Only samples whose cytokine levels were detected above the assay sensitivty limit are shown. $\mathrm{XTC} 58^{+}$cells, at all cell concentrations at both days, made significantly more IFN $\gamma$ than XTC58- cells. They also made less $\mathrm{IL}-4$ and IL-5. XTC58- cells at day 9 made dramatically increased levels of IL-2 at low cell concentrations, approaching the level detected in $\mathrm{XTC}^{+} 8^{+}$supernatants as cell concentration increased. At day 14, XTC58- made approximately twice as much IL-2 as the XTC58+ culture at all cell concentrations tested. 


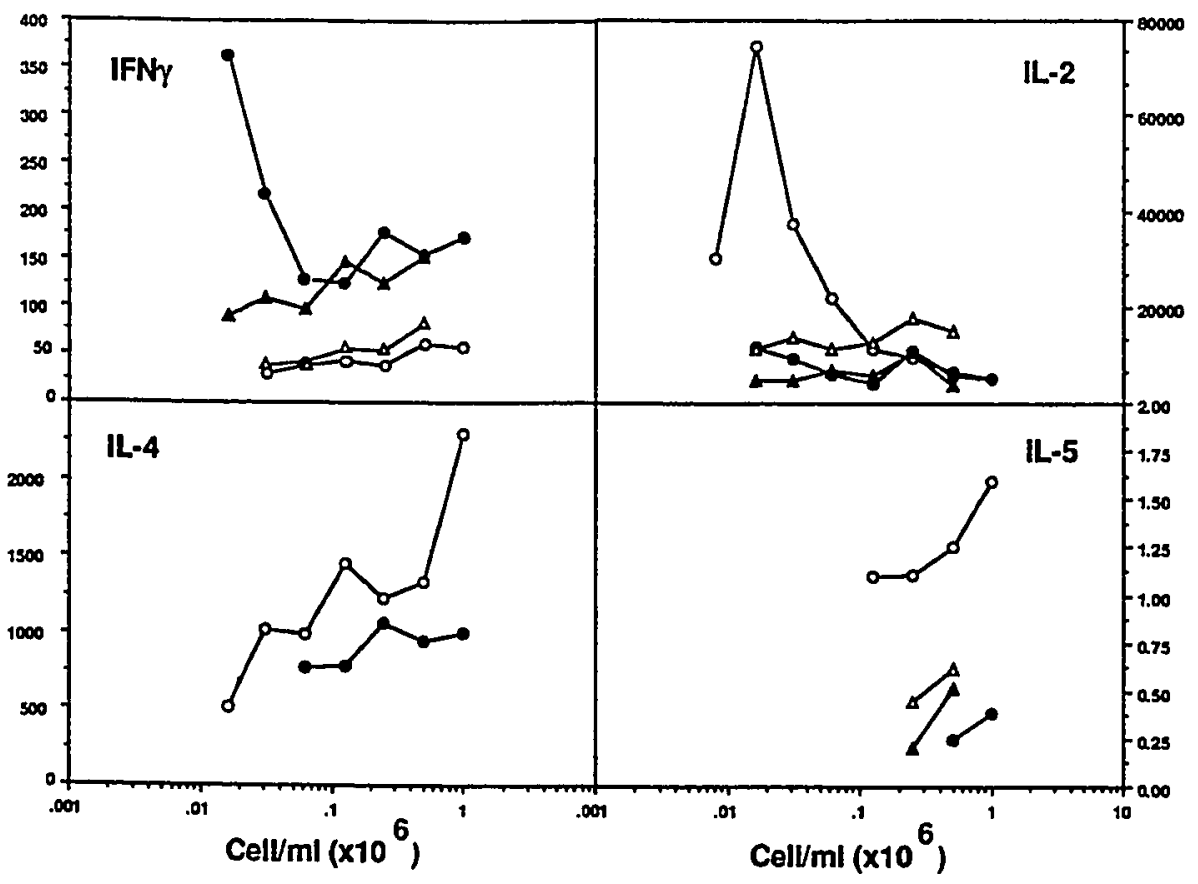

Figure 15. Cytokine profiles of XTC58+ and XTC58- cell populations at days 9 and 14 . XTC58 ${ }^{+}$and XTC58- cells were fractionated from Balb/c spleen as previously described for Procedure C. XTC58+ aliquots taken at days 9 (A) and14 (O), and XTC58- aliquots taken at days $9(\triangle)$ and 14 $(\bigcirc)$, were stimulated in vitro at $10^{6} / \mathrm{ml}$ with ConA/PMA/EBV. Results are shown as ng/ml per $10^{6}$ cells (IFN $\gamma$, IL-5) or stdU/mi per $10^{6}$ cells (IL-2, IL-4).

${\underline{\mathrm{XTC} 58^{+}}}^{+}$cells suppress IL-2 production by XTC58- cells. Original experiments examining the cytokine patterns of CD8- splenocytes depleted of $\mathrm{XTC}^{-1} 8^{+}$cells by complement-mediated cytotoxicity, suggested that removal of $\mathrm{XTC}^{+} 8^{+}$cells removed negative regulation of IL-2 production, as evidenced by consistently increased levels of IL-2 in XTC58-killed population (Fig. 11). Suppression can be addressed by mixing two populations at various ratios within a constant final 
cell concentration, and visualized in diagrams plotting expected versus observed values. Expected values are calculated for each mixture according to:

$$
\text { Units (expected })=(\text { Units A x \%A) + Units B x \%B })
$$

XTC58- and XTC58+-enriched cultures (Procedure B) were mixed at various ratios with a final total cell concentration of $1 \times 10^{6} / \mathrm{ml}$ one day after isolation. Figure 16 illustrates that, mixing XTC58 ${ }^{+}$-depleted with XTC58+-enriched cells one day after isolation, complex patterns were generated. Since the differences between cytokine levels of $100 \% \mathrm{XTC}^{+} 8^{+}$and $100 \%$ XTC58- were small, and the data was from single points, it was difficult to determine the significance of these results. Since XTC58 phenotypes of these populations were obscure (Fig. 10), it was difficult know if they differed enough (in terms of XTC58) to interact as different populations. Therefore, this experiment was repeated using 


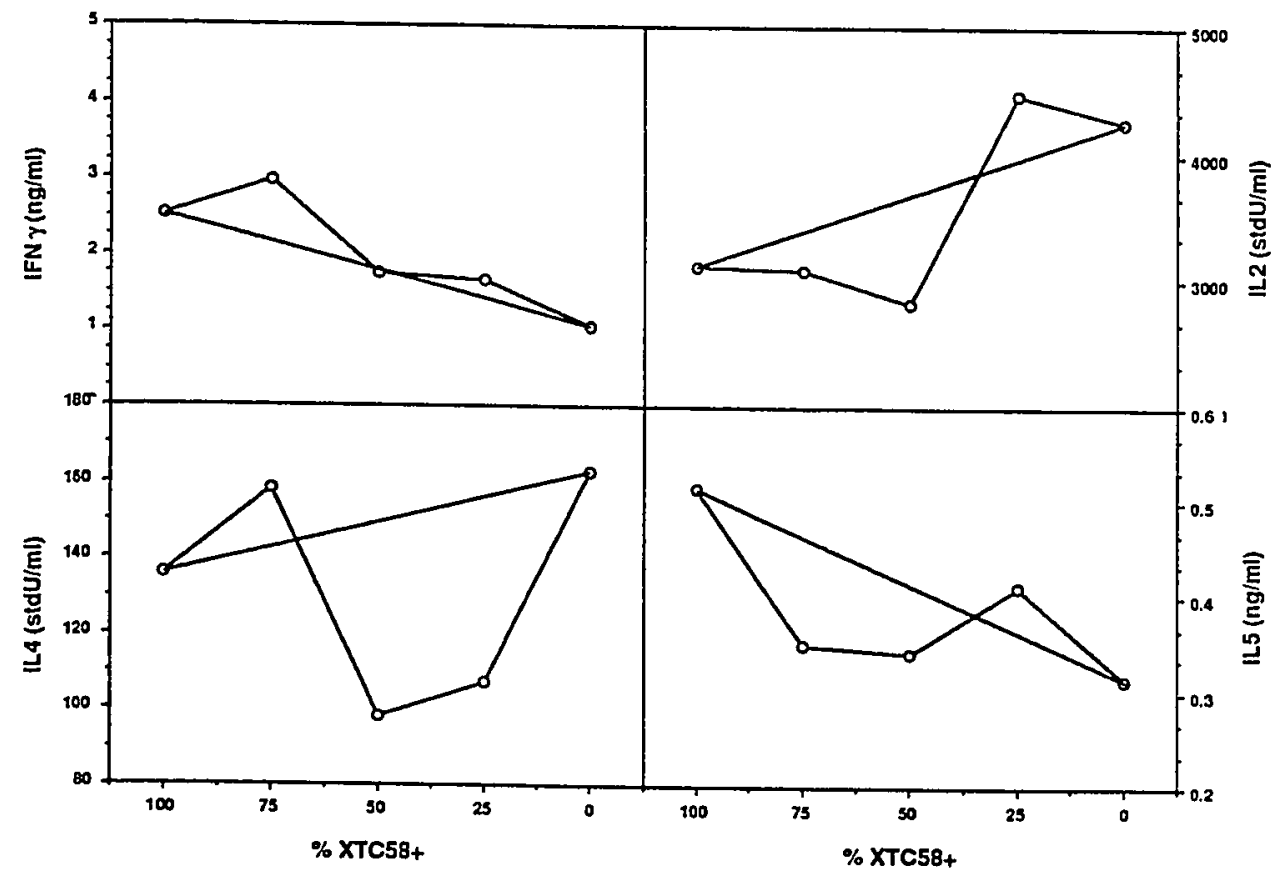

Figure 16. Regulation of cytokine production between day 1 XTC58+ and XTC58- cells. XTC58+ and XTC58- cells were mixed at various ratios in a final total cell concentration of $106 / \mathrm{ml}$, and stimulated with Con A/PMA/EBV. Expected (-) versus observed $(\mathrm{O})$ cytokine values are expressed as $\mathrm{ng} / \mathrm{ml}$ (IFN $\gamma, \mathrm{IL}-5)$, or stdU/ml (IL-2, IL-4).

day 14 cultures which had a more definable expression of XTC58, with the results shown in Figure 17. There does not seem to be any regulation of IL-5 production. IL-4 could not be calculated because of loss of data. Combination of a population enriched for XTC58+ cells (Fig. 12) with a population depleted of this phenotype, XTC58-, appeared to result in suppression of $\mathrm{IL}-2$ production by XTC58- cells (Fig. 17). When there is a large difference between the levels of cytokine produced by the two unmixed populations, the direction of suppression can be determined. Since the difference between the observed and 


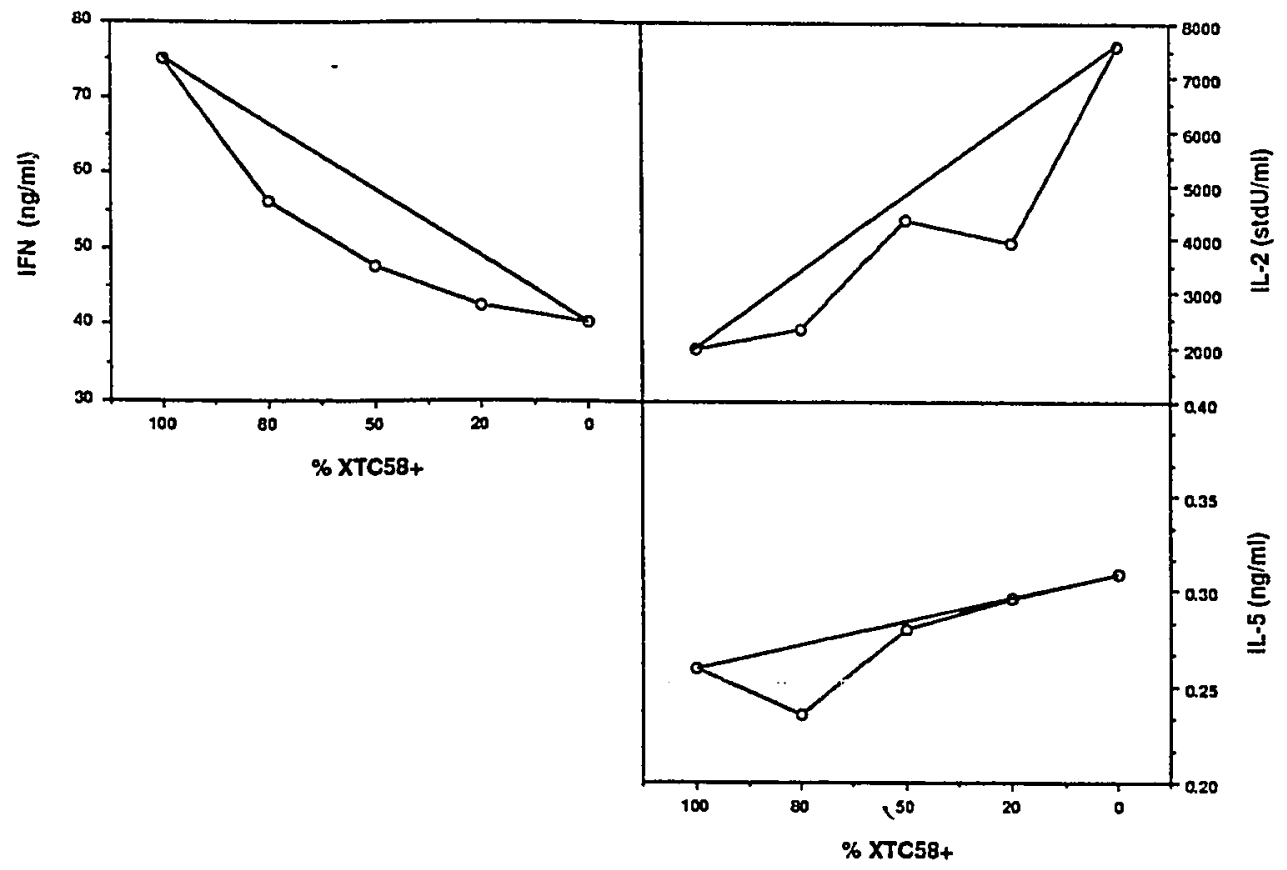

Figure 17. Regulation of cytokine production between day $14 \mathrm{XTC}^{+} 8^{+}$and XTC58- cells. XTC58+ and XTC58- cells were mixed at various ratios in a final total cell concentration of $106 / \mathrm{ml}$,and stimulated with Con A/PMA/EBV. Expected (-) versus observed $(\mathrm{O})$ cytokine values are expressed as $\mathrm{ng} / \mathrm{ml}$ (IFN $\gamma, \mathrm{IL}-5)$, or $\mathrm{stdU} / \mathrm{ml}(\mathrm{IL}-2, \mathrm{IL}-4)$.

expected values was greater than the expected contribution from the XTC58+ cells, it indicated that the XTC58+ cells were suppressing IL-2 production by the XTC58- cells. A surprising result was the apparent suppression of IFN $\gamma$ production in the mixed cell populations. Although not definitive, this provides the first direct evidence for the suppression of $\mathrm{IL}-2$ production by XTC58+ cells, and also suggests that XTC58- cells may be negatively regulating IFN $\gamma$ production by XTC58+ cells. 
Two-color fluorescent staining is useful for directly examining coordinate expression of cell surface molecules. Phenotypic analysis of depleted and in vitro-expanded cultures suggested that the XTC58 determinant may be expressed on a subset of $\mathrm{CD} 8^{+}$cells (Figs. 5,6,7,9,14). Although $\mathrm{CD} 8^{+}$cells were supposedly depleted, allogeneic stimulation of the residual $\mathrm{CD}^{+}$cells left after immunomagnetic bead separations would result in proliferation of any remaining $\mathrm{CD}^{+}$cells, and could explain the higher proportion of $\mathrm{CD} 8+$ cells observed in the $\mathrm{XTC}^{2} 8^{+}$cell cultures. To investigate the population of cells on which XTC58 could be found, two-color fluorescent staining was used here to directly examine the expression of XTC58 relative to that of the CD45R (T200 and B220), CD4 and CD8 cell surface markers.

Data from two-color fluorescent staining can be conveniently shown in the form of a contour-plot, similar in principle to a topographical map. The contour plots which follow have been analyzed using the LYSYS ${ }^{\mathrm{TM}}$ software program, and are displayed as $20 \%$ probability of staining intensity. Although other methods of display calculations are available, including linear and logarithmic representation, calculations and contour plots made using $20 \%$ probability usually provide the most real representation of the data (J. Cupp, personal communication).

A representative example of cells coordinately labelled for CD4 and CD8 determinants is shown in Figure 18. The relative degrees of CD8 fluorescence and CD4 fluorescence are indicated on the $\mathrm{X}$ and $\mathrm{Y}$ axes, respectively, with the respective histograms attached to each. Cells in the lower right quadrant are positive only for CD8, and cells in the upper left quadrant are positive only for CD4. In the mouse, expression of CD4 and CD8 on peripheral T lymphocytes is 
generally mutually exclusive $(2,3)$, hence no cells positive for both markers would be expected to appear in the upper right quadrant. In this experiment, $22.16 \%$ of the cells are $\mathrm{CD}^{+}$(upper left quadrant); $9.06 \%$ are $\mathrm{CD} 8^{+}$(lower right quadrant). This is within the expected values of $20-30 \% \mathrm{CD}^{+}$and 5-10\% CD8 ${ }^{+}$expected in a non-immune Balb/c spleen. Cells negative for both CD4 and CD8, e.g. B cells, macrophages, etc., will be shown in the lower left quadrant of the dot plot.

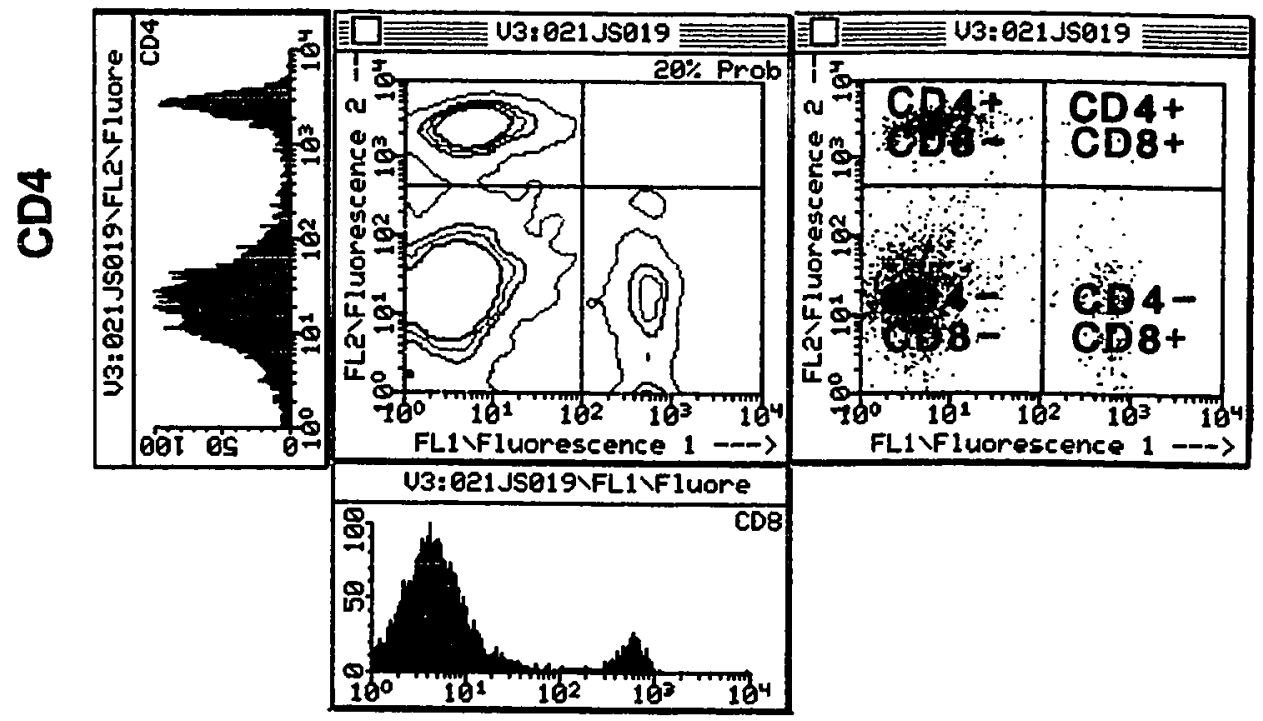

CD8

Figure 18. CD4 versus CD8 two-color FACS analysis of normal Balb/c splenocytes. Unfractionated Balb/c splenocytes, depleted of RBC, were incubated simultaneously with CD4-PE and CD8-FITC antibody conjugates, washed, and analyzed with using a FACScan ${ }^{\mathrm{TM}}$ instrument. Relative CD8 fluorescence ( $x$-axis, fluorescence 1 ) is plotted against CD4 fluorescence (y-axis, fluorescence 2 ). 
All XTC58 ${ }^{+}$cells express T200, but not necessarily the isoform recognized by the $2 \mathrm{C} 2 \mathrm{mAb}$. Normal splenocytes, devoid of RBC, were labelled with XTC58 or the J5/D isotype control, and either the pan-T200 mAb TIB122, or the $2 \mathrm{C} 2$ $\mathrm{mAb}$, which recognizes a particular CD45R isoform found primarily on $B$ cells and a small population ofT cells. An increase in XTC58 fluorescence over that produced by the isotype control J5/D, is again indicative of specific XTC58 staining. It is difficult to determine the expression of the XTC58 determinant relative to the expression of $\mathrm{T} 200$, as analyzed against TIB122 (Fig. 19). It appears that a small number of $\mathrm{T}^{200^{+}}$cells are XTC58+ $(6.44 \%$, $\left.\mathrm{CD} 45^{+} \mathrm{XTC}^{2} 8^{+} ; 0.00 \% \mathrm{CD}^{2} 5^{-} \mathrm{XTC} 58^{+}\right)$. However, there was a higher proportion of TIB $122^{+}$cells than that expected of an antibody whose binding is limited to $\mathrm{T}$ cells. It was suspected that this antibody was binding more CD45R isoforms than T200 alone. For this reason, it can not confidently be determined on what subpopulation of CD45-bearing cells the XTC58 determinant is displayed.

When XTC58 expression is examined relative to the particular CD45R isoform recognized by the $2 \mathrm{C} 2 \mathrm{mAb}$, it appears that the XTC58 marker is expressed on a small number of $2 \mathrm{C} 2^{+}$cells $\left(2.67 \% 2 \mathrm{C}^{+} \mathrm{XTC} 58^{+} ; 10.89 \% 2 \mathrm{C} 2^{-}\right.$ $\mathrm{XTC} 58^{+}$). Thus, although all XTC58+ cells display CD45, only a small percent express the $B$ cell CD45R isoform recognized by the $2 \mathrm{C} 2 \mathrm{mAb}$, with the primary expression of the XTC58 determinant restricted to 2C2- cells. 


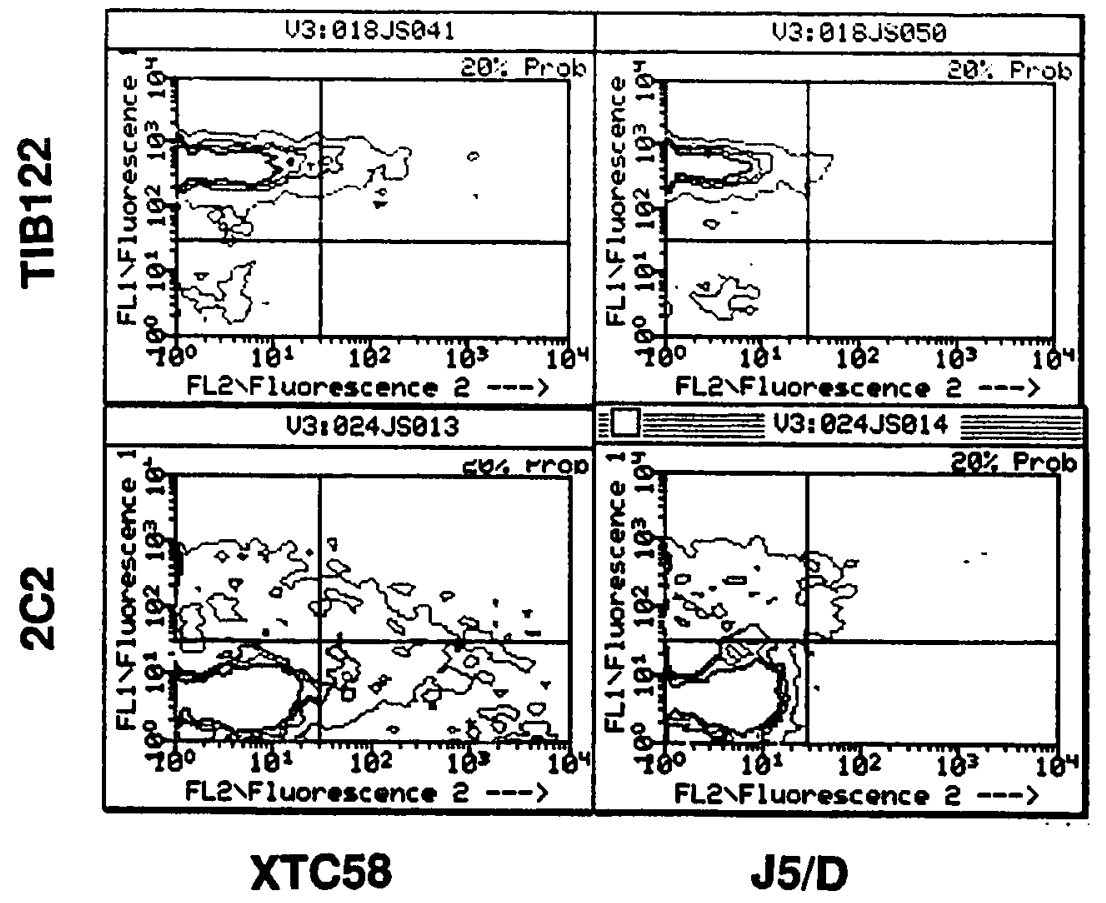

Figure 19. All XTC58+ cells express T200, but not necessarily the isoform recognized by the $2 \mathrm{C} 2 \mathrm{mAb}$. Unfractionated Balb/c splenocytes, devoidof RBC, were incubated with TIB 122 or $2 \mathrm{C} 2 \mathrm{mAbs}$, followed by anti-rat Ig-FITC. Non-specific binding was blocked with $10 \%$ normal rat serum, and cells were then incubated with XTC58-biotin or J5/D-biotin conjugates, followed by streptavidin-PE. Contour plots are indicated as the relative XTC58 or J5/D fluorescence (x-axis) versus TIB 122 or $2 \mathrm{C} 2$ fluorescence $y$-axis).

The XTC58 determinant is expressed on B220- cells. FACS analysis of XTC58+ populations fractionated using Procedures B and C, combined with the above FACS data, suggested that the XTC58 determinant may identify a B cell subpopulation. The expression of the CD45R isoform B220 relative to XTC58, was reexamined using the anti-B220 mAb $3 \mathrm{~A} 1$. The $2 \mathrm{C} 2 \mathrm{mAb}$ had been shown to poorly immunoprecipitate B220, probably because of low affinity (67). The 
$3 \mathrm{Al} \mathrm{mAb}$ immunoprecipitates the same $220,000 \mathrm{M}_{\mathrm{r}}$ molecule (B220) well, and has the same tissue distribution as $2 \mathrm{C} 2$. Thus it was chosen to confirm the original FACS results obtained with the $2 \mathrm{C} 2 \mathrm{mAb}$. There are apparently no $\mathrm{B} 220^{+}$cells, as identified using the $3 \mathrm{~A} 1 \mathrm{mAb}$, which specifically express the XTC58 determinant (Fig. 20.). However, there seems to be a substantial population of B220- cells on which the XTC58 determinant is detected (5.90\%). This would indicate that XTC58 is primarily expressed on a non-B cell type, consistent with FACS analysis of fractionated populations from Procedure A, but not Procedures B or C. Kincade et al. reported five mAbs, precipitating a

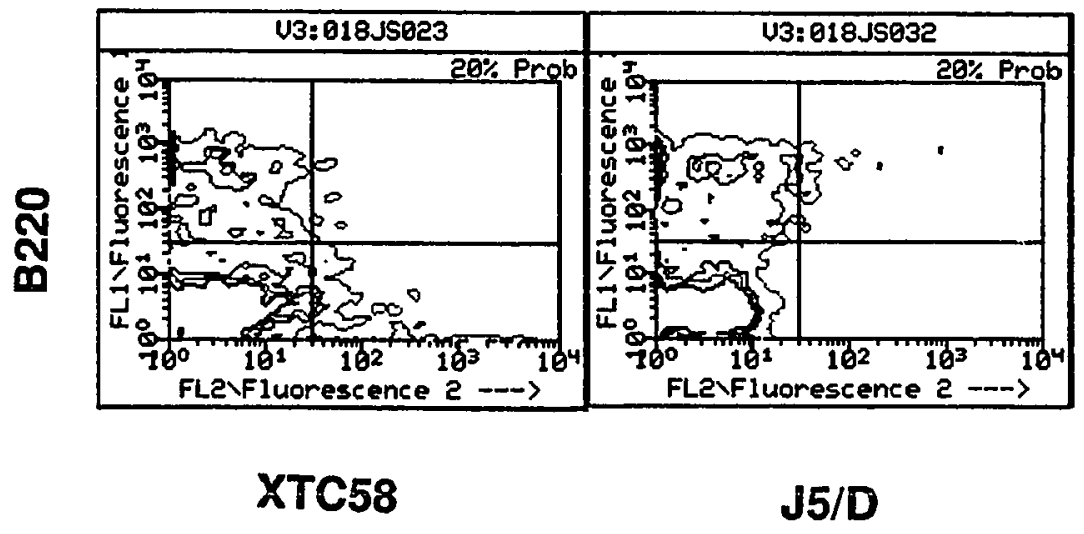

Figure 20. The XTC58 determinant is not expressed by $\mathrm{B}_{220^{+}}$cells. Unfractionated Balb/c splenocytes, devoid of RBC, were incubated with anti-B220 mAb, followed by anti-rat Ig-FITC, and then blocked with incubation in $10 \%$ normal rat serum in CBSS. Cells were then incubated with XTC58-biotin or J5/Dbiotin, followed by streptavidin-PE. Relative B220 fluorescence ( $y$-axis) is plotted against XTC58 fluorescence or J5/D control fluorescence (x-axes). 
cell-surface glycoprotein of $220,000 \mathrm{M}_{\mathrm{r}}$ with tissue distributions closely resembling that of $2 \mathrm{C} 2$, which demonstrated weak reactivity on a subpopulation of T cells (85). Thus, it is possible that the XTC58 determinant is expressed instead on a non-B cell type, and the apparent expression of XTC58 on B220+ cells is an artifact of crossreactivity of the anti-B220 mAbs with $\mathrm{T}$ cell-specific CD45R isoforms.

There is a small subset of CD4 ${ }^{+}{ }^{X T C 58}{ }^{+}$cells. The original assumption of this project was, since the immunogen was a Th cell line, that the XTC58 mAb would possibly identify a normal CD4+ subset. The expression of the XTC58

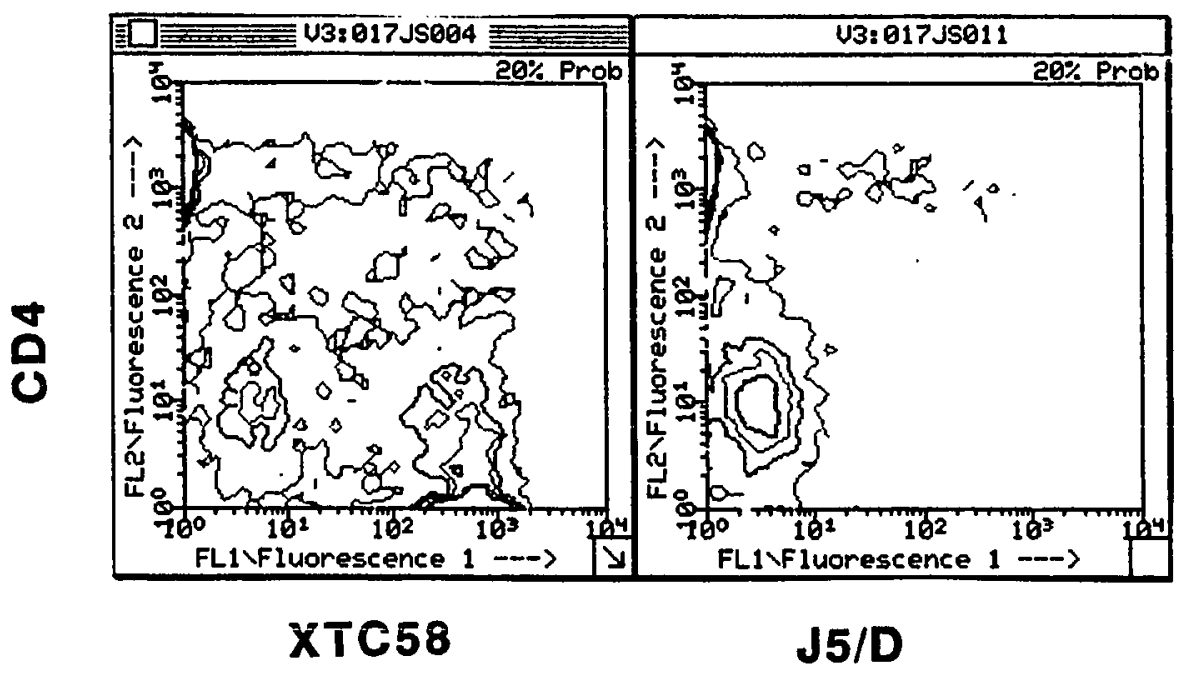

Figure 21. The XTC58 determinant identifies a small CD $4^{+}$subpopulation, but is primarily expressed by CD4- cells. Unfractionated Balb/c splenocytes, devoid of RBC, were incubated with XTC58-biotin or J5/Dbiotin, followed by streptavidin-FITC. Non-specific binding was blocked by incubation in $10 \%$ normal rat serum in CBSS. Cells were then incubated with CD4PE. Analysis was performed with a FACScan ${ }^{\mathrm{TM}}$ instrument, and the results plotted as relative CD4 fluorescence (y-axis) against XTC58 or J5/D fluorescence ( $x$-axes). 
determinant on normal CD4+ cells is shown in Figure 21. The XTC58 staining in this experiment was brighter than that typically seen in other experiments.

This XTC58 staining pattern was consistent between two separate experiments examining CD4 versus XTC58, and the results shown here are representative of the two experiments. There seems to be a small subpopulation of $\mathrm{CD}^{+}$cells which stain specifically for XTC58, relative to the isotype control $(2.76 \%$ $\mathrm{CD} 4^{+} \mathrm{XTC}^{-} 8^{+}$). There is also a significantly larger number of CD4- cells which specifically stain with the XTC58 mAb $(26.04 \%$ CD4-XTC58+). Taken together, these results suggest that although the XTC58 determinant can be found on a small subpopulation of normal $\mathrm{CD}^{+}$cells, it is primarily expressed on a non-CD4+ cell type.

The XTC58 determinant can also be found on a CD8 ${ }^{+}$cell subpopulation, but it does not appear to be an activation marker as assessed by cell size. FACS and cytokine analysis of separated, as well as expanded cultures, suggested that the XTC58 mAb recognized a molecule associated with the $\mathrm{CD} 8^{+}$phenotype. Twocolor fluorescent staining of RBC-depleted normal Balb/c splenocytes indicated that the XTC58 determinant could be found differentially expressed by cells within the $\mathrm{CD}^{+}$compartment (Fig. 22A). A small fraction (1.28\%) of $\mathrm{CD}^{+}$ cells stained specifically for XTC58 (CD8 $\left.{ }^{+} \mathrm{XTC}^{+} 8^{+}\right)$.

Since many studies have correlated changes in the expression of cell surface molecules following activation $(52,58,86)$, it was considered that the XTC58-defined CTL subsets differed in their activation state. Since activated cells are typically larger than resting cells, the comparative FSC of CD8 ${ }^{+} \mathrm{XTC} 58^{+}$and $\mathrm{CD} 8^{+} \mathrm{XTC} 58^{-}$was examined, with the results shown in 


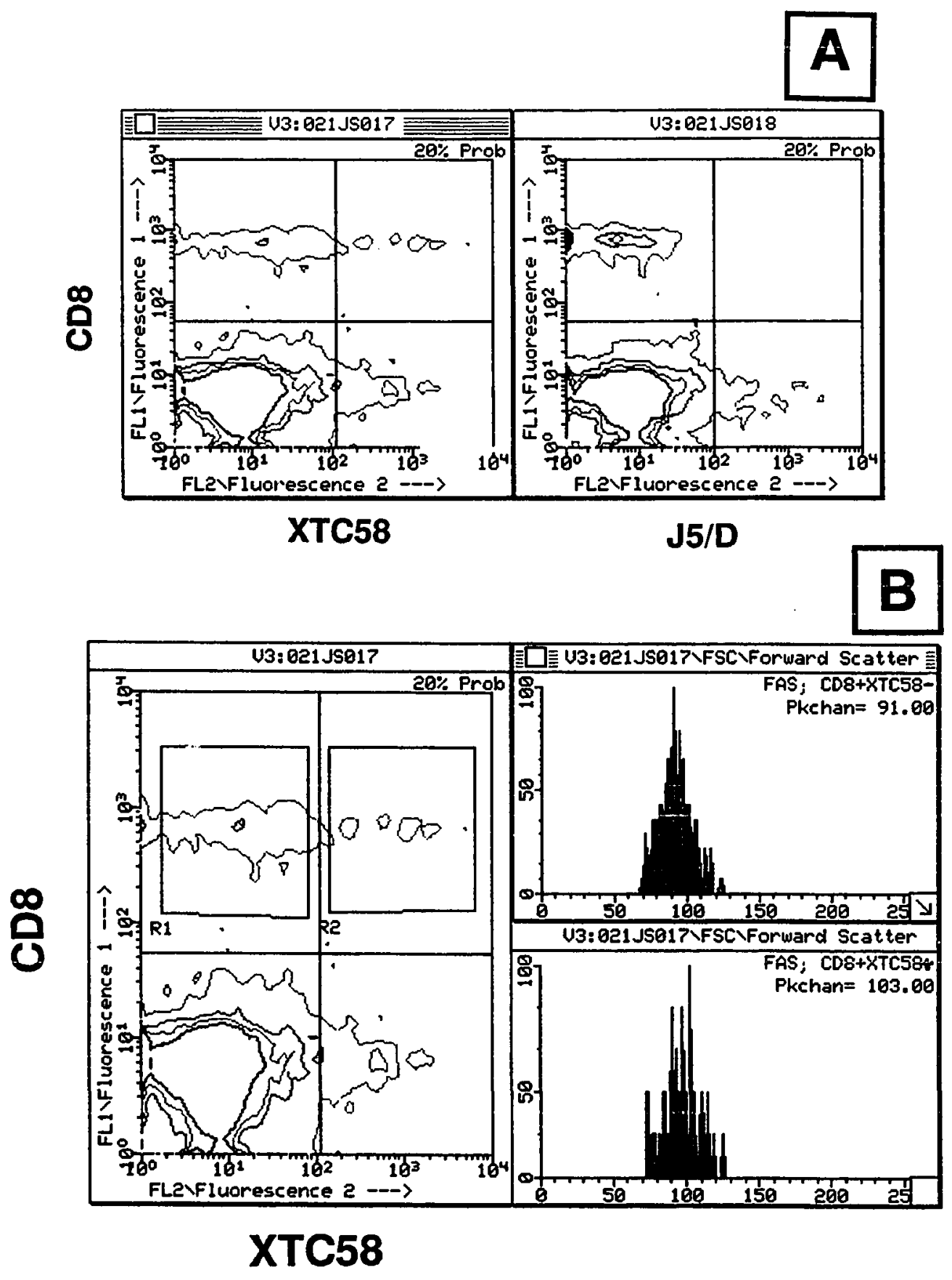


Figure 22. The XTC58 mAb identifies a $\mathrm{CD} 8+$ subset, but does not appear to be an activation marker as judged by cell size (FSC). Cells were incubated with XTC58-biotin or J5/D-biotin, followed by streptavidin-PE and blocking with $10 \%$ normal rat serum in CBSS. Following incubation with CD8FITC, cells were analyzed using a FACScan ${ }^{\mathrm{TM}}$, and (A) relative XTC58 or J5/D staining (x-axes) displayed against CD8 staining ( $y$-axis). (B) FSC (size) of $\mathrm{CD} 8+\mathrm{XTC} 58-(\mathrm{R} 1)$ and $\mathrm{CD} 8+\mathrm{XTC} 58^{+}(\mathrm{R} 2)$ cells.

Figure 22 (B). There is no significant difference in the FSC of these two populations. Thus, using cell size as an indicator of activation state, it therefore does not appear that the expression of XTC58 defines different CTL activation states. 


\section{DISCUSSION}

Immunomagnetic beads were shown here to be useful for enriching $\mathrm{CD}^{+}$ cells from whole splenocyte preparations. All three separation protocols consistently resulted in a final preparation that contained $61-83 \% \mathrm{CD} 4^{+}$cells. This represents a $230-290 \%$ increase in the proportion of $\mathrm{CD}^{+}$cells from the starting population. In contrast, B cells and CTL depletion appeared incomplete with the protocols used here. The separation procedure will have to be further optimized in order to use immunomagnetic beads as a reliable method for depletion.

Complement-mediated cytotoxicity is another method of depleting cell populations. Using titrated lots of antibody and complement, depletion as complete as $99 \%$ can be obtained. By killing undesired cell types, the remaining cells can be enriched to levels similar to that obtained using beads. An obvious drawback of this technique is that it can not be used for positive selection.

The most precise and definitive method for separating defined cell types is by sorting fluorescently-labelled cells with a fluorescence-activated cell sorter. Cells are labelled with sterile reagents in a manner identical to that used for the two-color analysis in these experiments, and selected on the basis of relative fluorescence intensities. Cell purities as high as $99 \%$ can be obtained., and both positive and negative selection is possible.

One caveat of using antibodies to positively select for cells is that the antibody binding to its determinant may alter the function of the cell (87-89).

CD4 and CD8, globally used to identify and select for Th and CTL respectively, are known to be accessory molecules in antigen recognition, and increase the 
efficiency of $\mathrm{T}$ cell receptor binding and signal transduction $(1,90,91)$. Occupying these sites with antibody may interfere with the cells' ability to respond to antigenic stimulation, rendering them refractory until the antibody is either released or internalized and the clean determinant reexpressed on the cell surface.

Artificial in vitro stimulation conditions have been developed which mimic stimulation by antigen via the $\mathrm{T}$ cell receptor. Lectins such as Con $\mathrm{A}$ and pokeweed mitogen (PWM), crosslink and aggregate surface molecules by binding to specific carbohydrate moieties on surface glycoproteins. Anti-CD3 mAb, coated onto culture vessels or displayed on the surface of accessory cells, crosslinks $\mathrm{T}$ cell receptor complexes by binding to the receptor accessory $\mathrm{CD} 3$ complex. Chemicals such as phorbol esters and calcium ionophores, internally activate protein kinase $\mathrm{C}$ and cause calcium influxes similar to, but greater in magnitude than, normal antigen triggering of the $T$ cell receptor. It must be kept in mind that these in vitro manipulations are used to characterize the immune response as to its functions in vivo, and every attempt should be made to minimize artifacts created by using artificial means of stimulation. Extrapolation of data obtained by these methods to in vivo systems must be done with caution.

Expansion of cells in vitro is a common method for obtaining greater numbers of cell populations to work with than can be isolated originally. Antigenic stimulation can be used to specifically expand a typically small population (1\%) of cells which will be antigen-specific. Allogeneic stimulation provides a strong polyclonal stimulus, and stimulates perhaps the largest population of responding cells $(92,93)$. In vitro expansion of any kind inherently selects for those cells best suited for survival in the conditions provided. More 
importantly, cells can differentiate in culture, changing the characteristics and responses dramatically from those of the original starting population. Thus, results obtained using cells which have been in culture for any length of time may not be accurately indicative of their original character, but can give information about the potential of the original cells.

Since the culture requirements of XTC58+ cells were unknown, allogeneic expansion of XTC58 cultures was chosen because of the global, polyclonal stimulus it provided. Both XTC58+ and XTC58- cultures proliferated equally well following allogeneic stimulation. Stimulation of cultures with soluble antiCD3 mAb and syngeneic splenocytes resulted in less proliferation by XTC58+ cells (data not shown). In contrast, XTC58- cultures proliferated well in response to this condition. Th cells respond well to either anti-CD3 or allogeneic stimulation, whereas $\mathrm{CD} 8^{+}$cells, while proliferating well following allogeneic stimulation, respond relatively poorly to anti-CD3 (A. Fong, personal communication). It makes sense, then, that the $\mathrm{CD} 8^{+}$-enriched, $\mathrm{XTC} 58^{+}$cells proliferated more following stimulation with allogeneic splenocytes, whereas the CD4+-enriched XTC58- cultures showed no preference.

Although the separated and expanded populations may not be the same as they exist in vivo, in vitro expansion was necessary to obtain a larger number of cells which could reproducibly be analyzed for XTC58 expression and cytokine production. Freshly isolated normal cells show a great degree of variability from day to day, which is often seen as inconsistencies between experiments which use normal cells. The probable degree of resolution in these experiments is not great enough to overcome these fluctuations, and in this regard, expanded populations proved valuable. It was difficult to characterize XTC58 expression 
immediately after isolation, or after overnight incubation and separation from the beads. This could be due to XTC58 mAb binding to the cell surface, causing internalizaton of the determinant and sequestering it within the time used in these experiments. The interaction between the XTC58 mAb and its determinant could also be reflected in the lack of cytokine production by freshly isolated XTC58+ cells. The XTC58 mAb, still bound to the surface, or internalized along with its determinant, could effectively remove a cell surface molecule required for the signal transduction necessary for cytokine production. To circumvent this phenomenon, it would be necessary to enrich for XTC58+ cells by deleting cells bearing a reciprocal marker.

Functional heterogeneity within the human $\mathrm{CD} 8^{+}$population has been described in terms of cytotoxic, suppressor and natural killer (NK) cell functions. These functions have recently been correlated with the differences in expression of the surface molecule Mol1 (94). It is expressed not only on macrophages and granular lymphocytes but particularly on a small subset of $\mathrm{CD} 8+$ cells. Alloantigen-specific cytotoxicity was limited to the $\mathrm{CD} 8+\mathrm{Mol}^{-}$ subset, which required prior activation by the $\mathrm{CD} 4+2 \mathrm{H} 4+$ (suppressor-inducer) subset to mediate suppression of PWM-induced Ig secretion by B cells. On the other hand, $\mathrm{CD} 8+\mathrm{Mol}^{+}$cells exert Th-independent suppression which could be augmented by recombinant IL-2 alone, and exclusively demonstrated NK and lymphokine activated killer cell (95) activity and cell morphology. The cytotoxic activity demonstrated by NK cells is a non-MHC restricted target cell lysis.

It will be difficult to correlate the expression of XTC58 with CD11 by fluorescent antibody-labelling, since as yet there is no known mAb which 
identifies murine CD11, and the anti-human Mol mAb does not cross-react with mouse cells. Perhaps a better way to correlate the expression of XTC58 with CD11 would be through functional studies, since the requirements of MHCrestriction for cytotoxic effector function differ between the human $\mathrm{CD} 8+\mathrm{Mol}^{+}$ and $\mathrm{CD}^{+} \mathrm{Mol}^{-}$subsets. Mouse $\mathrm{CD} 8^{+}$cells, separated on the basis of expression of the XTC58 determinant, might similarly display differences in their MHC requirements for mediating target cell lysis.

More recently, Fichtner et al. have described a rat anti- mouse $\mathrm{T}$ cell subset antibody, B4B2, which reacts with $40-50 \%$ of normal Thy $1+C D 8+$ cells from $\mathrm{C} 58 \mathrm{Bl} / 6$ mice (96). $\mathrm{B} 4 \mathrm{~B} 2$ expression is exclusive to the $\mathrm{CD} 8+$ lymphocyte compartment. The recognition of cells by B4B2 is strain-specific, limited to cells from B6-like mouse strains and not recognizing cells from $\mathrm{C} 3 \mathrm{H}$ mice. In younger mice, the proportion of $\mathrm{B}^{\mathrm{B}} \mathrm{B}^{+}$cells was high, declining as the mice aged and occurring with a reciprocal increase in the percent $\mathrm{CD} 8^{+}$cells. Based on tissue distribution and fluorescent staining of lectin-stimulated versus resting cells, B4B2 appears to be a lineage marker rather than an activation marker. Limited cytokine analysis of $\mathrm{CD} 8+\mathrm{B} 4 \mathrm{~B} 2+$ and $\mathrm{CD} 8+\mathrm{B} 4 \mathrm{~B} 2-$ cells indicated that $\mathrm{CD} 8+\mathrm{B} 4 \mathrm{~B} 2-$ cells made four to six times as much $\mathrm{IL}-2$ as the $\mathrm{CD} 8+\mathrm{B} 4 \mathrm{B2}+$ cells in response to lectin or alloantigen stimulation. Thus, specifically within the CTL compartment, B4B2 appears to discriminate different subpopulations.

Correlation of the XTC58 determinant with other markers describing similar cell populations can be performed directly using fluorescent analysis. Since it is now possible to label cells with two, three or four fluorochromes, simultaneously labelling CD8+ cells with B4B2 and XTC58 could in this instance 
provide direct evidence for the relative expression of the XTC58 and B4B2 determinants within the $\mathrm{CD}^{+}$compartment.

Two-color fluorescent analysis of XTC58 expression in relation to CD45 indicated that all XTC58+ cells express CD45. Although XTC58 expression can be seen in a small B220+ B cell subpopulation, as evidenced by correlation with $2 \mathrm{C} 2$ and $3 \mathrm{~A} 1 \mathrm{mAb}$ staining, the XTC determinant appears to be preferentially expressed on a non-B cell phenotype. Within the $\mathrm{T}$ cell compartment, the $\mathrm{XTC58}$ determinant is found primarily on a CD4-CD8+ cell type.

Other anti-CD45R antibodies have been proposed to describe Th subsets, but the expression of these isoforms on $\mathrm{CD} 8^{+}$cells has not been well documented. Perhaps it would be interesting to examine XTC58 expression relative to other CD45R species on $\mathrm{CD} 8^{+}$cells. If XTC58 can be shown to identify a CD8+-subset in terms of differential expression of a CD45R isoform, it might possibly be due to from differences in glycosylation. It has been previously shown that, concordant with activation state, $\mathrm{CD} 8^{+}$cells differ in the degree of glycosylation of the CD45R molecules they display $(50,97,98)$. The Ly-5 gene product has been shown to possess an unusually large amount of $\mathrm{N}$ linked high-mannose carbohydrate residues (99). An effect of endo-H digestion on XTC58 mAb binding would suggest the involvement of sugars in the XTC58 epitope.

The present study examined the expression of the XTC58 determinant on CD8+ cells only as it related to activation state, as measured by cell size. Correlation of XTC58 expression with other molecules known to be associated with activation, such as PGP-1 expression, or differences in biochemical changes 
asscoiated with $\mathrm{T}$ cell activation, e.g. $\mathrm{Ca}^{++}$fluxes or membrane physiology ( $\mathrm{F}$. Fitch, personal communication) (3), would perhaps be more definitive.

Mouse strain and tissue distribution of surface markers is a common means of characterizing and comparing cell surface molecules. Examining the distribution of XTC58+ cells between different mouse strains and different organs, such as bone marrow, thymus, spleen and lymph node, would allow comparison with the distributions of other known markers. Whether or not $\mathrm{XTC} 58^{+}$cells have a unique strain and tissue distribution, will help discern whether the XTC58 mAb defines a known or hopefully novel cell surface molecule.

The mixing experiments suggest XTC58+ cells mediate suppression of $\mathrm{IL}$ 2 secretion by XTC58- cells. The cell mixing method used in these studies is prone to large errors, especially when only single points are used as they were in these experiments. Also, these populations were merely enriched for the cell types of interest. It is possible, but not probable, that the regulatory cell phenotypes involved are independent of the expression of XTC58. More definitive evidence for $I L-2$ suppression could be obtained using pure, sorted cell populations, with tighter increments between ratios and each data point performed in triplicate.

A surprising finding of this work was the observation that XTC58- cells, enriched for $\mathrm{CD} 4^{+}$cells, seemed to suppress IFN $\gamma$ production by XTC $58^{+}$cells. Again, more defined mixing experiments will substantiate this apparent suppression. If in fact the XTC58- cells do negatively regulate XTC58+ cell IFN $\gamma$ production, and this effect is cytokine-mediated, a likely factor would be CSIF. Supernatants of XTC58- cells would be expected to contain greater 
amounts of CSIF than that of induced XTC58+ cells. Addition of exogenous CSIF should also inhibit IFN $\gamma$ production by XTC58 ${ }^{+}$cells in a dose response manner. Addition of neutralizing anti-CSIF antibodies, to cell mixing cultures, or cultures of $\mathrm{XTC}^{+} 8^{+}$cells with added CSIF, would be expected to block the suppression of IFN $\gamma$.

The original assumption of this project was, since a cloned helper $\mathrm{T}$ cell line was used for the immunogen and the fusion screened for antibodies which specifically recognized Th cell lines, that the XTC58 mAb would define Th subsets in vivo. The MD13-5.1 cell line used as the immunogen was $83 \% \mathrm{CD}^{+}$ and approximately $15 \% \mathrm{XTC}^{2} 8^{+}$at the time of immunization (data not shown). It was not entirely surprising that the XTC58 mAb recognized determinants on lymphocyte populations other than Th. Birkeland et al. used anti-Ig-stimulated B cell blasts as the immunogen against which the MB23G2/15C11 mAbs were raised. These antibodies immunoprecipitated molecules of $180,000-200,00 \mathrm{Mr}$, believed to be members of the T200 family, which were expressed on subpopulations of $\mathrm{CD}^{+}$peripheral $\mathrm{T}$ cells and $\mathrm{T} 200^{+}$thymocytes. Since we assumed that the XTC58 mAb would recognize a CD4+ subpopulation, normal splenocytes were enriched for $\mathrm{CD} 4^{+}$cells to provide a more concentrated pool of potentially XTC58+ cells. Phenotypic analysis of these cells showed that, although the XTC58 mAb probably does recognize a CD4+ subpopulation, it appears to preferentially identify a $\mathrm{CD} 4-\mathrm{CD} 8^{+}$subset. For this reason, future experiments should be performed on $\mathrm{CD}^{+}{ }_{-}^{+}$enriched cultures. Using $\mathrm{CD} 8{ }^{+}-$ enriched populations, correlation of XTC58 with known CD8 ${ }^{+}$cell surface markers, analysis of functional differences and variety in cytokine production 
will be important experiments in more fully characterizing the XTC58 subsets of nö̈mal CTL.

CTL clones have been found to express a cytokine pattern similar to the Th1 subset (A. Fong and Mosmann, manuscript in preparation)(Appendix B). They can be found to make detectable levels of IFN $\gamma$, IL-2, GM-CSF and IL-3 as determined by dot blot mRNA analysis. Their most abundant known cytokine produced upon stimulation is IFN $\gamma$. The observation that XTC58+-enriched cultures produce greater amounts of IFNy than a population devoid of these cells is consistent with the assumption that the XTC58 determinant is expressed mainly by CTL. The expanded $\mathrm{XTC} 58^{+}$cultures were predominantly $\mathrm{CD} 8^{+}$, whereas the XTC58- expanded cultures were enriched for the CD4+ phenotype. It is possible that the observed differences in cytokine production did not correspond to differential expresstion of XTC58, but rather the differential expansion of the $\mathrm{CD}^{+}$and $\mathrm{CD} 8^{+}$phenotypes. The effects of in vitro culture on cell populations has already been discussed. Fluorescent staining and sorting of XTC58 subsets of normal $\mathrm{CD}^{+}$or $\mathrm{CD}^{+}$cells remains to be done, in order to definitively test whether the expression of the XTC58 determinant on subpopulations of normal $\mathrm{CD}^{+}$and $\mathrm{CD}^{+}{ }^{+}$cells correlates with differences in cytokine production and function. 


\section{REFERENCES}

1. Dialynas, D. P., D. B. Wilde, P. Marrack, A. Pierres, K. A. Wall, W. Havran, G. Otten, M. R. Loken, M. Pierres, J. Kappler, and F. W. Fitch. 1983. Characterization of the murine antigenic determinant, designated L3T4a, recognized by monoclonal antibody GK1.5: expression of L3T4a by functional T cell clones appears to correlate primarily with class II MHC antigen-restriction. Immunol.Rev. 74:29.

2. Klein, J. 1982. Immunology: the science of self-nonself discrimination. John Wiley \& Sons, Inc., New York.

3. Paul, W. E. 1984. Fundamental immunology. Raven Press, New York.

4. Parish, C. R. 1972. The relationship between humoral and cell-mediated immunity. Transplant.Rev. 13:35.

5. Katsura, Y. 1977. Cell-mediated and humoral immune responses in mice. III. Dynamic balance between delayed-type hypersensitivity and antibody response. Immunology 32:227.

6. Kappler, J. W., P. C. Hunter, D. Jacobs, and E. Lord. 1974. Functional heterogeneity among the T-derived lymphocytes of the mouse. I. Analysis by adult thymectomy. J.Immunol. 113:27.

7. Araneo, B. A., P. C. Marrack, and J. W. Kappler. 1975. Functional heterogeneity among the T-derived lymphocytes of the mouse. II. Sensitivity of subpopulations to anti-thymocyte serum. J.Immunol. 114:747.

8. Araneo, B. A., P. Marrack, and J. W. Kappler. 1977. Functional heterogeneity among the T-derived lymphocytes of the mouse. VII. Conversion of $\mathrm{T} 1$ cells to $\mathrm{T} 2$ cells by antigen. J.Immunol. 119:765.

9. Simpson, E., and H. Cantor. 1975. Regulation of the immune response by subclasses of $\mathrm{T}$ lymphocytes. II. The effect of adult thymectomy upon humoral and cellular responses in mice. Eur.J.Immunol. 5:337.

10. Raff, M.C., and H. Cantor. 1971. Subpopulations of thymus cells and thymus-derived lymphocytes. In Proc. First Int.Congr.Immunol. Academic Press, New York. 
11. Kim, J., A. Woods, E. Becker-Dunn, and K. Bottomly. 1985. Distinct functional phenotypes of cloned Ia-restricted helper T cells. J.Exp.Med. 162:188. 12. Mosmann, T. R., H. Cherwinski, M. W. Bond, M. A. Giedlin, and R. L. Coffman. 1986. Two types of murine helper $T$ cell clone. I. Definition according to profiles of lymphokine activities and secreted proteins. J.Immunol. 136:2348.

13. Cherwinski, H. M., J. H. Schumacher, K. D. Brown, and T. R. Mosmann. 1987. Two types of mouse helper T cell clone. III. Further differences in lymphokine synthesis between Th1 and Th2 clones revealed by RNA hybridization, functionally monospecific bioassays, and monoclonal antibodies. J.Exp.Med. 166:1229.

14. Brown, K. D., S. M. Zurawski, T. R. Mosmann, and G. Zurawski. 1989. A family of small inducible proteins secreted by leukocytes are members of a new superfamily that includes leukocyte and fibroblast-derived inflammatory agents, growth factors, and indicators of various activation processes. J.Immunol. 142:679.

15. Savelkoul, H. F., D. A. Lebman, R. Benner, and R. L. Coffman. 1988. Increase of precursor frequency and clonal size of murine IgE-secreting cells by IL-4. J.Immunol. 141:749.

16. Fiorentino, D. F., M. W. Bond, and T. R. Mosmann. 1989. Two types of mouse helper T cell IV: TH2 cells secrete a factor that inhibits cytokine production by TH1 clones. J.Exp.Med. In press.

17. Coffman, R. L., J. Ohara, M. W. Bond, J. Carty, A. Zlotnik, and W. E. Paul. 1986. B cell stimulatory factor 1 enhances the IgE response of lipopolysaccharide-activated B cells. J.Immunol. 136:4538.

18. Vitetta, E. S., J. Ohara, C. D. Myers, J. E. Layton, P. Krammer, and W. E. Paul. 1985. Serological, biochemical, and functional identity of B cellstimulatory factor 1 and B cell differentiation factor for IgG1. J.Exp.Med. 162:1726.

19. Bergstedt-Lindqvist, S., P. Sideras, H. R. MacDonald, and E. Severinson. 1984. Regulation of Ig class secretion by soluble products of certain T-cell lines. Immunol.Rev. 78:25.

20. Snapper, C. M., and W. E. Paul. 1987. Interferon-gamma and B cell stimulatory factor-1 reciprocally regulate Ig isotype production. Science 236:944. 
21. Bottomly, K., M. Luqman, L. Greenbaum, S. Carding, J. West, T. Pasqualini, and D. B. Murphy. 1989. A monoclonal antibody to murine CD45R distinguishes CD4 $\mathrm{T}$ cell populations that produce different cytokines. Eur.J.Immunol. 19:617.

22. Quintans, J., and R. F. Dick. 1983. B cell destruction by $\mathrm{T}$ cell-derived factors. J.Immunol. 131:1609.

23. Gajewski, T. F., and F. W. Fitch. 1988. Anti-proliferative effect of IFNgamma in immune regulation. I. IFN-gamma inhibits the proliferation of Th2 but not Th1 murine helper T lymphocyte clones. J.Immunol. 140:4245.

24. Cher, D. J., and T. R. Mosmann. 1987. Two types of murine helper T cell clone. II. Delayed-type hypersensitivity is mediated by TH1 clones. J.Immunol. 138:3688.

25. Fong, T. A. T., and T. R. Mosmann. 1989. The role of IFN- $\gamma$ in Delayed Type Hypersensitivity mediated by TH1 clones. J.Immunol. 143:2887.

26. Heinzel, F. P., M. D. Sadick, B. J. Holaday, R. L. Coffman, and R. M. Locksley. 1989. Reciprocal expression of interferon gamma or IL 4 during the resolution or progression of murine leishmaniasis. Evidence for expansion of distinct helper T cell subsets. J.Exp.Med. 169:59.

27. Scott, P., P. Natovitz, R. L. Coffman, E. Pearce, and A. Sher. 1988. Immunoregulation of cutaneous leishmaniasis. $T$ cell lines that transfer protective immunity or exacerbation belong to different $\mathrm{T}$ helper subsets and respond to distinct parasite antigens. J.Exp.Med. 168:1675.

28. Carvalho, E. M., R. Badaro, S. G. Reed, T. C. Jones, and W. D Jr. Johnson. 1985. Absence of gamma interferon and interleukin 2 production during active visceral leishmaniasis. J.Clin.Invest. 76:2066.

29. Sileghem, M., R. Hamers, and P. DeBaetselier. 1986. Active suppression of interleukin 2 secretion in mice infected with Trypanosoma brucei. Paras.Immunol. 8:641.

30. Brinkmann, V., S. D. Sharma, and J. S. Remington. 1986. Different regulation of the L3T4-T cell subset by B cells in different mouse strains bearing the H-2k haplotype. J.Immunol. 137:2991.

31. Nutman, T. B., V. Kumaraswami, and E. A. Ottesen. 1987. Parasite-specific anergy in human filariasis. Insights after analysis of parasite antigen-driven lymphokine production. J.Clin.Invest. 79:1516. 
32. Finkelman, F. D., I. M. Katona, J. F. Jr. Urban, J. Holmes, J. Ohara, A. S. Tung, J. vG. Sample, and W. E. Paul. 1988. Interleukin 4 is required to generate and sustain in vivo IgE responses. J.Immunol. 141:2335.

33. Nutman, T. B., D. J. Volkman, R. Hussain, A. S. Fauci, and E. A. Ottesen. 1985. Filarial parasite-specific T cell lines: induction of IgE synthesis. J.Immunol. 134:1178.

34. Coffman, R. L., B. W. P. Seymour, S. Hudak, J. Jackson, and D. Rennick. 1989. Antibody to Interleukin-5 inhibits helminth-induced eosinophilia in mice. Science 245:308.

35. Finkelman, F. D., I. M. Katona, J. F Jr. Urban, C. M. Snapper, J. Ohara, and W. E. Paul. 1986. Suppression of in vivo polyclonal IgE responses by monoclonal antibody to the lymphokine B-cell stimulatory factor 1 . Proc.Natl.Acad.Sci.USA. 83:9675.

36. Finkelman, F. D., I. M. Katona, T. R. Mosmann, and R. L. Coffman. 1988. IFN-gamma regulates the isotypes of Ig secreted during in vivo humoral immune responses. J.Immunol. 140:1022.

37. Liew, F. Y., J. A. Schmidt, D. S. Liu, S. M. Millott, M. T. Scott, J. S. Dhaliwal, and S. L. Croft. 1988. Suppressive substance produced by T cells from mice chronically infected with Trypanosoma cruzi. II. Partial biochemical characterization. J.Immunol. 140:969.

38. Swain, S. L., D. T. McKenzie, A. D. Weinberg, and W. Hancock. 1988. Characterization of $\mathrm{T}$ helper 1 and 2 cell subsets in normal mice. Helper $T$ cells responsible for $\mathbb{I L}-4$ and IL-5 production are present as precursors that require priming before they develop into lymphokine-secreting cells. J.Immunol. 141:3445.

39. Firestein, G. S., W. D. Roeder, J. A. Laxer, K. S. Townsend, C. T. Weaver, J. T. Hom, J. Linton, B. E. Torbett, and A. L. Glasebrook. 1989. A new murine $\mathrm{CD}^{+} \mathrm{T}$ cell subset with an unrestricted cytokine profile. J.Immunol. 143:518.

40. Paliard, X., R. de Waal Malefijt, H. Yssel, D. Blanchard, I. Chretien, J. Abrams, J. E. de Vries, and H. Spits. 1988. Simultaneous production of IL-2, $\mathrm{IL}-4$, and IFN-gamma by activated human CD4+ and CD8+ T cell clones. J.Immunol. 141:849. 
41. Budd, R. C., J. C. Cerottini, C. Horvath, C. Bron, T. Pedrazzini, R. C. Howe, and H. R. MacDonald. 1987. Distinction of virgin and memory $T$ lymphocytes. Stable acquisition of the Pgp-1 glycoprotein concomitant with antigenic stimulation. J.Immunol. 138:3120.

42. Butterfield, K., C. G. Fathman, and R. C. Budd. 1989. A subset of memory CD4+ helper $\mathrm{T}$ lymphocytes identified by expression of Pgp-1. J.Exp.Med. 169:1461.

43. Fernandez-Botran, R., V. M. Sanders, T. R. Mosmann, and E. S. Vitetta. 1988. Lymphokine-mediated regulation of the proliferative response of clones of T Helper 1 and T Helper 2 cells. J.Exp.Med. 168:543.

44. Charbonneau, H., N. K. Tonks, K. A. Walsh, and E. H. Fischer. 1988. The leukocyte common antigen (CD45): a putative receptor-linked protein tyrosine phosphatase. Proc.Natl.Acad.Sci.U.S.A. 85:7182.

45. Ledbetter, J. A., N. K. Tonks, E. H. Fischer, and E. A. Clark. 1988. CD45 regulates signal transduction and lymphocyte activation by specific association with receptor molecules on T or B cells. Proc.Natl.Acad.Sci.U.S.A. 85:8628.

46. Saga, Y., J. S. Tung, F. W. Shen, and E. A. Boyse. 1987. Alternative use of 5 ' exons in the specification of $\mathrm{Ly}-5$ isoforms distinguishing hematopoietic cell lineages. Proc.Natl.Acad.Sci.USA. 84:5364.

47. Thomas, M. L., P. J. Reynolds, A. Chain, Y. Ben-Neriah, and I. S. Trowbridge. 1987. B-cell variant of mouse T200 (Ly-5): evidence for alternative mRNA splicing. Proc.Natl.Acad.Sci.USA. 84:5360.

48. Rudd, C. E., C. Morimoto, L. L. Wong, and S. F. Schlossman. 1987. The subdivision of the T4 (CD4) subset on the basis of the differential expression of L-C/T200 antigens. J.Exp.Med. 166:1758.

49. Serra, H. M., J. F. Krowka, J. A. Ledbetter, and L. M. Pilarski. 1988. Loss of CD45R (Lp220) represents a post-thymic $T$ cell differentiation event. J.Immunol. 140:1435.

50. Smith, S. H., M. H. Brown, D. Rowe, R. E. Callard, and P. C. Beverley. 1986. Functional subsets of human helper-inducer cells defined by a new monoclonal antibody, UCHL1. Immunology 58:63. 
51. Dohlsten, M., G. Hedlund, H. Fischer, H. O. Sjögren, and R. Carlsson. 1989. Proliferation of human CD4 $+45 R^{+}$and $C D 4+45 R^{-} T$ helper cells is promoted by both IL-2 and IL-4 while interferon-gamma production is restricted to IL-2 activated CD4+45R- T cells. Immunol.Lett. 20:29.

52. Clement, L. T., N. Yamashita, and A. M. Martin. 1988. The functionally distinct subpopulations of human CD4+ helper/irducer T lymphocytes defined by anti-CD45R antibodies derive sequentially from a differentiation pathway that is regulated by activation-dependent post-thymic differentiation. J.Immunol. $141: 1464$.

53. Mason, D. W., R. P. Arthur, M. J. Dallman, J. R. Green, G. P. Spickett, and M. L. Thomas. 1983. Functions of rat T-lymphocyte subsets isolated by means of monoclonal antibodies. Immunol.Rev. 74:57.

54. Spickett, G. P., M. R. Brandon, D. W. Mason, A. F. Williams, and G. M. Woollett. 1983. MRC OX-22, a monoclonal antibody that labels a new subset of $\mathrm{T}$ lymphocytes and reacts with the high molecular weight form of the leukocytecommon antigen. J.Exp.Med.

55. Hayakawa, K., and R. R. Hardy. 1988. Murine CD4+ T cell subsets defined. J.Exp.Med. 168:1825.

56. Hayakawa, K., and R. R, Hardy. 1989. Phenotypic and functional alteration of CD4+ T cells after antigen stimulation. J.Exp.Med. 169:2245.

57. Johnson, P., L. Greenbaum, K. Bottomly, and I. S. Trowbridge. 1989. Identification of the alternatively spliced exons of murine CD45 (T200) required for reactivity with B220 and other T200-restricted antibodies. J.Exp.Med. 169:1179.

58. Birkeland, M. L., J. Metlay, V. M. Sanders, R. Fernandez-Botran, E. S. Vitetta, R. M. Steinman, and E. Pure. 1988. Epitopes on CD45R (T200) molecules define differentiation antigens on murine $\mathrm{B}$ and $\mathrm{T}$ lymphocytes. J. Mol. Cell. Immunol. 4:71.

59. Milstein, C. 1980. Monoclonal antibodies. Sci.Am. 243:66.

60. Kohler, G., and C. Milstein. 1975. Continuous cultures of fused cells secreting antibody of predefined specificity. Nature 256:495. 
61. Kipps, T.J., and L.A. Herzenberg. 1986. Schemata for the production of monoclonal antibody-producing hybridomas. In Handbook of Experimental Immunology. D. M. Weir, ed.,Chap. 108: 1-9.

62. Oi, V., P. P. Jones, J. W. Goding, and L. A. Herzenberg. 1978. Properties of monoclonal antibodies to mouse Ig antigens, $\mathrm{H}-2$ and Ia antigens. Curr.Top.Microbiol.Immunol. 81:115.

63. Youngner, J. S., and W. R. Stinebring. 1965. Interferon appearance stimulated by endotoxin, bacteria, or viruses in mice pre-treated with Escherichia coli endotoxin or infected with Mycobacterium tuberculosis. Nature 208:456.

64. Kaye, J., S. Porcelli, J. Tite, G. Jones, and C. A Jr. Janeway. 1983. Both a monoclonal antibody and antisera specific for determinants unique to individual cloned helper $\mathrm{T}$ cell lines can substitute for antigen and antigen-presenting cells in the activation of T cells. J.Exp.Med. 158:836.

65. Paul, W. E., and J. Ohara. 1987. B-cell stimulatory factor-1/interleukin 4. Annu.Rev.Immunol. 5:429.

66. Coffman, R. L., and I. L. Weissman. 1981. B220: a B cell-specific member of th T200 glycoprotein family. Nature 289:681.

67. Coffman, R. L. 1982. Surface antigen expression and immunoglobulin gene rearrangement during mouse pre-B cell development. Immunol.Rev. 69:5.

68. Coffman, R. L., and I. L. Weissman. 1981. A monoclonal antibody that recognizes B cells and B cell precursors in mice. J.Exp.Med. 153:269.

69. Ledbetter, J. A., and L. A. Herzenberg. 1979. Xenogeneic monoclonal antibodies to mouse lymphoid differentiation antigens. Immunol.Rev. 47:63.

70. Weston, P. D., and S. Avrameas. 1971. Proteins coupled to polyacrylamide beads using glutaraldehyde. Biochem.Biophys.Res.Commun. 45:1574.

71. Mosmann, T. R. 1983. Rapid colorimetric assay for cellular growth and survival: application to proliferation and cytotoxicity assays. J.Immunol.Methods. 65:55.

72. Mosmann, T. R., and T. A. T. Fong. 1989. Specific assays for cytokine production by $T$ cells. J.Immunol.Methods. 116:151. 
73. Schumacher, J. H., A. O'Garra, B. Shrader, A. van Kimmenade, M. W. Bond, T. R. Mosmann, and R. L. Coffman. 1988. The characterization of four monoclonal antibodies specific for mouse IL5 and development of mouse and human IL5 enzyme-linked immunosorbent assays. J.Immunol. 141:1576.

74. Bond, M. W., B. Shrader, T. R. Mosmann, and R. L. Coffman. 1987. A mouse $\mathrm{T}$ cell product that preferentially enhances IgA production. II. Physicochemical characterization. J.Immunol. 139:3691.

75. Lewis, G. K., and J. W. Goodman. 1978. Purification of functional, determinant specific idiotype-bearing murine T cells. J.Exp.Med. 148:915.

76. Mage, M. G., L. L. McHugh, and T. L. Rothstein. 1977. Mouse lymphocytes with and without surface immunoglobulin: preparative scale separation on polystyrene tissue culture dishes coated woth specifically purified antiimmunoglobulin. J.Immunol.Methods 15:47.

77. Wysocki, L. J., and V. L. Sato. 1978. "Panning" for lymphocytes: A method for cell selection. Proc.Natl.Acad.Sci.USA. 75:2844.

78. Bonner, W. A., H. R. Hulett, R. G. Sweet, and L. A. Herzenberg. 1972. Fluorescence activated cell sorting. The Review of Scientific Instruments 43:404.

79. Herzenberg, L. A., and R. G. Sweet. 1976. Fluorescence-activated cell sorting. Sci.Am. 234:108.

80. Loken, M. R., D. R. Parks, and I.. A. Herzenberg. 1977. Two-color immunofluorescence using a fluorescence-activated cell sorter. J.Histochem.Cytochem. 25:899.

81. Whitesides, G. W., R. J. Kazlauskas, and L. Josephson. 1983. Magnetic separations in biotechnology. Trends in Biotechnology 5:144.

82. Dunlop, E. H., W. A. Feiler, and M. J. Mattione. 1984. Magnetic separation in biotechnology. Biotech.Advs. 2:63.

83. Watson, J. 1979. Continuous proliferation of murine antigen-specific helper T lymphocytes in culture. J.Exp.Med. 150:1510.

84. Ohara, J., and W. E. Paul. 1985. Production of a monoclonal antibody to and molecular characterization of B-cell stimulatory factor-1. Nature 315:333.

85. Kincade, P. W., L. Grace, W. Takeshi, S. Leslie, and M. P. Scheid. 127. Antigens displayed on murine B lymphocyte precursors. J.Immunol. 2262:2268. 
86. Sanders, M. E., M. W. Makgoba, S. O. Sharrow, D. Stephany, T. A. Springer, H. A. Young, and S. Shaw. 1988. Human memory T lymphocytes express increased levels of three cell adhesion molecules (LFA-3, CD2, and LFA-1) and three other molecules (UCHL1, CDw29, and Pgp-1) and have enhanced IFN-gamma production. J.Immunol. 140:1401.

87. Hollander, N. 1982. Effects of anti-Lyt antibodies on T-cell functions. Immunol.Rev. 68:43.

88. Veillette, A., J. B. Bolen, and M. A. Bookman. 1989. Alterations in tyrosine protein phosphorylation induced by antibody-mediated cross-linking of the CD4 receptor of T lymphocytes. Mol.Cell.Biol. 9:4441.

89. Nakayama, E. 1982. Blocking of effector cell cytotoxicity and T-cell proliferation by Lyt antisera. Immunol.Rev. 68:117.

90. Janeway, C. A. , Jr. 1989. The role of CD4 in T-cell activation: Accessory molecule or co-receptor?. Immunol.Today 10:234.

91. MacDonald, H. R., A. L. Glasebrook, C. Bron, A. Kelso, and J. C. Cerottini. 1982. Clonal heterogeneity in the functional requirement for Lyt- $2 / 3$ molecules on cytolytic T lymphocytes (CTL): possible implications for the affinity of CTL antigen receptors. Immunol.Rev. 68:89.

92. Fischer, L. K., and D. B. Wilson. 1977. Histocompatibility antigen-activated cytotoxic T lymphocytes. II. Estimates of the frequency and specificity of precursors. J.Exp.Med. 145:508.

93. Teh, H. S., E. Harley, R. A. Phillips, and R. G. Miller. 1977. Quantitative studies of the precursors of cytotoxic $T$ lymphocytes. I. Characterization of a clonal assay and determination of the size of clones derived from a single precursor. J.Immunol. 118:1049.

94. Takeuchi, T., M. DiMaggio, H. Levine, S. F. Schlossman, and C. Morimoto. 1988. CD11 molecule defines two types of suppressor cells within the $\mathrm{T}^{+}$ population. Cell.Immunol. 111:398.

95. Grimm, E. A., A. Mazumder, H. Z. Zhang, and S. A. Rosenberg. 1982. Lymphokine-activated killer cell phenomenon. Lysis of natural killer-resistant fresh solid tumor cells by interleukin 2-activated autologous human peripheral blood lymphocytes. J.Exp.Med. 155:1823. 
96. Fichtner, A. T., S. Anderson, M. G. Mage, S. O. Sharrow, C. A Thomas III, and J. T. Kung. 1987. Subpopulations of mouse Lyt-2+ T cells defined by the expression of an Ly- 6-linked antigen, B4B2. J.Immunol. 138:2024.

97. Lefrancois, L., L. Puddington, C. E. Machamer, and M. J. Bevan. 1985. Acquisition of cytotoxic $\mathrm{T}$ lymphocyte-specific carbohydrate differentiation antigens. J.Exp.Med. 162:1275.

98. Lefrancois, L., and M. J. Bevan. 1985. Novel antigenic determinants of the T200 glycoprotein expressed preferentially by activated cytotoxic $T$ lymphocytes. J.Immunol. 135:374.

99. Lefrancois, L., M. L. Thomas, M. J. Bevan, and I. S. Trowbridge. 1986. Different classes of $\mathrm{T}$ lymphocytes have different mRNAs for the leukocytecommon antigen. J.Exp.Med. 163:1337. 
APPENDIX A 


\section{CYTOKINES OF MOUSE T CELL CLONES}

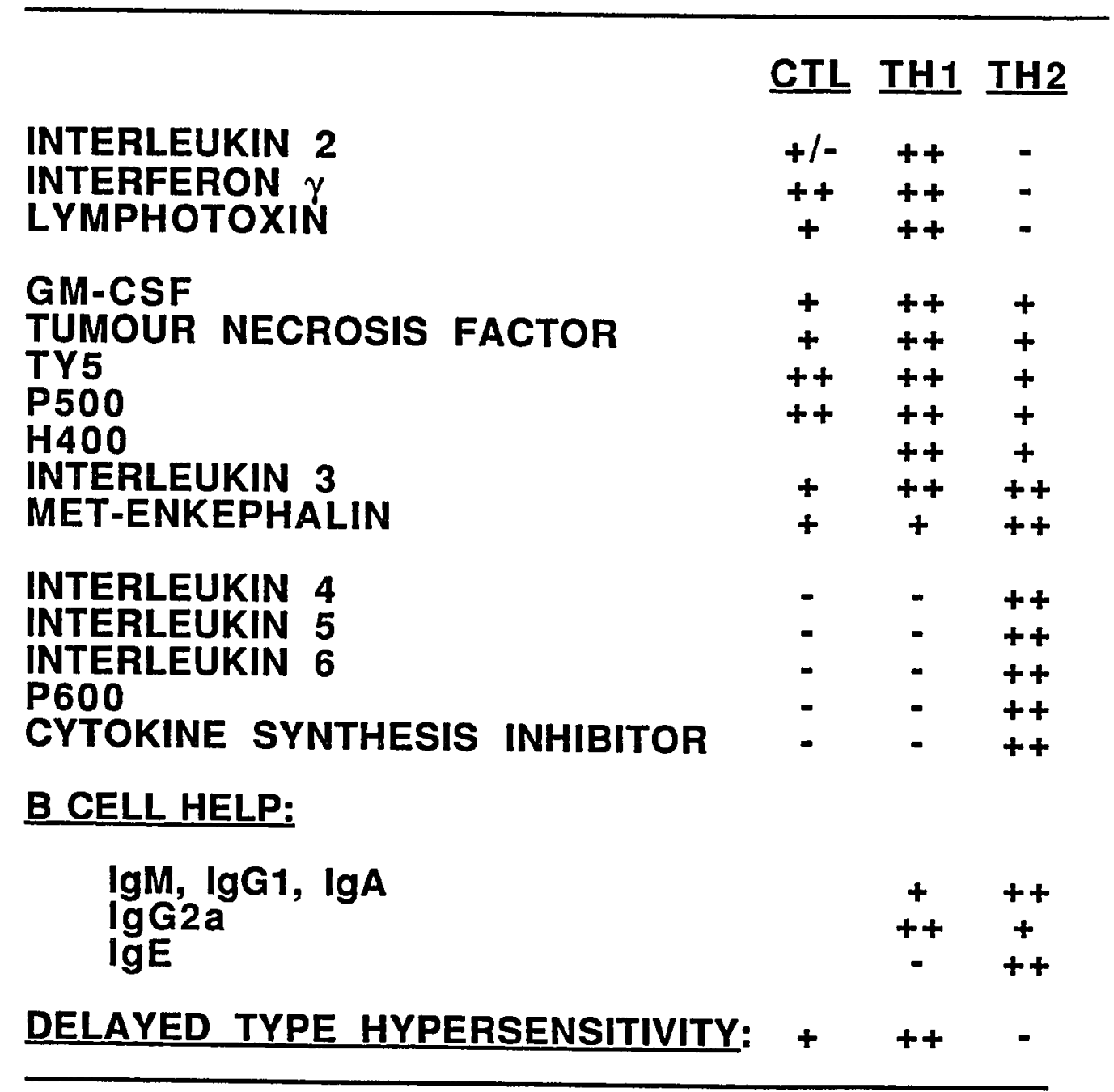


APPENDIX B 


\section{TH1 AND TH2 REGULATION OF IgE RESPONSES}

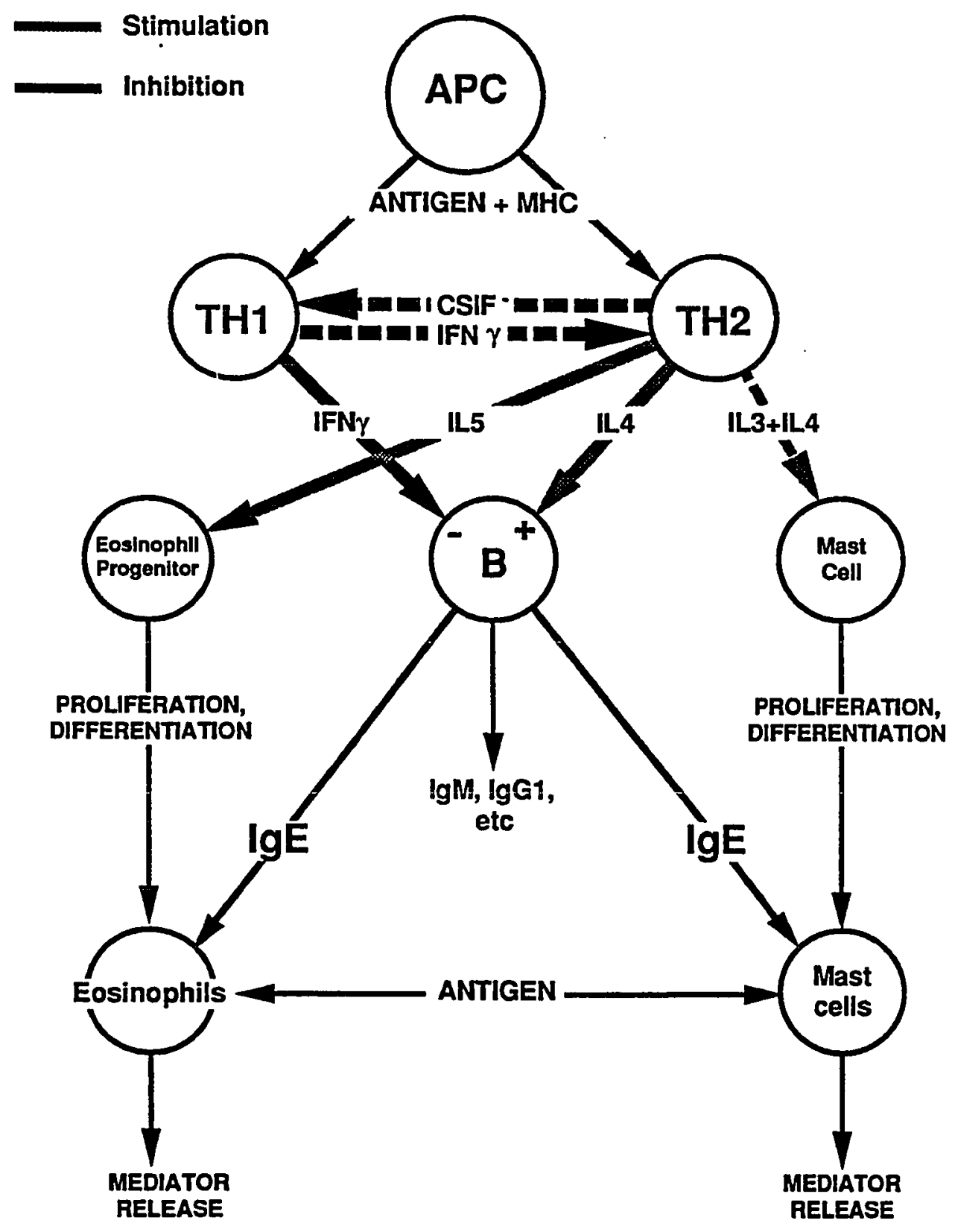




\section{APPENDIX C}




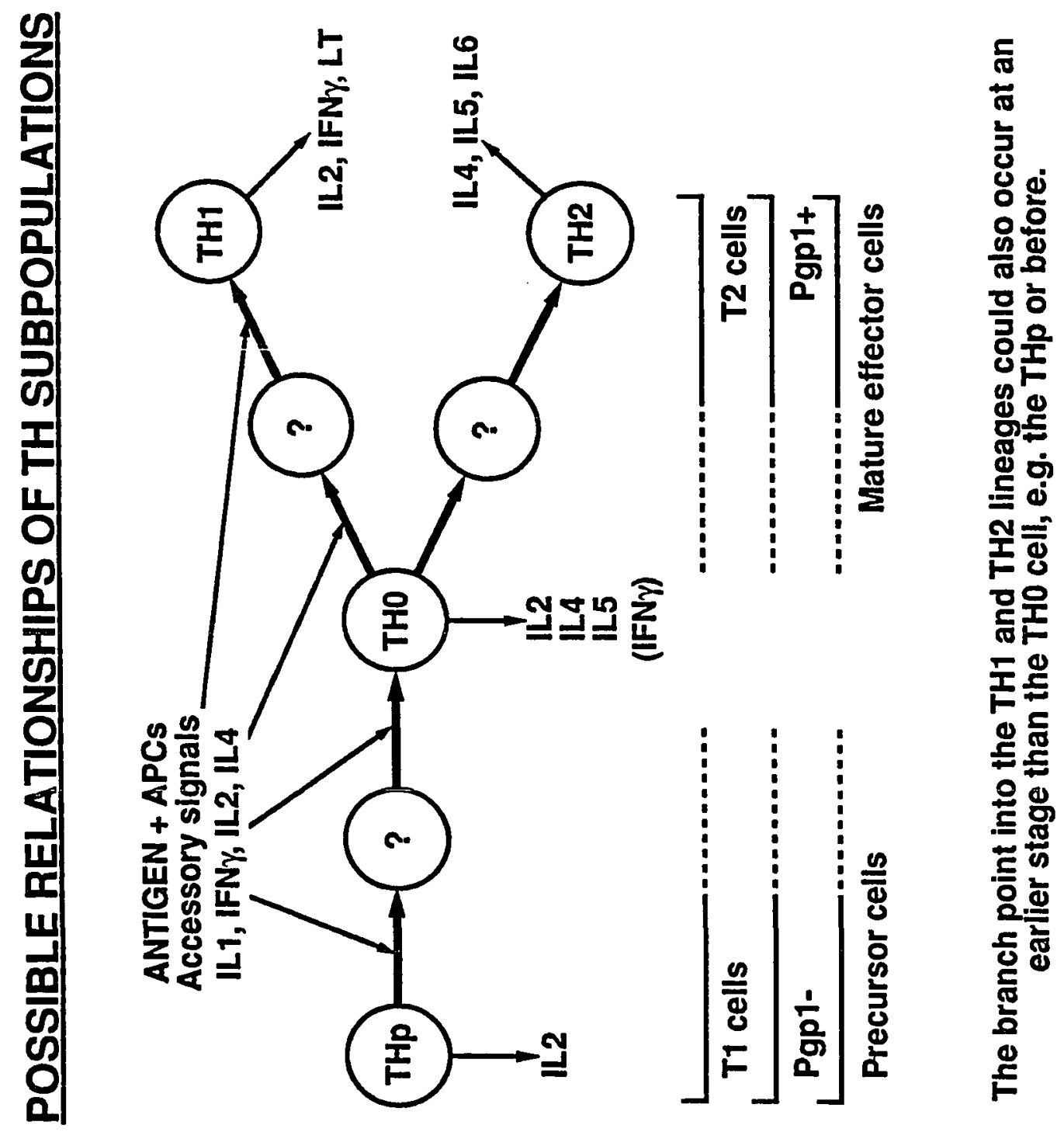

